\title{
WestVirginiaUniversity
}

THE RESEARCH REPOSITORY @ WVU

Graduate Theses, Dissertations, and Problem Reports

2002

\section{Numerical modeling of air blast effects on hybrid structures}

Matthew J. Fox

West Virginia University

Follow this and additional works at: https://researchrepository.wvu.edu/etd

\section{Recommended Citation}

Fox, Matthew J., "Numerical modeling of air blast effects on hybrid structures" (2002). Graduate Theses, Dissertations, and Problem Reports. 1891.

https://researchrepository.wvu.edu/etd/1891

This Thesis is protected by copyright and/or related rights. It has been brought to you by the The Research Repository @ WVU with permission from the rights-holder(s). You are free to use this Thesis in any way that is permitted by the copyright and related rights legislation that applies to your use. For other uses you must obtain permission from the rights-holder(s) directly, unless additional rights are indicated by a Creative Commons license in the record and/ or on the work itself. This Thesis has been accepted for inclusion in WVU Graduate Theses, Dissertations, and Problem Reports collection by an authorized administrator of The Research Repository @ WVU. For more information, please contact researchrepository@mail.wvu.edu. 


\title{
NUMERICAL MODELING OF AIR BLAST EFFECTS ON HYBRID STRUCTURES
}

\author{
Matthew J. Fox \\ Thesis Submitted to the \\ College of Engineering and Mineral Resources \\ At West Virginia University \\ In Partial Fulfillment of the Requirements for the \\ Degree of \\ Master of Science
in
Mechanical Engineering
}

Ever Barbero, Ph.D., Chair

Julio Davalos, Ph.D.

Victor Mucino, Ph.D.

Department of Mechanical and Aerospace Engineering

Morgantown, West Virginia

2002

Keywords: composites, concrete, blast, modeling, LS-DYNA3D 


\title{
Abstract \\ NUMERICAL MODELING OF AIR BLAST EFFECTS ON HYBRID STRUCTURES
}

\author{
Matthew J. Fox
}

Blast resistant structures are gaining increased need in today's society. This research addresses adding composite reinforcement to existing concrete structures to decrease blast damage. An upgraded material model for concrete is presented. This model, used in LSDYNA3D, incorporates tensile damage, which allows the concrete to degrade as it is loaded. The concrete model is tested using existing unreinforced and reinforced concrete beam tests. Some beams were plain, others were externally reinforced with composites, bonded to the exterior of the beams. There is a very good correlation between the predicted and existing data. The concrete model was then used to predict the mean residual displacement of a plain and composite reinforced concrete wall subjected to a blast load. 


\section{Acknowledgements}

I would like to express my gratitude to my advisor, Dr. Ever J. Barbero, for his support and guidance throughout this research. His dedication to academics has given me and many others a better understanding of the composite materials industry. I would also like to thank the other members of my committee, Drs. Julio Davalos and Victor Mucino, for their time and resources.

I am indebted to Eric Saunders for his continuous support, with all aspects of the computer modeling. Without his repeated assistance, this research would not have been completed. I am also grateful for the encouragement and friendship of Ed Wen.

Also, this research would not have been completed without the support of Dr.

Anthony J. Vizzini at the University of Maryland Composites Research Laboratory. His patience, guidance and understanding have allowed me to finish this research.

Thank you to my family, who support me through each and every thing. No one could ask for better.

Finally, thank you, Charlotte. :) You are the greatest! 


\section{Table of Contents}

Title Page

Abstract $\quad$ ii

$\begin{array}{ll}\text { Acknowledgements } & \text { iii }\end{array}$

Table of Contents $\quad$ iv

List of Tables $\quad$ vii

List of Figures $\quad$ viii

Nomenclature $\quad x$

Chapter 1: Introduction and Literature Review 1

1.1 Introduction 1

1.2 Literature Review 3

$\begin{array}{ll}\text { Chapter 2: Blast Loading of a Hybrid Wall } & 6\end{array}$

2.1 Blast Wave Phenomena 6

2.2 Determining Pressure Curves 9

$\begin{array}{ll}\text { Chapter 3: Damping Calculations } & 13\end{array}$

$\begin{array}{ll}3.1 \text { Background } & 13\end{array}$

3.2 Plain Concrete Modeled as a Wall 13

3.3 Unreinforced Concrete Beam Model 15

3.4 Reinforced Concrete Beam Model 16 
$\begin{array}{ll}\text { Chapter 4: Material Modeling } & 19\end{array}$

4.1 The Concrete Damage Model 19

4.2 The Unreinforced Concrete Beam Model 24

4.3 The Steel Reinforced Concrete Beam Model 27

4.4 The Concrete Wall 31

Chapter 5: Results 33

5.1 The Unreinforced Concrete Beam 33

5.2 The Reinforced Concrete Beam 35

5.3 The Concrete Wall 36

Chapter 6: Conclusions and Recommendations $\quad 40$

$\begin{array}{ll}\text { 6.1 Conclusions } & 40\end{array}$

6.2 Recommendations $\quad 41$

$\begin{array}{ll}\text { Chapter 7: References } & 42\end{array}$

$\begin{array}{ll}\text { Appendices } & 46\end{array}$

Appendix A: T\&P.BAS Program 46

Appendix B: T\&P.BAS Output Files $\quad 52$

Appendix C: RC Damping Example $\quad 71$

Appendix D: Input Format for LS-DYNA3D 77

Appendix E: UMAT43 Damage Model Fortran Program 80

Appendix F: UMAT43 Driver Program $\quad 92$

Appendix G: UC Model - Plain Concrete 96 
Appendix H: UC Model - CFRP Reinforced 100

Appendix I: RC Model - Internally Reinforced Concrete 104

Appendix J: Concrete Wall Model 108

Appendix K: CFRP Reinforced Concrete Wall Model 111 


\section{List of Tables}

Chapter 2: Blast Loading of a Hybrid Wall

2.1 General Purpose Bomb

Chapter 3: Damping Calculations

3.1 Concrete Wall Properties

Chapter 4: Material Modeling

4.1 Properties of Unreinforced Concrete Beam Model

4.2 Pressure vs. Time Curve Used in Beam Loading of the Plain UC Beam

4.3 CFRP Material Properties

4.4 Pressure vs. Time Curve Used in Beam Loading of the CFRP Reinforced Concrete Beam

4.5 Properties of Steel Reinforcing Bars

4.6 Properties of CFRP Used on RC Beams

4.7 Initial RDA Concrete Properties

4.8 Final RC Concrete Properties

Appendix C: RC Damping Example

C.1 Modulus of Elasticity and Density

C.2 Neutral Surface Calculations

C.3 Area Moments of Inertia

C.4 System Damping for Faza's Beams 


\section{List of Figures}

Chapter 2: Blast Loading of a Hybrid Wall

2.1 Idealized Pressure vs. Time Blast Wave 7

2.2 Incident vs. Reflected Pressures $\quad 8$

2.3 Blast Wave Depiction 9

2.4 Wall as Modeled in CONWEP 10

2.5 Bomb Dimensions 10

2.6 Peak Pressure Distribution on the Target Surface 12

Chapter 3: Damping Calculations

3.1 Wall Dimensions 14

3.2 Transformed Section Method Used With the RC Model 18

Chapter 4: Material Modeling

4.1 The Yield Surface of the Two-Invariant Cap Model in Pressure $\sqrt{\mathrm{J}_{2 \mathrm{D}}}-J_{1} \quad 20$ Space

4.2 Effect of Damage on Apparent Stress 22

4.3 Comparison of UMAT43 with LS-DYNA3D Material Type 25 23

4.4 Visualization of the Imaginary Intersection FCUT 24

4.5 UC Beam Model 25

4.6 Cross-Section of RC Beams 27

4.7 RC Beam Model 28

4.8 Different Wrapping Configurations of RC Beam Model 29

4.9 IC Test Diagram 30 
Chapter 5: Results

5.1 Comparison of the UC Beam 33

5.2 Comparison of the CFRP Reinforced UC Beam 34

5.3 Comparison of the RC Beam Containing No External Reinforcement 35

5.4 Displacement Vectors at First Response 36

5.5 Comparison of Concrete Wall and Concrete Wall with Undamaged Concrete 37

5.6 Comparison of Plain Concrete Wall and Concrete Wall with Composite on 38 the Back

5.7 Mean Residual Deflection Value of All Three Concrete Wall Curves

Appendix C: RC Damping Example

C.1 The Original Concrete Beam With a Steel Plate on the Bottom

C.2 Beam after Transforming the Steel

C.3 Completely Transformed Beam

Appendix D: Input Format for LS-DYNA3D

D.1 The Yield surface of the Two-Invariant Cap Model in Pressure $\sqrt{\mathrm{J}_{2 \mathrm{D}}}-J_{1}$ Space

D.2 Representation of the Parameter FCUT 


\section{Nomenclature}

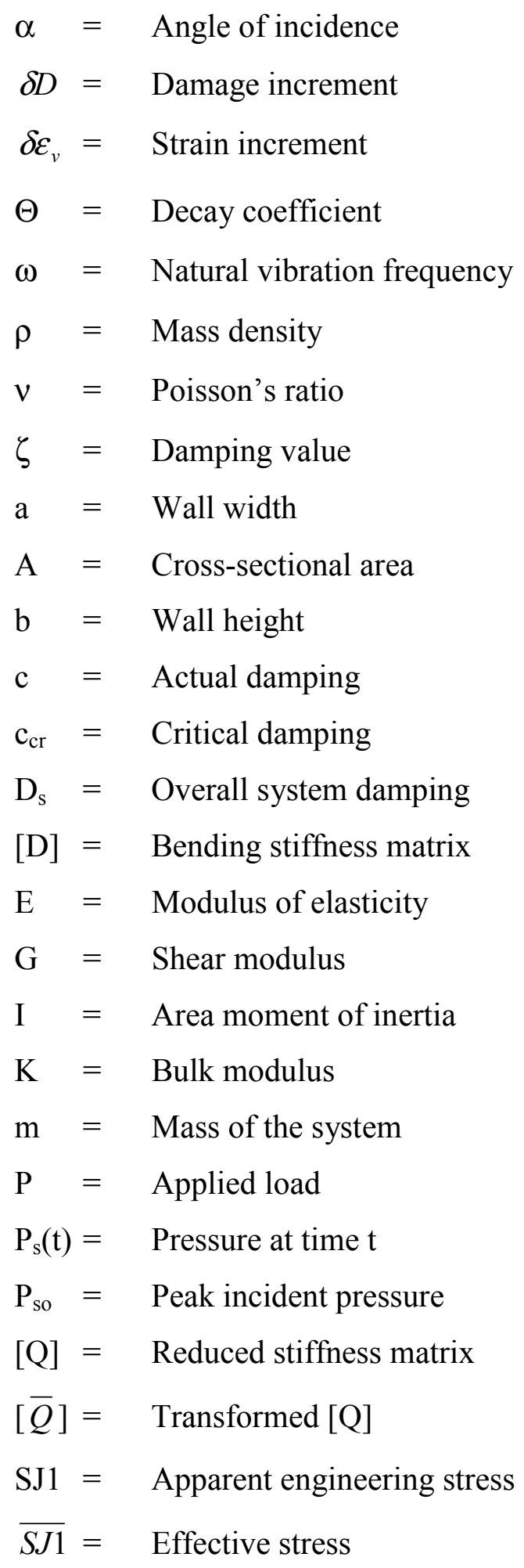




\section{CHAPTER 1}

\section{Introduction and Literature Review}

\subsection{Introduction:}

The value of externally reinforcing existing structures with fiber reinforced composite materials is becoming increasingly important in today's society. For military applications, there are obviously many circumstances where added protection of structures is important, including protection against bombs, mortars, grenades and small caliber rounds. Applications in the civilian world are becoming more important following major bombings around the world, including two major ones recently in the United States, the World Trade Center Building in New York in February, 1993 and the Alfred P. Murrah Federal Building in Oklahoma City in April, 1995.

Blast loads from bomb explosions are unlike other types of loading, in that the maximum load occurs at the initial wave impact with the structure and the entire load is applied within milliseconds instead of seconds. This dynamic loading is very destructive compared to static loadings and therefore, added protection for existing structures is needed to ensure the survival of the structure and what it is housing during a blast.

A finite element model was developed for predicting the value of adding a composite material to an existing structure. There are many different finite element material models for the multitude of materials that exist. For example, there are models for elastic, orthotropic elastic, kinematic/isotropic plasticity, linear viscoelastic, etc. Also, within the many models there are variations, including whether or not there is failure. Some of these models 
represent their prospective materials very well when compared to experimental data. However, others do not provide the acceptable values obtained in documented experimental procedures. Concrete is not a homogeneous material, therefore, it is very difficult to model, especially as the specimen accumulates damage (i.e. cracks). Concrete is the basic model developed in this research due to the many applications in military and civilian structures.

The efficiency of modeling concrete using a finite element program is apparent when considering the time and cost of full-scale tests. An acceptable material model is developed by comparing a finite element model with previously completed experimental work. This model can then be expanded to design and test full-scale structures without the need to physically build them.

One key problem encountered is that there are so many types of concrete that few people agree on any one model. Therefore, models that are developed are usually material and application specific and kept within the company using them.

To successfully model a concrete wall, a concrete model with damage must first be developed and tested using existing concrete data. This is accomplished using a variation of the two-invariant cap model, LS-DYNA3D material model 25. LS-DYNA3D is an explicit, nonlinear finite element modeling program developed by Livermore Software Technology Corporation [LSTC, 1996]. A damage model, UMAT43, was developed using this cap model and validated using the experimental work of Jerome [1996] and Faza, et al [1995].

Once the concrete material model was developed and successfully compared to other experimental work, a concrete wall was modeled and subjected to a blast load. The same wall was then covered with a layer of composite material and again subjected to the same blast load. The results were then compared. 


\subsection{Literature Review:}

Blast mitigation is a subject of much consideration for research in today's society. Unfortunately, much of the data is considered proprietary by private companies, so many do not publish the results of their testing, be it experimental or theoretical. Few facilities have adequate setups to perform explosive testing. However, there are recurring conferences and technical sessions with pertinent information relating to this research. These include, but are not limited to, Structures Under Shock and Impact [Bulson, 1989], American Concrete Institute (ACI) Short Duration Dynamic and Vibratory Load Effects [Bounds, 1998] and American Society of Mechanical Engineers (ASME) Pressure Vessels and Piping Conference [Shin and Zukas, 1996].

The feasibility of retrofitting existing structures with advanced composite materials (ACM) for blast protection was studied by Barbero, et al. [1997]. They found an increase in strength and energy absorption under static loads and expected to have similar effects for blast loads. The U.S. Army Engineer Waterways Experimental Station (WES) also evaluated the use of ACM for use in field construction and retrofitting of existing structures [Cummins, et al., 1997]. They believe that ACM have potential in blast protection, but express the importance of future research to be able to adopt these materials effectively.

The military has studied the effects of blast loading for years. The task of transferring this information to the civilian world has been studied by the National Research Council [1995]. They found that several barriers exist that hinder the effective transfer of information to the civilian sector. These include the lack of proper education transfer to students for designing for blast effects, the military being slow to funnel the classified information to the 
public, and the extra costs associated with designing and manufacturing structures that incorporate blast-hardening. Unclassified technical design manuals exist that can greatly help designers and engineers with blast protection of civilian structures, such as Structures to Resist the Effects of Accidental Explosions Manual [TM 5-1300, 1990]. This manual includes fundamental principles, analysis and design procedures for dynamic loading.

Experimental studies have been carried out by Ross, et al. [1997]. They used ammonium-nitrate-fuel-oil (ANFO) to subject concrete beams and slabs to blast loads. They tested both control specimens of internally reinforced concrete beams and slabs and the same specimens externally reinforced with carbon fiber reinforced plastic (CFRP). The results showed most of the damage to the CFRP specimens occurred due to the blast wave (Chapter 2) reflected from the test stand.

There are companies that have developed composite blast proofing systems to protect workers from industrial explosions and terrorist attacks. These systems are fundamental in protecting people from collapsing walls and shattering masonry, which often kill more people than the explosion. For instance, it has been estimated that at least 80 percent of the deaths at the Alfred P. Murrah Federal Building in Oklahoma City were caused by the structure falling on occupants, who might otherwise have survived the explosion [Prendergast, 1995]. DuPont ${ }^{\mathrm{TM}}$ is one of the companies that currently sell such a blastproofing system [Hranac, 2001].

Finite-element modeling of concrete by itself has been a focus of research for many. There are numerous forms of concrete and adding reinforcements only complicates the model. There has been experimental work with reinforcement arrangement [Taylor, et al., 1966] and efforts to generate efficient reinforcement modeling in finite-element concrete 
structures [Barzegar and Maddipudi, 1994]. Miyamoto, et al. [1994] also pointed out that static based analysis is not acceptable for dynamic loading of concrete structures.

Many researchers that have worked on modeling the intricacies of concrete. Marzouk and Chen [1993] performed direct finite-element analysis of high-strength concrete slabs by varying the reinforcement ratios, width-to-thickness ratios, various concrete strengths and reinforcement yield strengths. In depth modeling of deformation and cracking of early-age concrete due to the curing process has been studied by de Borst and van den Boogaard [1994].

Beshara and Virdi [1992] developed their own finite-element linear and nonlinear dynamic analysis computer program to study the effects of impulsive and blast loading on two-dimensional reinforced concrete structures. The results obtained for the deflection at mid-span and along the beam were in good agreement with results published by experimental researchers.

Existing concrete models, specifically in LS-DYNA3D, have been calibrated to better represent experimentally observed material behavior [Malvar, et al., 1995 and 1997]. This was using material model 16, the pseudo tensor concrete/geological model. The twoinvariant plasticity model was first enhanced to a three-invariant formulation in compression. The second enhancements also addressed the issues of the model in tension. This model was even used in blast load configurations [Crawford, et al., 1997]. They studied the effectiveness of jacketing columns of reinforced concrete with steel and composite and subjecting them to blast loads. They found that jacketing the columns prevented the ultimate failure of most of the beams and kept the reinforced concrete structure being supported from collapsing. 


\section{CHAPTER 2}

\section{Blast Loading of a Hybrid Wall}

\subsection{Blast Wave Phenomena}

During typical pressure loading, a structure starts at an initial zero state and is incrementally loaded until the desired load is reached. This may be a specified maximum or until failure. Step loading if very helpful in understanding structural responses. Unfortunately, blast loads behave very differently.

Blast loads due to an explosion are very violent releases of energy. The shock wave travels radially from the center of the explosion as a hot gas sphere [Kornhauser, 1964]. The blast wave generated creates an almost instantaneous rise to the peak pressure from an ambient pressure (Fig. 2.1). The intensity of the peak incident pressure decreases with the distance from the initial blast and the application of the overpressure is dissipated in milliseconds. 


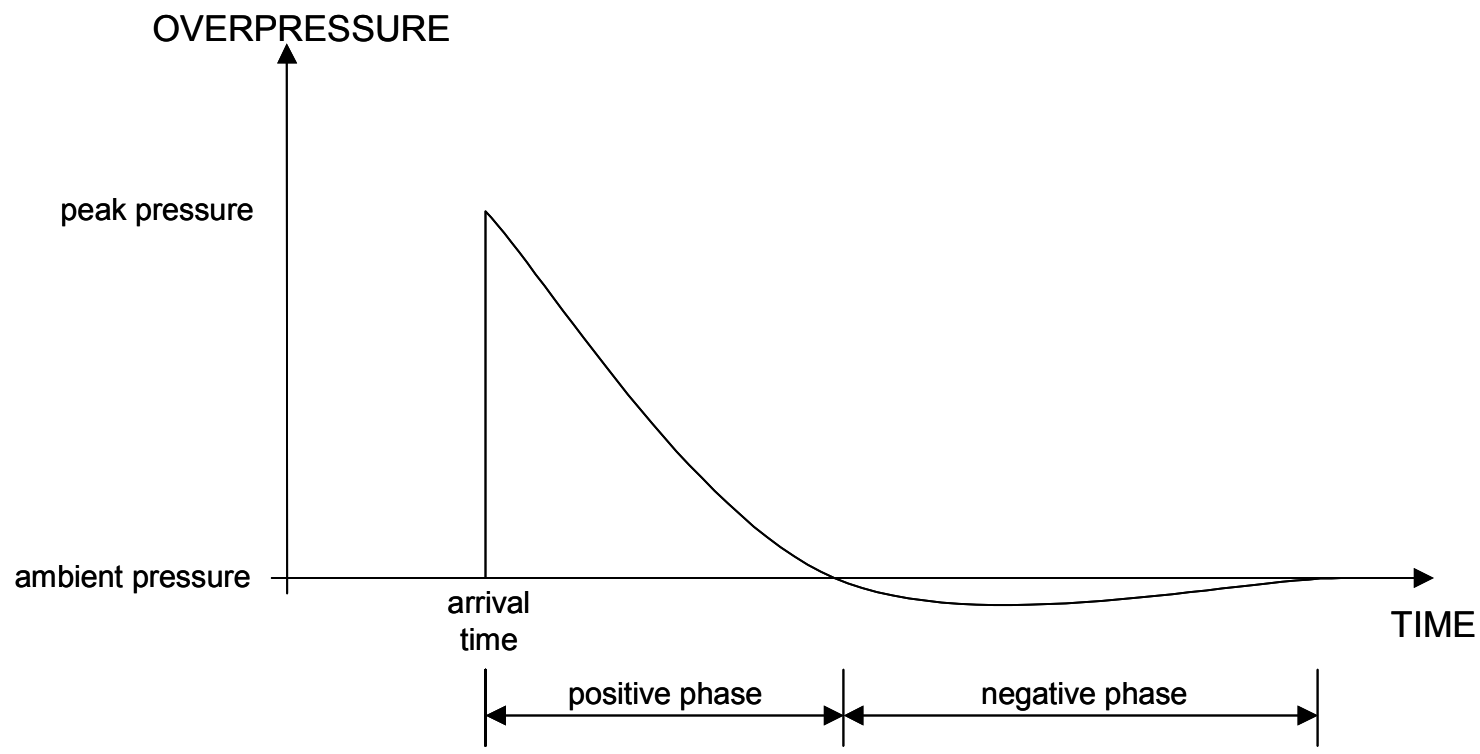

Figure 2.1 - Idealized Pressure vs. Time Blast Wave

The overpressure versus time curve of Fig. 2.1 can be described as follows. At any location within the blast zone, there is an arrival time of the blast wave. For all practical purposes, this is considered the time the peak incident pressure occurs. The pressure then decreases during the positive phase duration until it reaches the original ambient pressure. From here, there is a reversal of the particle flow creating a negative overpressure. This is the negative phase duration, which lasts longer than the positive phase duration. The negative phase is not as important in the design of structures as the positive phase [TM 5855-1, 1986]; therefore, it will be neglected in this research. Although these incident pressures can cause severe damage, the greatest pressures incurred are from the reflection of the shock wave (Fig 2.2). 


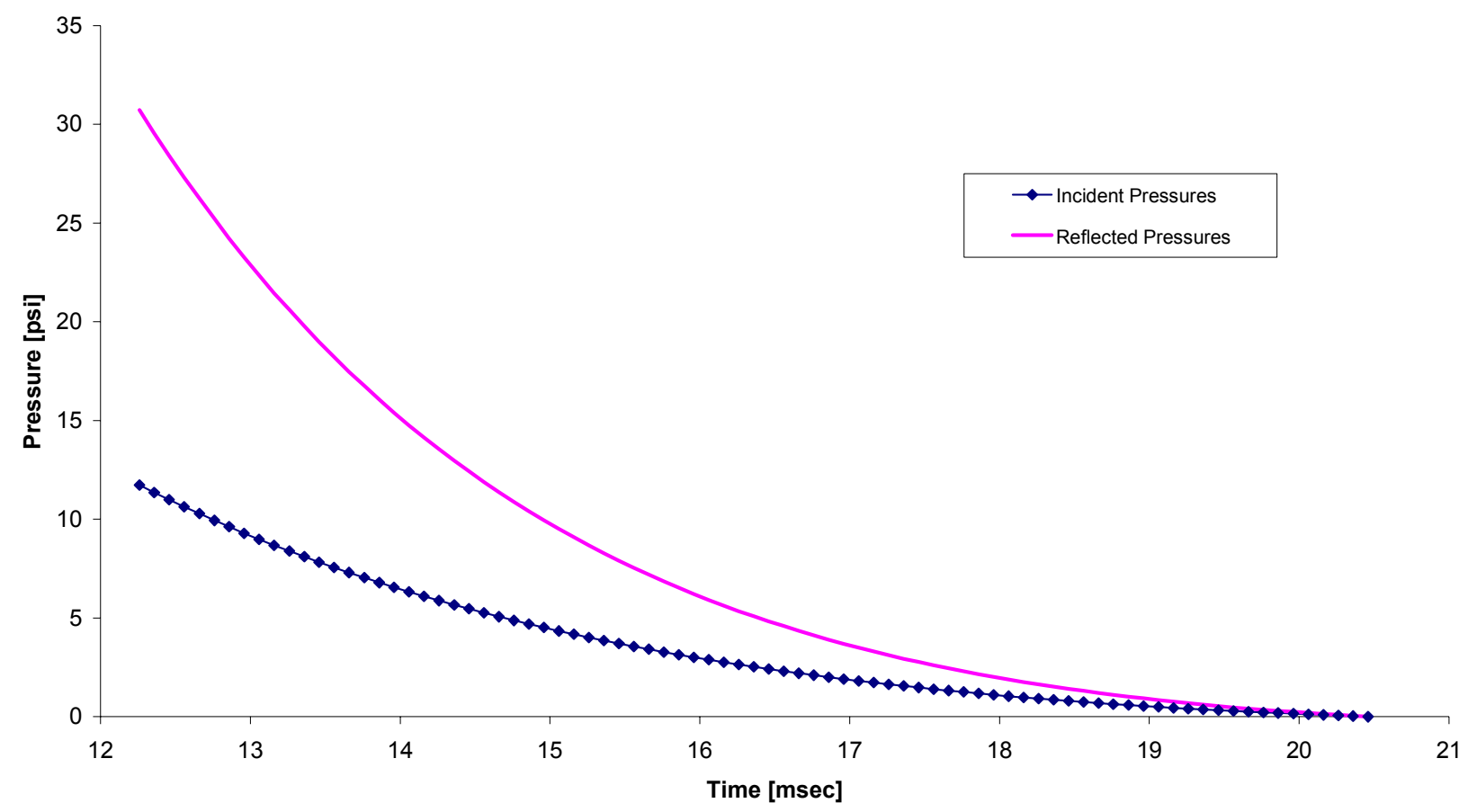

Figure 2.2 - Incident vs. Reflected Pressures

If the wave encounters a surface as it moves away from the initial blast, that wave is reinforced and reflected. The magnitude of this reflected wave corresponds directly to the incident pressure and the angle of the surface. The peak reflected pressure is maximum at the point of initial shock wave contact. As the angle of incidence, $\alpha$, of the surface increases, becomes more parallel with the blast wave, the magnitude of the reflected wave decreases (Fig. 2.3). 


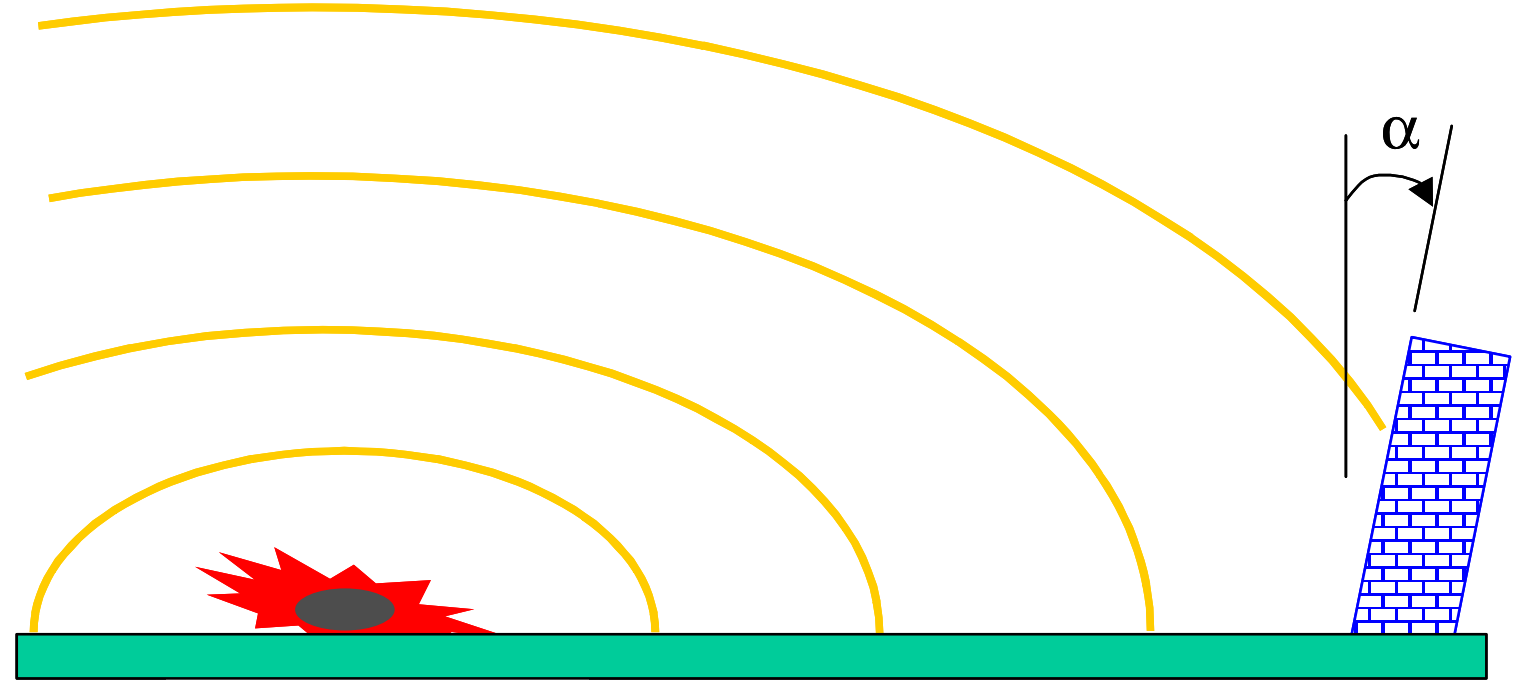

Figure 2.3 - Blast Wave Depiction

Except for the duration of the blast event, it is recommended for design purposes to use the reflected overpressure and corresponding parameters [Baker, 1973]. The duration used should be calculated with the incident values.

\subsection{Determining Pressure Curves}

To symbolize blast loads in LS-DYNA3D, pressure versus time curves must be developed and entered as load curves into the model. These load curves can then be associated with the location of the pressure acting on the wall. To determine the input pressure curves from an explosion, the US Army's Conventional Weapons Effects Program, CONWEP [1992], was used. The wall was modeled as an $8 \times 12$ feet target area on a $24 \times 36$ feet reflecting surface with a wall thickness of 6 inches (Fig. 2.4). These areas were chosen to represent the side of small building. 


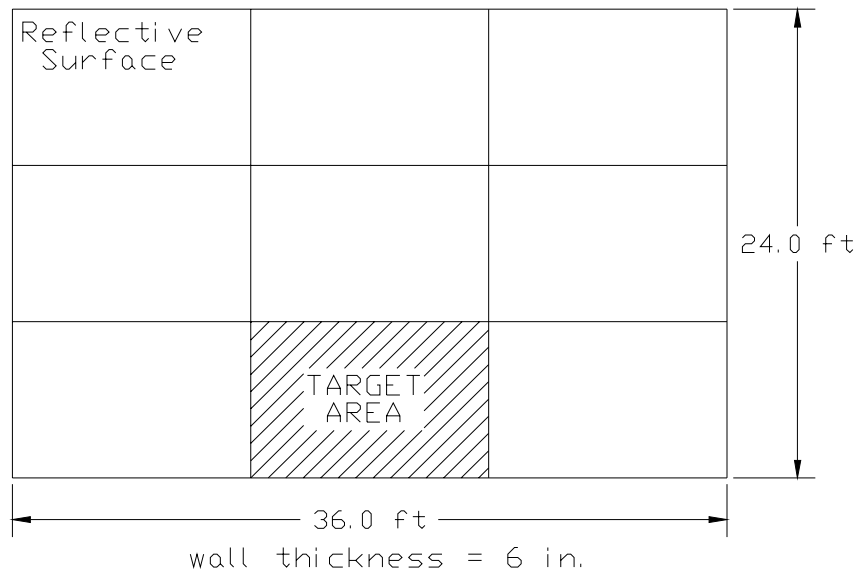

Figure 2.4 -- Wall as Modeled in CONWEP

To produce the desired blast strength, a general-purpose bomb was created using CONWEP. The bomb consisted of 37 pounds of trinitrotoluene (TNT) and was placed at a standoff distance of 30 feet from the wall (Table 2.1 and Fig. 2.5).

Table 2.1 -- General Purpose Bomb

\begin{tabular}{|l|c|}
\hline Name & Matt Prototype 1 \\
\hline Total Weight, lb. & 80 \\
\hline Charge Weight, lb. & 37 \\
\hline Case Weight, lb. & 43 \\
\hline Explosive Used & TNT \\
\hline Assembled Length, in & 24 \\
\hline Case Diameter, in & 8.25 \\
\hline Caliber Radius Head & 0 (flat ends) \\
\hline Armor-Piercing? & No \\
\hline
\end{tabular}
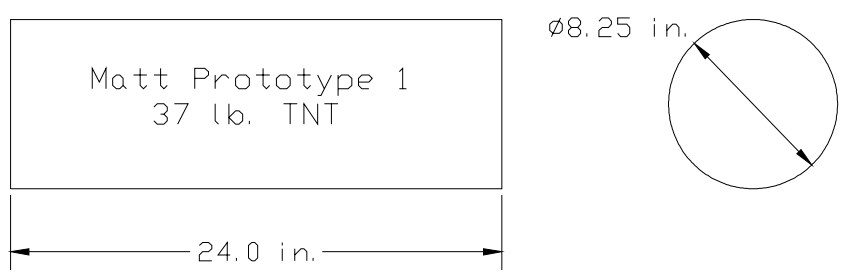

Figure 2.5 -- Bomb Dimensions 
The pressure versus time curves needed for LS-DYNA3D were calculated with a QuickBasic program, “T\&P.BAS,” (Appendix A) using the time dependent pressure equation given by Kingery and Bulmash [1984].

$$
P_{s}(t)=P_{s o} *\left[1-\left(t-t_{a}\right) / t_{o}\right] * \exp \left[-\left(t-t_{a}\right) / \Theta\right]
$$

where: $P_{S}(t)=$ pressure at time $t$

$P_{\text {so }}=$ peak incident pressure

$t_{o} \quad=$ positive phase duration

$t_{a} \quad=$ arrival time

$\Theta \quad=$ decay coefficient

All of the unknowns in the equation, the peak incident pressures, the positive phase duration, the arrival times and the decay coefficient, were found using CONWEP. First, the decay coefficient and the positive phase duration were computed using the Hemispherical surface burst option, which is found under the Airblast and Aboveground detonation menus. For a 37 pound TNT bomb at a range of 30 feet, the reflected pressure decay coefficient was found to be 3.700 milliseconds and the duration of the blast was 8.222 milliseconds.

Next, the initial peak pressure distribution was found for the target area of the wall. This was accomplished by using the Loads on structures option found under the Airblast menu. After entering the wall dimensions, as shown in Fig. 2.4, the pressure distribution was displayed using contour lines. The peak pressures were then found using the read command at 81 nodes symmetrically located across the wall (Fig. 2.6). 


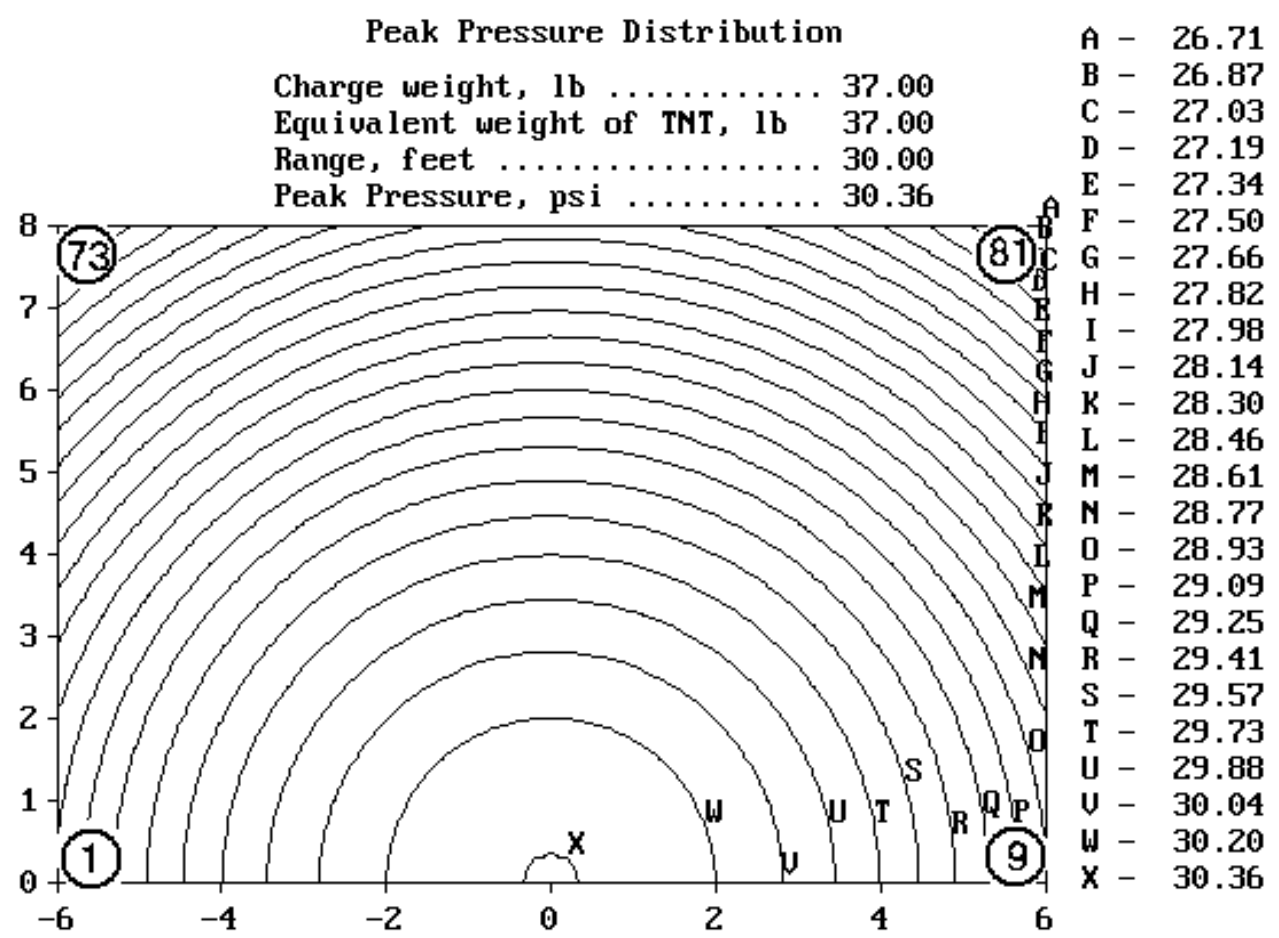

Figure 2.6 -- Peak Pressure Distribution on the Target Surface

The time of arrival of the initial pressure for each of the 81 nodes was then found.

This is accomplished by first finding the distance to each node from the 30 feet standoff distance. These values can then be entered, one at a time, into CONWEP under the Airblast, Aboveground detonation, Hemispherical surface burst options. The range to target is changed to the distance for each of the 81 nodes and CONWEP returns a value for the arrival time. It should be noted that the arrival times are symmetric about the vertical centerline of the wall. This procedure was simplified by deriving the above equations and adding them directly to the QuickBasic program, "T\&P.BAS."

All of the variables of Eq. 2.1 were then known, so the pressure versus time curves for LS-DYNA3D were calculated using the QuickBasic program. The program then returns the pressure-time curves and the pressure/node locations needed for input into LS-DYNA3D as data files (Appendix B). These files are used in LS-INGRID [LSTC, 1995] to create the input geometry for use with LS-DYNA3D. 


\section{CHAPTER 3}

\section{Damping Calculations}

\subsection{Background:}

All materials and structures exhibit a damping factor. Damping occurs as the vibration input into a system diminishes in amplitude with time. This energy is generally transformed to heat by friction.

LS-DYNA3D allows materials to have individual damping constants. These can be input as a constant value if only one material is being modeled. If more than one material is used, this damping constant can be applied as a load curve for each of the materials. Models using the critical damping constant are generally the best for convergence.

\subsection{Plain Concrete Modeled as a Wall:}

The concrete wall was modeled as a composite plate to determine the natural frequencies. An equation was derived to associate the natural frequency and the damping ratio to the overall system damping constant for LS-DYNA3D. The natural frequency of the system was calculated using the following equations, obtained from Reddy [1997].

$$
\begin{gathered}
\omega_{m n}^{2}=\frac{\pi^{4}}{\tilde{I}_{o} b^{4}}\left[D_{11} m^{4}\left(\frac{b}{a}\right)^{4}+2\left(D_{12}+2 D_{66}\right) m^{2} n^{2}\left(\frac{b}{a}\right)^{2}+D_{22} n^{4}\right] \\
\tilde{I}_{o}=I_{o}+I_{2}\left[\left(\frac{m \pi}{a}\right)^{2}+\left(\frac{n \pi}{b}\right)^{2}\right]
\end{gathered}
$$




$$
\mathrm{I}_{\mathrm{o}}=\sum_{\mathrm{k}=1}^{\mathrm{L}} \rho_{\mathrm{o}}^{(\mathrm{k})}\left(\mathrm{z}_{\mathrm{k}+1}-\mathrm{z}_{\mathrm{k}}\right) \quad \mathrm{I}_{2}=\frac{1}{3} \sum_{\mathrm{k}=1}^{\mathrm{L}} \rho_{\mathrm{o}}^{(\mathrm{k})}\left(\mathrm{z}_{\mathrm{k}+1}^{3}-\mathrm{z}_{\mathrm{k}}^{3}\right)
$$

The wall dimensions are shown in Fig. 3.1 and the properties of the concrete wall are given in Table 3.1. This is assuming that the properties of the concrete are equivalent in all directions when modeled as a composite.

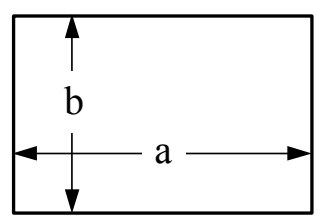

Figure 3.1 -- Wall Dimensions

Table 3.1 -- Concrete Wall Properties

\begin{tabular}{|c|c|c|c|c|c|c|}
\hline $\begin{array}{c}\text { Length } \\
\text { (a) }[\mathrm{in}]\end{array}$ & $\begin{array}{c}\text { Height } \\
\text { (b) }[\mathrm{in}]\end{array}$ & $\begin{array}{c}\text { Thickness } \\
(\mathrm{t})[\mathrm{in}]\end{array}$ & $\begin{array}{c}\text { Modulus of } \\
\text { Elasticity (E) [psi] }\end{array}$ & $\begin{array}{c}\text { Density ( }()_{1} \\
{\left[\mathrm{lbs} \cdot \mathrm{sec}^{2} / \mathrm{in}^{4}\right]}\end{array}$ & $\begin{array}{c}\text { Shear Modulus } \\
(\mathrm{G})[\mathrm{psi}]\end{array}$ & $\begin{array}{c}\text { Poisson's } \\
\text { Ratio (v) }\end{array}$ \\
\hline 144 & 96 & 6 & $3.00 \mathrm{e} 6$ & $1.77 \mathrm{e}-4$ & $1.15 \mathrm{e} 6$ & 0.2 \\
\hline
\end{tabular}

Using the properties of Table 3.1, the values of the reduced stiffness matrix [Q] were computed by applying the equations given in Barbero [1999].

$$
[Q]=\left[\begin{array}{ccc}
3.13 & 0.625 & 0 \\
0.625 & 3.13 & 0 \\
0 & 0 & 1.15
\end{array}\right] \times 10^{6} \mathrm{psi}
$$

Assuming that the fibers are oriented along the $\mathrm{x}$-axis $\left(0^{\circ}\right)$, then the transformed reduced stiffness matrix [Q̄] equals the reduced stiffness matrix [Q]. Next, the bending stiffness matrix [D] was computed [Barbero, 1999].

$$
[D]=\left[\begin{array}{ccc}
56.3 & 11.3 & 0 \\
11.3 & 56.3 & 0 \\
0 & 0 & 20.8
\end{array}\right] \times 10^{6} \mathrm{psi} \cdot \mathrm{in}^{3}
$$


The moments of inertia were calculated using Eq. 3.3 and then $\tilde{I}_{o}$ was found with Eq. 3.2. Two fundamental frequencies were examined to determine the minimum natural frequency. These were $\omega_{11}$ and $\omega_{21}$, and were subsequently solved using Eq. 3.1. The results were

\begin{tabular}{|c|c|}
\hline$\omega_{11}(\mathrm{rad} / \mathrm{sec})$ & $\omega_{21}(\mathrm{rad} / \mathrm{sec})$ \\
\hline 350.5 & 671.9 \\
\hline
\end{tabular}

Finally, the overall damping constant for the entire system, to be used in the LSDYNA3D input file, can be computed. The damping value, $\zeta$, used for a concrete wall was 0.02 [Steidel, 1989]. The overall damping equation is derived from the following equations [Beards, 1983, Bachmann, 1987, Hallquist, 1993].

$$
\begin{gathered}
\zeta=\frac{\mathrm{c}}{\mathrm{c}_{\mathrm{cr}}} \\
\mathrm{c}_{\mathrm{cr}}=2 \omega_{1} \mathrm{~m} \\
\mathrm{D}_{\mathrm{s}}=\frac{\mathrm{c}}{\mathrm{m}}
\end{gathered}
$$

Where $\mathrm{c}$ is the actual damping, $\mathrm{c}_{\mathrm{cr}}$ is the critical damping and $\mathrm{m}$ is the mass of the system. The overall damping equation can then be derived.

$$
\mathrm{D}_{\mathrm{s}}=2 \zeta \omega_{1}
$$

Since $\omega_{11}$ is the smallest frequency, it was used as the natural frequency, $\omega_{1}$. Therefore, the system damping constant was found using Eq. 3.5 to be 14.02 .

\subsection{Unreinforced Concrete Beam Model:}

This model contains the actual dynamic loading of the system; therefore, the system damping constant should be that of the actual system. To find this value, the natural frequency of the beam must first be calculated [Nashif, et al., 1985]. 


$$
\omega_{n}=\frac{\xi_{n}^{2}}{L^{2}} \sqrt{\frac{E I}{\rho H b}} \quad \xi_{n}=n \pi \quad(n=1,2, \ldots)
$$

Where $L$ is the length, $H$ is the height, $b$ is the width of the beam, $E$ is the modulus of elasticity, $I$ is the area moment of inertia and $\rho$ is the mass density. For a rectangle, the area moment of inertia can be calculated using Eq. 3.7.

$$
I=\frac{1}{12} b H^{3}
$$

Finally, the overall damping constant for the entire system (to be used in LSDYNA3D) can be computed. The damping value, $\zeta$, used for concrete beams, was 0.007 [Bachmann and Ammann, 1987]. Since $\omega_{1}$ is the smallest frequency, it was used as the natural frequency and solved using Eq. 3.5. Therefore, the system damping constant was found to be 18.6. For the unreinforced concrete beam with CFRP reinforcement, the system damping constant was found to be 46.4. The CFRP calculations were performed using a variation of the previous equations as explained in the next section.

\subsection{Reinforced Concrete Beam Model:}

During the actual test, the load was applied at a constant rate with brief stops every 2000 pounds for data collection. Because LS-DYNA3D is a dynamic program, modeling a quasistatic loading case is very time consuming and computationally expensive. At faster loading rates, the beam has a tendency to oscillate and take time to approach the real solution. This can be overcome by setting the overall damping constant of the system $\left(D_{s}\right)$ equal to its critical value. To achieve this, the damping ratio $(\zeta)$, in Eq. 3.5 , is set equal to one. 
Finding the natural frequency $\left(\omega_{1}\right)$ of the reinforced concrete model is somewhat complicated. The problem occurs in finding the area moment of inertia because several different materials are used. Using the case of a steel plate on the bottom, tensile side, of the beam as an example, the Transformed Section Method [Barbero, 1999] is applied to find the area moment of inertia. For this problem, the value of $\rho H b$ in the denominator of Eq. 3.6 is transformed to $\rho_{\mathrm{c}}\left(\Sigma \mathrm{A}_{\mathrm{c}}\right)+\rho_{\mathrm{s}}\left(\Sigma \mathrm{A}_{\mathrm{s}}\right)$, where the subscripts $\mathrm{c}$ and $\mathrm{s}$ denote concrete and steel, respectively.

Figure 3.2(a) shows the original cross-section of the reinforced concrete beam with a steel plate on the bottom, tensile side. The steel plate has a width of 5.906 inches and a thickness of 0.177 inches. Next, the reinforcement bars are changed to equivalent steel rectangles, spanning the width of the concrete beam (Fig. 3.2(b)). After the reinforcement bars are adjusted, the concrete width has to be adjusted based upon the following ratio, assuming steel is the reference material.

$$
\eta_{c}=\frac{E_{c}}{E_{s}}
$$



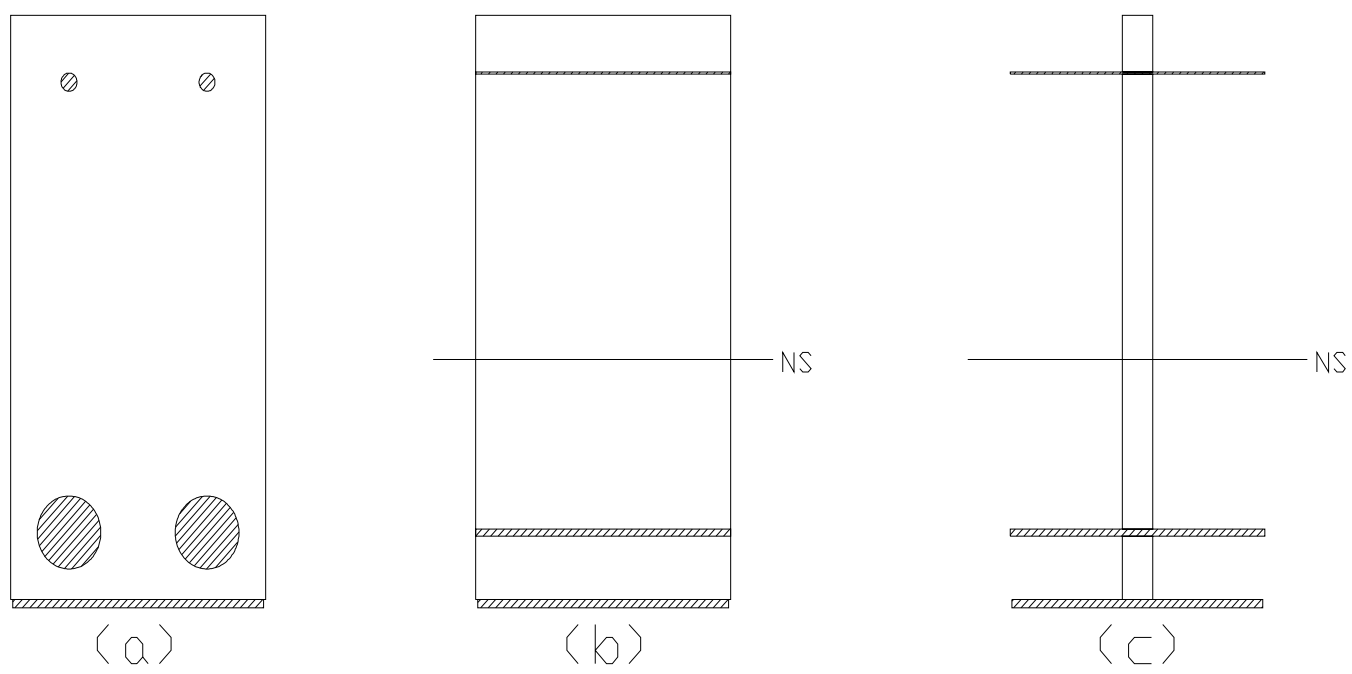

Figure 3.2 - Transformed Section Method Used With the Reinforced Concrete Model

The new width of concrete, $\mathrm{w}_{\mathrm{c}}$, , can then be found.

$$
w_{c}{ }^{\prime}=\eta_{c} w_{c}
$$

Where $w_{c}$ is the original width of the concrete, in this case 6 inches (Fig. 3.2(c)). To find the area moment of inertia, the neutral surface (NS) has to first be found using statics. After finding the neutral surface, the area moment of inertia can also be found using statics techniques. Finally, the values can be substituted into Eq. 3.6, using the reference modulus of elasticity ( $E_{\mathrm{s}}$ in this case) to solve for the natural frequency. Assuming critical damping $(\zeta$ $=1$ ), Eq. 3.5 can be solved for the overall damping constant. For the case of the steel plate reinforced concrete, the value was found to be 1643. This example is solved step-by-step in Appendix C. The values for all of reinforced concrete beams can be found in Table C.4. 


\section{CHAPTER 4}

\section{Material Modeling}

\subsection{The Concrete Damage Model:}

A large portion of this research was dedicated to developing a new concrete material model for LS-DYNA3D. The new designation is material type 43 or UMAT43. The input format for LS-DYNA3D, in structured format, can be found in Appendix D.

An inviscid, two-invariant geologic cap model (Fig. 4.1), was chosen as a basis to develop the damage model. This is LS-DYNA3D material type 25 [LSTC, 1996]. Surface $F_{e}$ is the failure envelope (yield surface), $F_{c}$ is the cap surface and the tension cutoff is the vertical line above T. The elements used were eight node, solid hexahedron elements, which were chosen for their efficiency in modeling simple rectangular structures. The existing code for the two-invariant cap model, obtained from Chen and Baladi [1985], was implemented into a Fortran program (Appendix E). A driver program (Appendix F) was also developed to simulate the results, so that LS-DYNA3D would not have to be compiled and executed each time a change was made. This saved time, because only basic information was needed while the program was being developed. After ensuring that the original cap model provided by Chen and Baladi performed the same as the original LS-DYNA3D cap model, the model was further developed to include damage. 


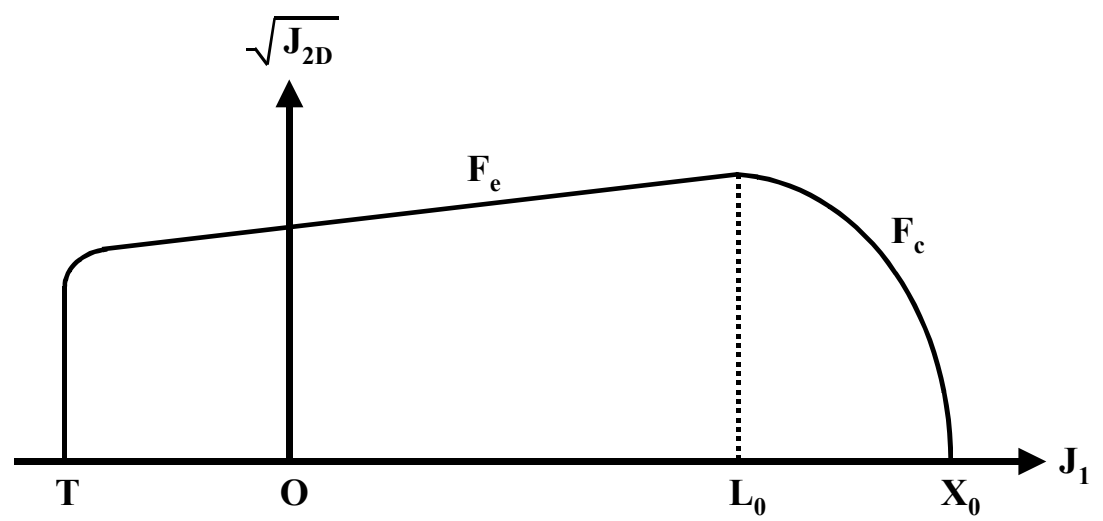

Figure 4.1 - The Yield Surface of the Two-Invariant Cap Model in Pressure $\sqrt{\mathrm{J}_{2 \mathrm{D}}}-J_{1}$ Space

The cap model works satisfactorily in compression. The existing code allows for movement of the cap, which allows for material hardening to occur. In tension, however, the strength of the concrete remains constant. Even after cracking and subsequent deterioration occurs, the tensile strength of the concrete remains at the user specified value of the tension cutoff. This value is not acceptable for a material that has cracking and must be adjusted to account for damage. Variations to the cap model are not uncommon. Others that have made modification to it are Simo, et al. [1988] and Schwer and Murray [1994].

To adjust the new cap model to include damage, the following equations had to be included in the program. First, the apparent engineering stress, $S J 1$, had to be computed using the load $(P)$ and the original area $\left(A_{o}\right)$.

$$
S J 1=\frac{P}{A_{o}}=\sigma_{X}+\sigma_{Y}+\sigma_{Z}
$$

Next, the effective stress $(\overline{S J 1})$ had to be calculated for use internally in the UMAT43 program. This needed to include a damage parameter (D), which is initially set to zero (no damage).

$$
\overline{S J 1}=\frac{S J 1}{1-D}
$$


Now, if the effective stress is less than the tension cutoff $(T)$, damage has to be introduced. The reason the effective stress is less than the tension cutoff, instead of more, is that the cap model assumes that compression is positive and tension is negative. When it is less than the tension cutoff, it has migrated to the left of the tension cutoff surface. Once damage is introduced, the effective stress is reset to the current value of the tension cutoff and the apparent stress is recalculated.

$$
S J 1=\overline{S J 1} *(1-D)
$$

LS-DYNA3D then uses this value when making computations on the modeled structure.

Finally, the damage increment and total damage have to be calculated and implemented into the model. To calculate the damage increment, the modulus of elasticity $(E)$ has to first be computed using the shear $(G)$ and bulk $(K)$ modulii [Aboudi, 1991].

$$
E=\frac{9 G K}{3 K+G}
$$

Next, the damage increment can be calculated using the tensile damage parameter $(T D P)$, which is equal to the tension cutoff divided by four [Janson and Hult, 1977], and the current strain increment $\left(\delta \varepsilon_{v}\right)$.

$$
\delta D=\frac{E^{*} \delta \varepsilon_{v}}{T D P}
$$

This damage increment is then added to the previous damage parameter (initially zero) to compute the damage for the current increment of strain. This damage value is then used during the next strain increment iteration. The difference in modeling with and without damage can be seen in Fig. 4.2. The damage value never reaches a value of one, which could cause the model to crash. Instead, a limit of 0.95 is given to $\mathrm{D}$, allowing the smallest value of the apparent stress to be equal to $0.05 * \overline{S J 1}$. 


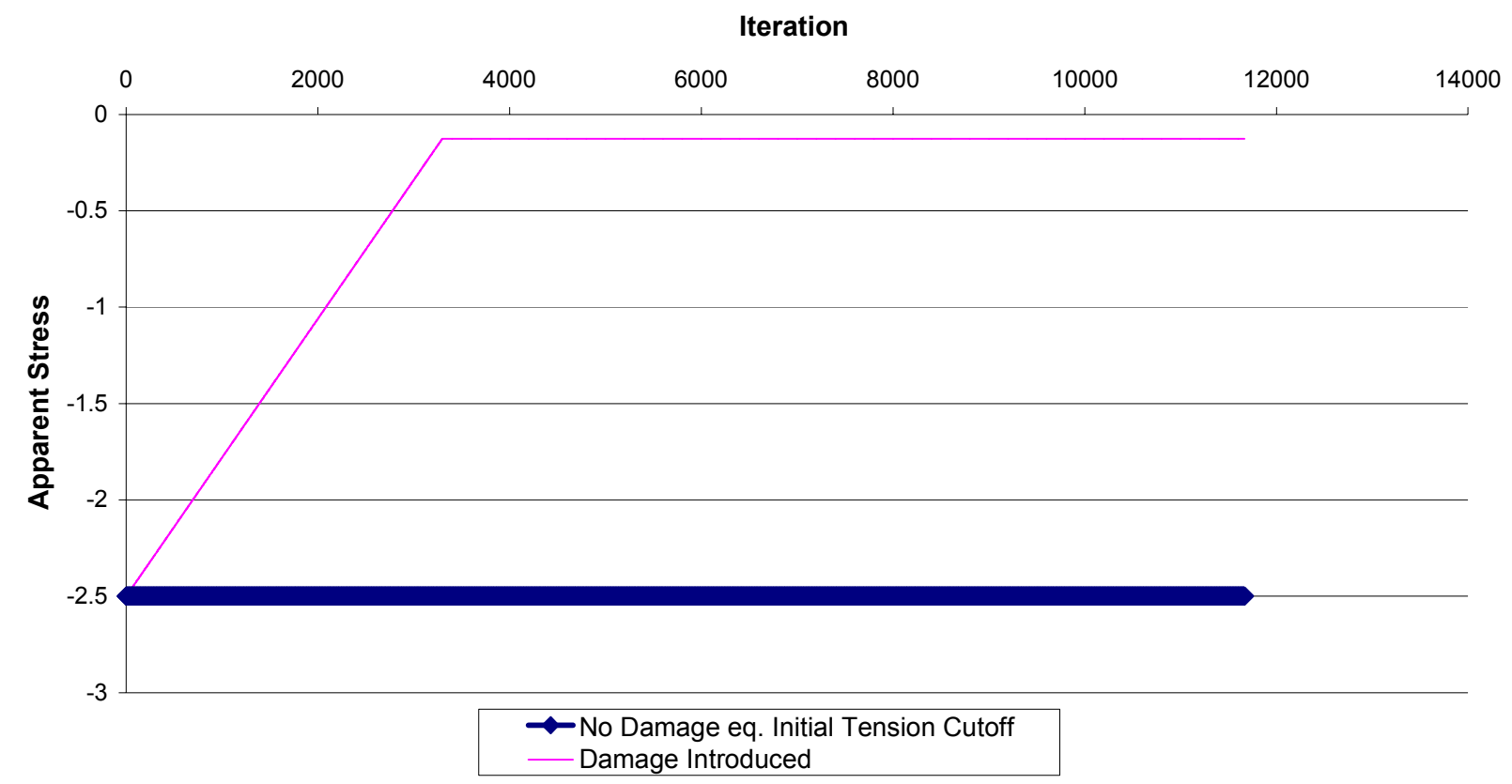

Figure 4.2 - Effect of Damage on Apparent Stress

To test the UMAT43 damage model, the value of TDP was set to $10^{12}$. As can be seen in Eq. 4.5, this causes the damage increment to be zero for all practical purposes, therefore, no damage is ever introduced. This was used with the UC concrete model and compared to the original LS-DYNA3D cap model, material model 25, that did not incorporate tensile damage (Fig. 4.3). 


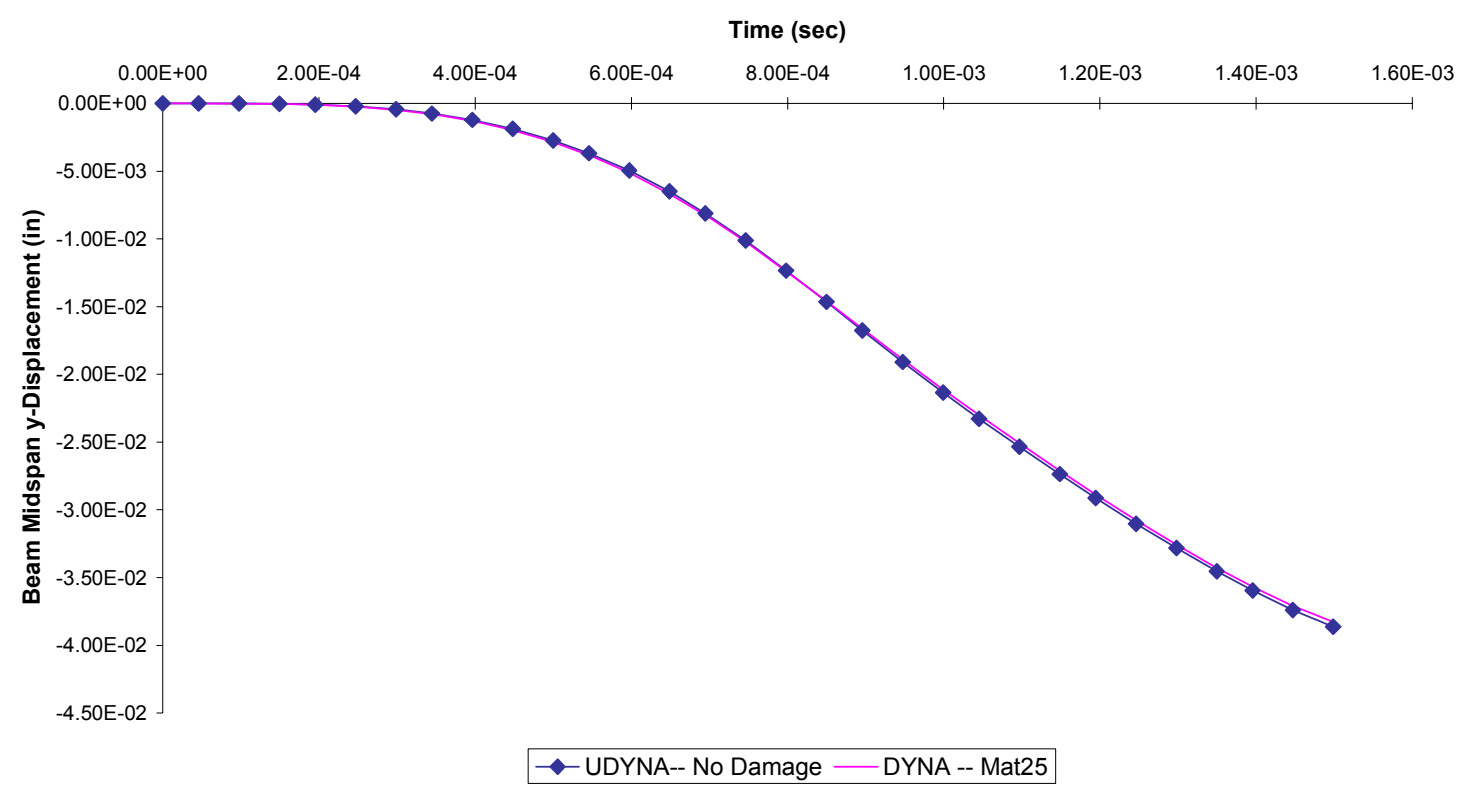

Figure 4.3 - Comparison of UMAT43 with LS-DYNA3D Material Type 25

Three additional parameters were added to the UMAT43 damage model. These were the initial $\mathrm{J}_{1}$ intersection of $\mathrm{F}_{\mathrm{e}}$ and $\mathrm{F}_{\mathrm{c}}$, denoted as $\mathrm{L}_{0}$ (Fig. 4.1), the tensile damage parameter (TDP), which is used in computing the damage accumulation, and FCUT (Fig. 4.4), the imaginary intersection of $\mathrm{J}_{1}$ and the $\mathrm{F}_{\mathrm{e}}$ curve. Eq. 4.6 is used to calculate $\mathrm{L}_{0}$ [Chen and Baladi, 1985].

$$
\alpha-\gamma e^{-\beta L_{0}}-\frac{X_{0}-L_{0}}{R}=0
$$

This equation was solved for $\mathrm{L}_{0}$ using a symbolic mathematical calculation program. The properties were then substituted and the resulting equation solved. 


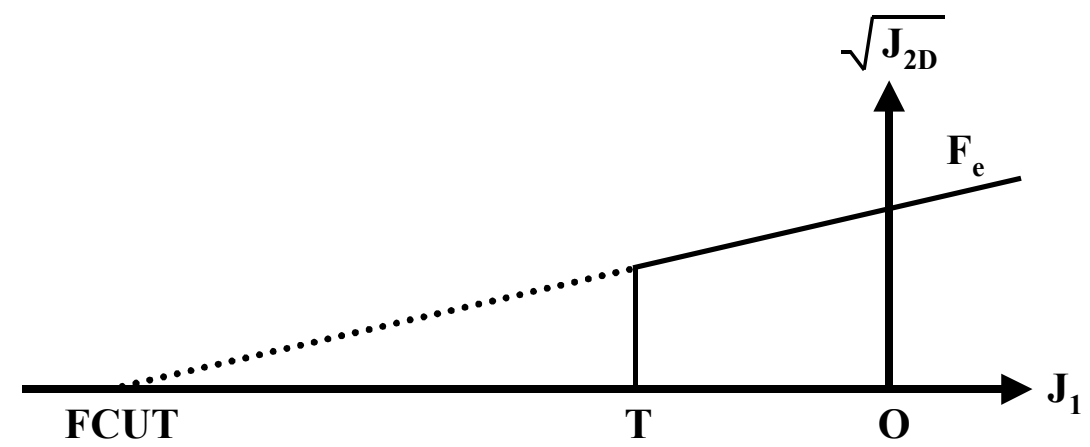

Figure 4.4 - Visualization of the Imaginary Intersection FCUT

The TDP and FCUT were calculated using the following equations.

$$
\begin{gathered}
T D P=\frac{T}{4} \\
F C U T=\frac{-1}{\beta} \ln \left(\frac{\alpha}{\gamma}\right)
\end{gathered}
$$

\subsection{The Unreinforced Concrete Beam Model:}

The properties of the concrete used for material type 43 are found in Table 4.1 [Jerome, 1996].

Table 4.1 - Properties of Unreinforced Concrete Beam Model

\begin{tabular}{|c|c|c|c|}
\hline $\boldsymbol{K}(\mathrm{psi})$ & $1.928 \times 10^{6}$ & $\boldsymbol{X}_{\boldsymbol{0}}(\mathrm{psi})$ & 18000 \\
\hline $\boldsymbol{G}(\mathrm{psi})$ & $1.446 \times 10^{6}$ & $\boldsymbol{L}_{\boldsymbol{0}}(\mathrm{psi})$ & 10440 \\
\hline $\boldsymbol{\rho}\left(\mathrm{lb}_{-} \mathrm{sec}^{2} / \mathrm{in}^{4}\right)$ & $1.77 \times 10^{-4}$ & $\boldsymbol{W}($ unitless $)$ & 0.884 \\
\hline $\boldsymbol{\alpha}(\mathrm{psi})$ & $0.7 \times 10^{3}$ & $\boldsymbol{D}\left(\mathrm{psi}^{-1}\right)$ & $1.54 \times 10^{-6}$ \\
\hline $\boldsymbol{\theta}$ (unitless) & 0.1 & $\boldsymbol{T}(\mathrm{psi})$ & -630 \\
\hline $\boldsymbol{x}(\mathrm{psi})$ & $0.2 \times 10^{3}$ & $\boldsymbol{T D P}(\mathrm{psi})$ & -157.5 \\
\hline $\boldsymbol{\beta}\left(\mathrm{psi}^{-1}\right)$ & $1.473 \times 10^{-3}$ & $\boldsymbol{F C U T}(\mathrm{psi})$ & -850.5 \\
\hline $\boldsymbol{R}$ & 10.8 & & \\
\hline
\end{tabular}


The plain concrete beams used for the unreinforced concrete (UC) beam model (Fig. 4.5) have a total length of 30 inches, a width and height of three inches and are simply supported 1.5 inches from each end. These beams were modeled using solid hexahedron elements of length 1.5 inches, height one inch and width one inch. By using a symmetry plane through the center of the beam, only half of the beam had to be modeled. This reduces computation time without sacrificing the accuracy of the results.

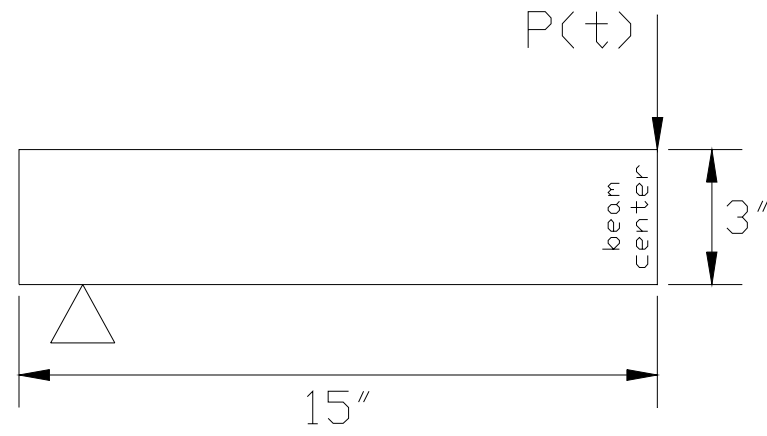

Figure 4.5 - UC Beam Model

All of the UC beams were loaded in three-point bending, using a drop weight impact machine. The pressure versus time loading curve for the plain concrete beams is given in Table 4.2.

Table 4.2 -- Pressure vs. Time Curve Used in Beam Loading of the Plain UC Beam

\begin{tabular}{|c|c|c|c|c|c|c|c|}
\hline $\begin{array}{c}\text { Time } \\
\left(\mathbf{1 0}^{-6} \mathbf{s e c}\right)\end{array}$ & $\begin{array}{c}\text { Pressure } \\
(\mathbf{k s i})\end{array}$ & $\begin{array}{c}\text { Time } \\
\left(\mathbf{1 0}^{-6} \mathbf{~ s e c )}\right.\end{array}$ & $\begin{array}{c}\text { Pressure } \\
(\mathbf{k s i})\end{array}$ & $\begin{array}{c}\text { Time } \\
\left(\mathbf{1 0}^{-6} \mathbf{~ s e c )}\right.\end{array}$ & $\begin{array}{c}\text { Pressure } \\
(\mathbf{k s i})\end{array}$ & $\begin{array}{c}\text { Time } \\
\left(\mathbf{1 0}^{-6} \mathbf{s e c}\right)\end{array}$ & $\begin{array}{c}\text { Pressure } \\
(\mathbf{k s i})\end{array}$ \\
\hline 0 & 0.000 & 300 & 0.903 & 600 & 2.457 & 900 & 0.893 \\
\hline 50 & 0.024 & 350 & 1.202 & 650 & 2.530 & 950 & 0.540 \\
\hline 100 & 0.067 & 400 & 1.568 & 700 & 2.385 & 1000 & 0.199 \\
\hline 150 & 0.189 & 450 & 1.925 & 750 & 2.192 & 1050 & 0.000 \\
\hline 200 & 0.397 & 500 & 2.173 & 800 & 1.537 & 1600 & 0.000 \\
\hline 250 & 0.645 & 550 & 2.324 & 850 & 1.189 & & \\
\hline
\end{tabular}

The second set of beams that Jerome tested was externally reinforced with three layers of carbon fiber reinforced plastic (CFRP) with a total thickness of 0.0195 inches. 
This layer of composite was added to the bottom, tensile side, of the beam. This material was also modeled using eight node, solid hexahedron elements, 1.5 inches long, one inch wide and 0.0195 inches thick. LS-DYNA3D material type 1 was used to model the CFRP (Table 4.3). This is a perfectly elastic model, but it is assumed that the concrete cracks before any significant damage occurs in the composite. The CFRP is assumed to be perfectly bonded to the concrete, which is a limitation of this finite element model. The pressure versus time loading curve for the CFRP reinforced concrete beams is given in Table 4.4.

Table 4.3 - CFRP Material Properties

\begin{tabular}{|c|c|}
\hline $0^{\circ}$ Tensile Strength (psi) & $320 \times 10^{3}$ \\
\hline $0^{\circ}$ Tensile Modulus (psi) & $20 \times 10^{6}$ \\
\hline Poisson's Ratio (unitless) & 0.3 \\
\hline Fiber Volume Fraction (\%) & 60 \\
\hline
\end{tabular}

Table 4.4 -- Pressure vs. Time Curve Used in Beam Loading of the CFRP Reinforced Concrete Beam

\begin{tabular}{|c|c||c|c||c|c||c|c|}
\hline $\begin{array}{c}\text { Time } \\
(\mathbf{1 0 - 6} \mathbf{~ s e c})\end{array}$ & $\begin{array}{c}\text { Pressure } \\
\mathbf{( k s i )}\end{array}$ & $\begin{array}{c}\text { Time } \\
(\mathbf{1 0 - 6} \mathbf{~ s e c})\end{array}$ & $\begin{array}{c}\text { Pressure } \\
\mathbf{( k s i )}\end{array}$ & $\begin{array}{c}\text { Time } \\
(\mathbf{1 0 - 6} \mathbf{~ s e c})\end{array}$ & $\begin{array}{c}\text { Pressure } \\
\mathbf{( k s i )}\end{array}$ & $\begin{array}{c}\text { Time } \\
(\mathbf{1 0 - 6} \text { sec) }\end{array}$ & $\begin{array}{c}\text { Pressure } \\
(\mathbf{k s i})\end{array}$ \\
\hline 0 & 0.000 & 250 & 6.950 & 500 & 6.090 & 750 & 0.205 \\
\hline 50 & 0.669 & 300 & 7.430 & 550 & 3.955 & 800 & 0.062 \\
\hline 100 & 2.178 & 350 & 7.763 & 600 & 2.027 & 850 & 0.000 \\
\hline 150 & 4.168 & 400 & 7.970 & 650 & 0.892 & 1600 & 0.000 \\
\hline 200 & 5.912 & 450 & 7.545 & 700 & 0.423 & & \\
\hline
\end{tabular}

This model contains the actual dynamic loading of the system; therefore, the system damping constant should be that of the actual system, as found in Section 3.3. Both input files for LS-DYNA3D, the plain beams and the reinforced beams, can found in Appendices $\mathrm{G}$ and $\mathrm{H}$, respectively. 


\subsection{The Steel Reinforced Concrete Beam Model:}

All of the reinforced concrete $(\mathrm{RC})$ beams that Faza tested contained internal reinforcement, primarily steel reinforcement bars (rebars). The beam cross-section contains two \#3 bars (3/8 inch diameter) in the upper section and two \#6 bars (6/8 or 3/4 inch diameter) in the lower section (Fig. 4.6) [Faza, et al., 1995]. The rebars were modeled using material type 3, kinematic/isotropic elastic-plastic. Truss elements were chosen to model the beams due to compatibility with solid elements. The properties of the steel used in the material model are found in Table 4.5.

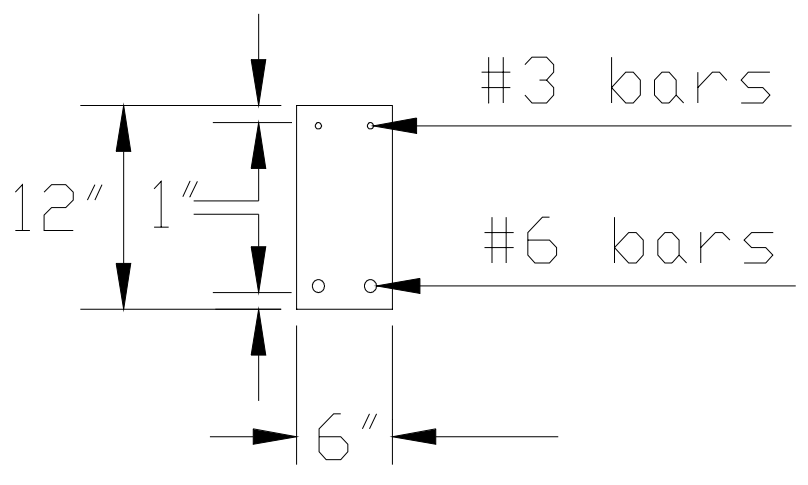

Figure 4.6 - Cross-Section of RC Beams

Table 4.5 - Properties of Steel Reinforcing Bars

\begin{tabular}{|c|c|}
\hline Density $\left(\mathrm{lb}^{*} \mathrm{sec}^{2} / \mathrm{in}^{4}\right)$ & $7.34 \times 10^{-4}$ \\
\hline Young's Modulus (psi) & $29.0 \times 10^{6}$ \\
\hline Poisson's Ratio (unitless) & 0.29 \\
\hline Yield Stress (psi) & $40.0 \times 10^{3}$ \\
\hline Hardening Modulus (psi) & $73.6 \times 10^{3}$ \\
\hline Hardening Parameter (unitless) & 1 \\
\hline
\end{tabular}

The beam has a total length of 120 inches, with 108 inches between the supports. The beam is six inches wide and has a height of 12 inches. The beam was loaded in four-point 
bending and is shown in Fig. 4.7 [Hota, et al., 1998]. Like the UC beams, a symmetry plane was placed through the center of the beam so only half had to be modeled, reducing computation time.

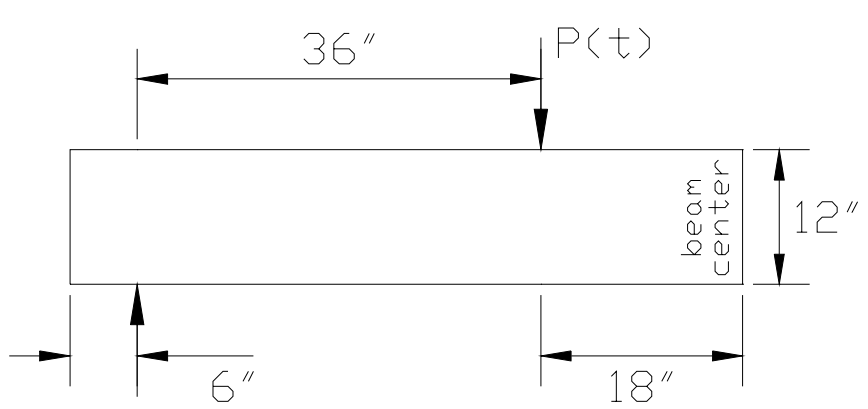

Figure 4.7 - RC Beam Model

The other types of reinforcement used on RC beams can be found in Fig. 4.8. It is noted that some of the composite wraps cover only eight inches of the beam height, while others cover the entire 12 inches.
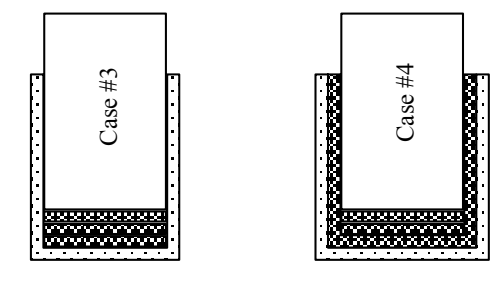

$\square$ concrete
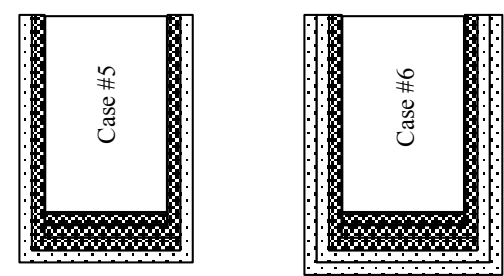

Fiber in transverse direction 0.00433 inches thick each

Figure 4.8 -- Different Wrapping Configurations of RC Beam Model 
The composite was made using a carbon fiber forca tow sheet with epoxy FR-E3P resin. The properties of the composite used in the RC beam models are found in Table 4.6.

Table 4.6 -- Properties of CFRP Used on RC Beams

\begin{tabular}{|c|c|}
\hline Composite Wrap & \\
\hline $\mathrm{E}_{1 \mathrm{w}}(\mathrm{psi})$ & $4.88 \times 10^{6}$ \\
\hline $\mathrm{E}_{2 \mathrm{w}}(\mathrm{psi})$ & $0.583 \times 10^{6}$ \\
\hline$\rho_{\mathrm{W}}\left(\mathrm{lbs}^{*} \mathrm{sec}^{2} / \mathrm{in}^{4}\right)$ & $1.1992 \times 10^{-4}$ \\
\hline
\end{tabular}

The RC beams contain multiple sliding interfaces. These include: between the steel reinforcement bar and the concrete, between the steel plate and the concrete, between the composite material and the concrete and between the differently oriented composite materials. Each of these interfaces make the model more complex and add significant CPU time to the process.

The initial properties of the RC concrete were chosen as the properties used by Logicon R \& D Associates (RDA) [Murray and Lewis, 1995] and are shown in Table 4.7. Because the properties greatly differ for each type of concrete, these parameters had to be adjusted to match Faza's concrete data.

Table 4.7 - Initial RDA Concrete Properties

\begin{tabular}{|c|c|c|c|c|c|}
\hline & Given (Metric) & Converted (English) & $\boldsymbol{\beta}$ & $1.6 \mathrm{e}-3 \mathrm{MPa}^{-1}$ & $1.103 \mathrm{e}-5 \mathrm{psi}^{-1}$ \\
\hline $\boldsymbol{K}$ & $14700 \mathrm{MPa}$ & $2.132 \mathrm{e} 6 \mathrm{psi}$ & $\boldsymbol{R}$ & 1.2 & 1.2 \\
\hline $\boldsymbol{G}$ & $11025 \mathrm{MPa}$ & $1.599 \mathrm{e} 6 \mathrm{psi}$ & $\boldsymbol{X}_{\boldsymbol{0}}$ & $210 \mathrm{MPa}$ & $30450 \mathrm{psi}$ \\
\hline $\boldsymbol{\rho}$ & $2.28 \mathrm{gm} / \mathrm{cm}^{3}$ & $2.13 \mathrm{e}-4{\mathrm{lb}-\mathrm{sec}^{2} / \mathrm{in}^{4}}^{3}$ & $\boldsymbol{L}_{\boldsymbol{\theta}}$ & $144.468 \mathrm{MPa}$ & $20953 \mathrm{psi}$ \\
\hline $\boldsymbol{\alpha}$ & $230 \mathrm{MPa}$ & $33350 \mathrm{psi}$ & $\boldsymbol{W}$ & 0.12 & 0.12 \\
\hline $\boldsymbol{\theta}$ & 0 & 0 & $\boldsymbol{D}$ & $1.35 \mathrm{e}-4 \mathrm{MPa}^{-1}$ & $9.31 \mathrm{e}-7 \mathrm{psi}^{-1}$ \\
\hline $\boldsymbol{\gamma}$ & $221 \mathrm{MPa}$ & $32045 \mathrm{psi}$ & $\boldsymbol{T}$ & $-2.5 \mathrm{MPa}$ & $-362.6 \mathrm{psi}$ \\
\hline
\end{tabular}

The first step was to match the slope of Faza's load vs. deflection diagram for plain concrete before any cracking occurred. To change the slope, the shear modulus, G, was 
adjusted. By changing the shear modulus, the bulk modulus, $\mathrm{K}$, also changed according to Eq. 4.10 [Barbero, 1999, Aboudi, 1991].

$$
\begin{gathered}
G=\frac{E}{2(1+v)} \\
K=\frac{2 v G}{(1-2 v)}+\frac{2 G}{3}
\end{gathered}
$$

After duplicating the initial slope, the concrete needed to exhibit cracking at approximately 4000 pounds. This was accomplished by changing the tension cutoff until cracking occurred at the desired load. At this point, the slope of the deflection versus load diagram decreases in magnitude.

Next, the hardening law exponent, D, was adjusted to match the isostatic compression (IC) test data. This test was modeled using a solid cube of concrete in LS-DYNA3D. A pressure, in the form of a velocity, was applied to three sides of the cube, while the sides opposite the velocities were restrained in the corresponding directions (Fig. 4.9).

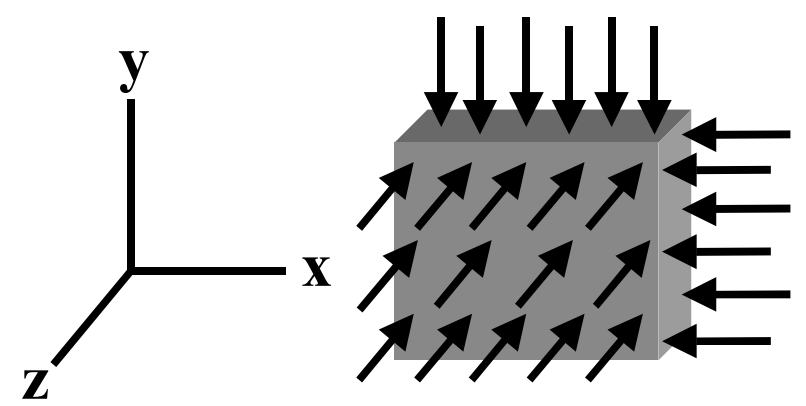

Figure 4.9 - IC Test Diagram

The initial intersection of the cap with the $J_{1}$ axis, denoted as $X_{0}$ (Fig. 4.1), was changed to correspond to three times the pressure of the IC test. The parameters $\mathrm{L}_{0}$, TDP and FCUT were calculated for RC beams using Eqs. 4.6 - 4.8. 
The remainder of the properties were obtained from Simo, et al [1988], using their Colorado concrete data. The final concrete properties of the RC model are shown in Table 4.8. The LS-DYNA3D input file for the RC beam can be found in Appendix I.

Table 4.8-Final RC Concrete Properties

\begin{tabular}{|c|c|c|c|}
\hline $\boldsymbol{K}(\mathrm{psi})$ & $1.714 \times 10^{6}$ & $\boldsymbol{X}_{\boldsymbol{0}}(\mathrm{psi})$ & 16000 \\
\hline $\boldsymbol{G}(\mathrm{psi})$ & $1.565 \times 10^{6}$ & $\boldsymbol{L}_{\boldsymbol{0}}(\mathrm{psi})$ & 1526 \\
\hline$\rho\left(1 \mathrm{~b}-\sec ^{2} / \mathrm{in}^{4}\right)$ & $1.77 \times 10^{-4}$ & $\boldsymbol{W}$ (unitless) & 0.42 \\
\hline$\alpha(\mathrm{psi})$ & 3860 & $\boldsymbol{D}\left(\mathrm{psi}^{-1}\right)$ & $3.2 \times 10^{-6}$ \\
\hline $\boldsymbol{\theta}$ (unitless) & 0.11 & $\boldsymbol{T}$ (psi) & -414.2 \\
\hline$\gamma(\mathrm{psi})$ & 1160 & $\boldsymbol{T D P}$ (psi) & -103.6 \\
\hline $\boldsymbol{\beta}\left(\mathrm{psi}^{-1}\right)$ & $4.4 \times 10^{-4}$ & $\overline{F C U T}$ (psi) & -2732 \\
\hline$R$ & 4.43 & & \\
\hline
\end{tabular}

\subsection{The Concrete Wall:}

The concrete wall was modeled as a $12 \times 8 \times 0.5$ feet wall (Fig. 4.10). Only one quarter of the wall was modeled for computational speed. The wall was restrained across the entire six inch thickness on the outside edges. All displacements and rotations were restrained. 


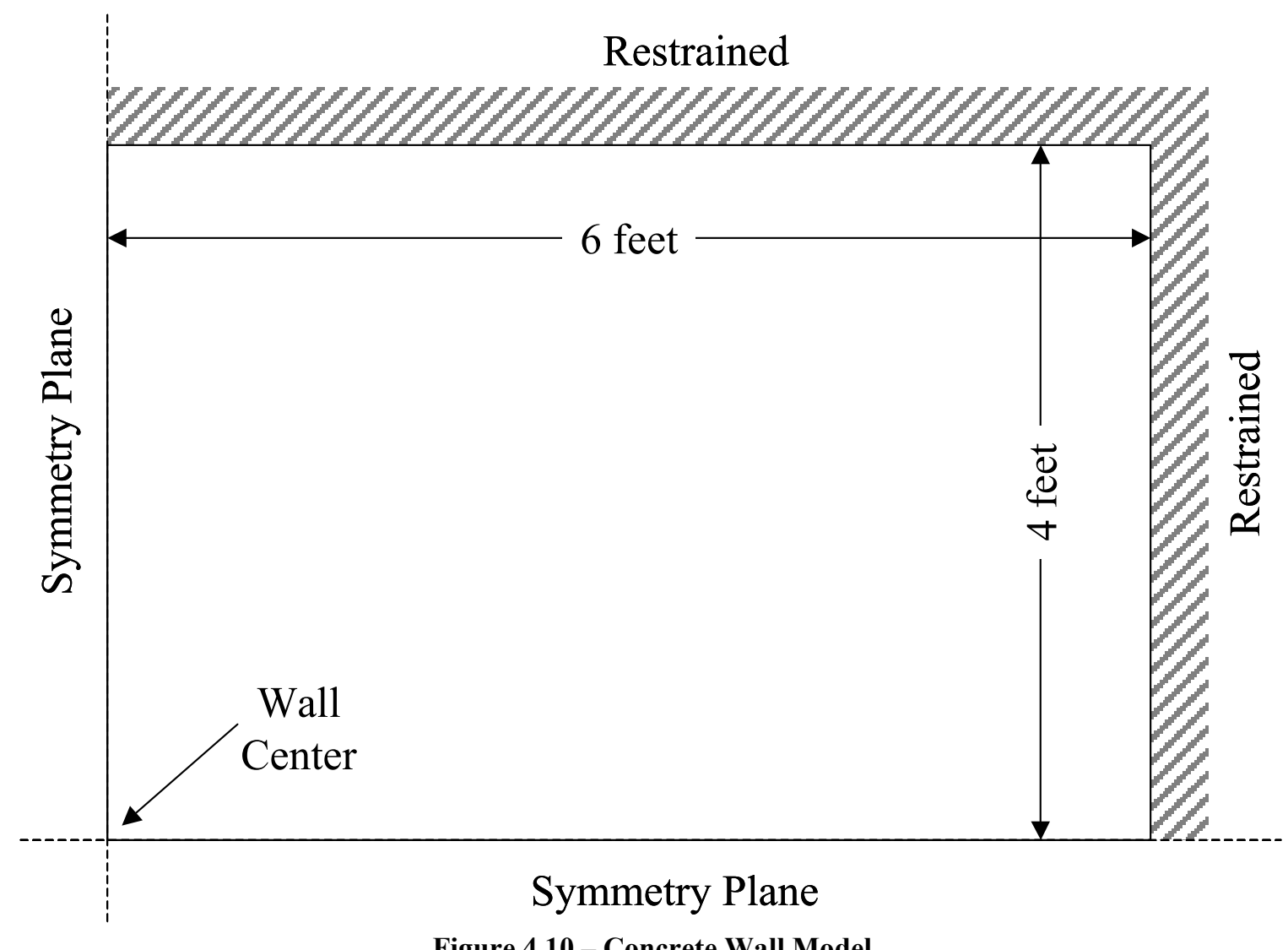

Figure 4.10 - Concrete Wall Model

The wall was meshed as three inch cubes, resulting in 24 elements in the x-direction, 16 in the $y$-direction and two in the z-direction. The values of the concrete were the same ones derived for the RC Beams (Table 4.8). The CFRP was modeled as elastic, material type 1 and the properties were those used in the UC model (Table 4.3). The CFRP was assumed to be perfectly bonded to the concrete wall, modeled as a tied interface. This allowed coincident nodes to be merged. The composite covered the entire span of the wall, was 0.072 inches thick and meshed into 3-inch elements in the $\mathrm{x}$ and $\mathrm{y}$-directions. This produced 24 elements in the x-direction and 16 in the y-direction. The LS-DYNA3D input files for the plain and reinforced concrete walls are found in Appendices $\mathrm{J}$ and $\mathrm{K}$, respectively. 


\section{CHAPTER 5}

\section{Results}

\subsection{The Unreinforced Concrete Beam}

The LS-DYNA3D models of the UC beams, both plain and CFRP reinforced, showed excellent agreement with Jerome's experimental data (Figs. $5.1 \& 5.2$ ). This shows that the properties of the UMAT material type 43 were chosen effectively to simulate the behavior of Jerome's concrete beams.

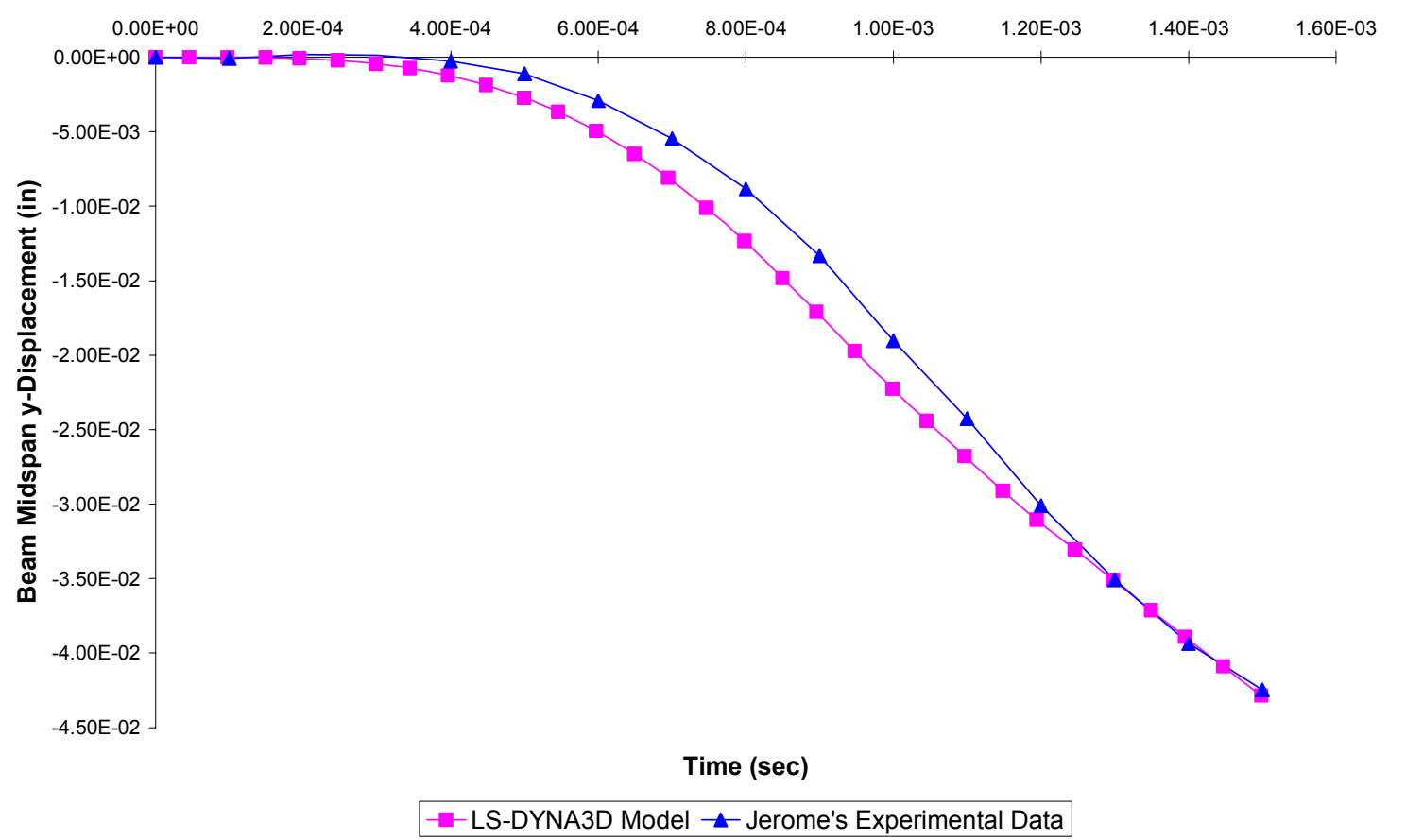

Figure 5.1 - Comparison of the UC Beam 


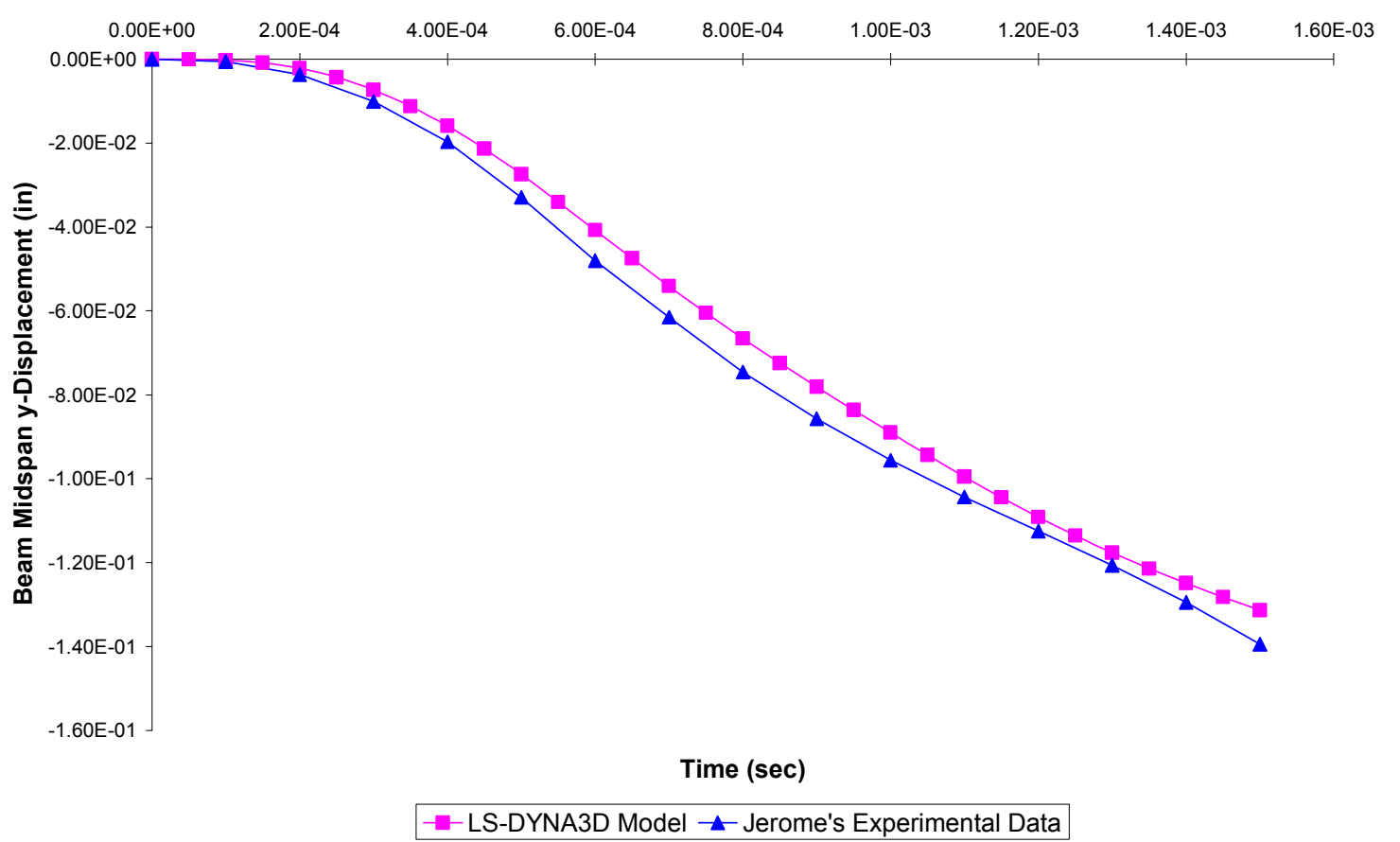

Figure 5.2 - Comparison of the CFRP Reinforced UC Beam 


\subsection{The Reinforced Concrete Beam}

The data obtained from LS-DYNA3D is shown in Fig. 5.3 as compared to the experimental data obtained from Faza. This beam contained no external reinforcement. As can be seen from the figure, the initial slope of the UMAT43 curve closely matches the slope of Faza's data. At approximately 4000 pounds, cracking begins and the slopes change.

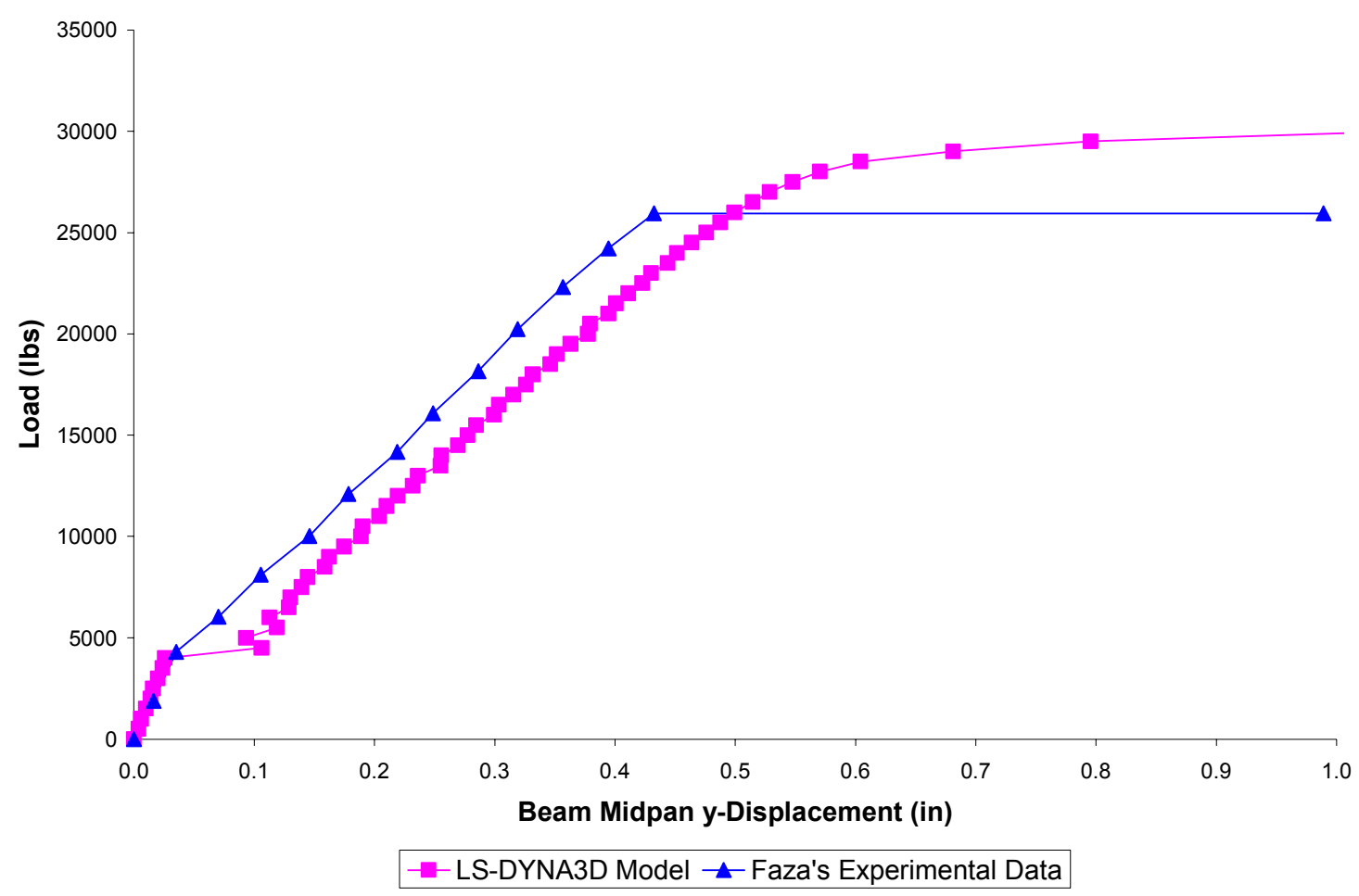

Figure 5.3 - Comparison of the RC Beam Containing No External Reinforcement 


\subsection{The Concrete Wall}

All of the plots for the concrete walls are for the center element of the entire wall. This is the lower left corner on Fig. 5.4 and represented by element 2. To compare the results of the modeling, the residual deflection was chosen. This value is defined as the displacement of the wall after the blast load has subsided. This is a measurable value if future experimental tests are conducted for comparison.

\section{Concrete Only (New Model)}

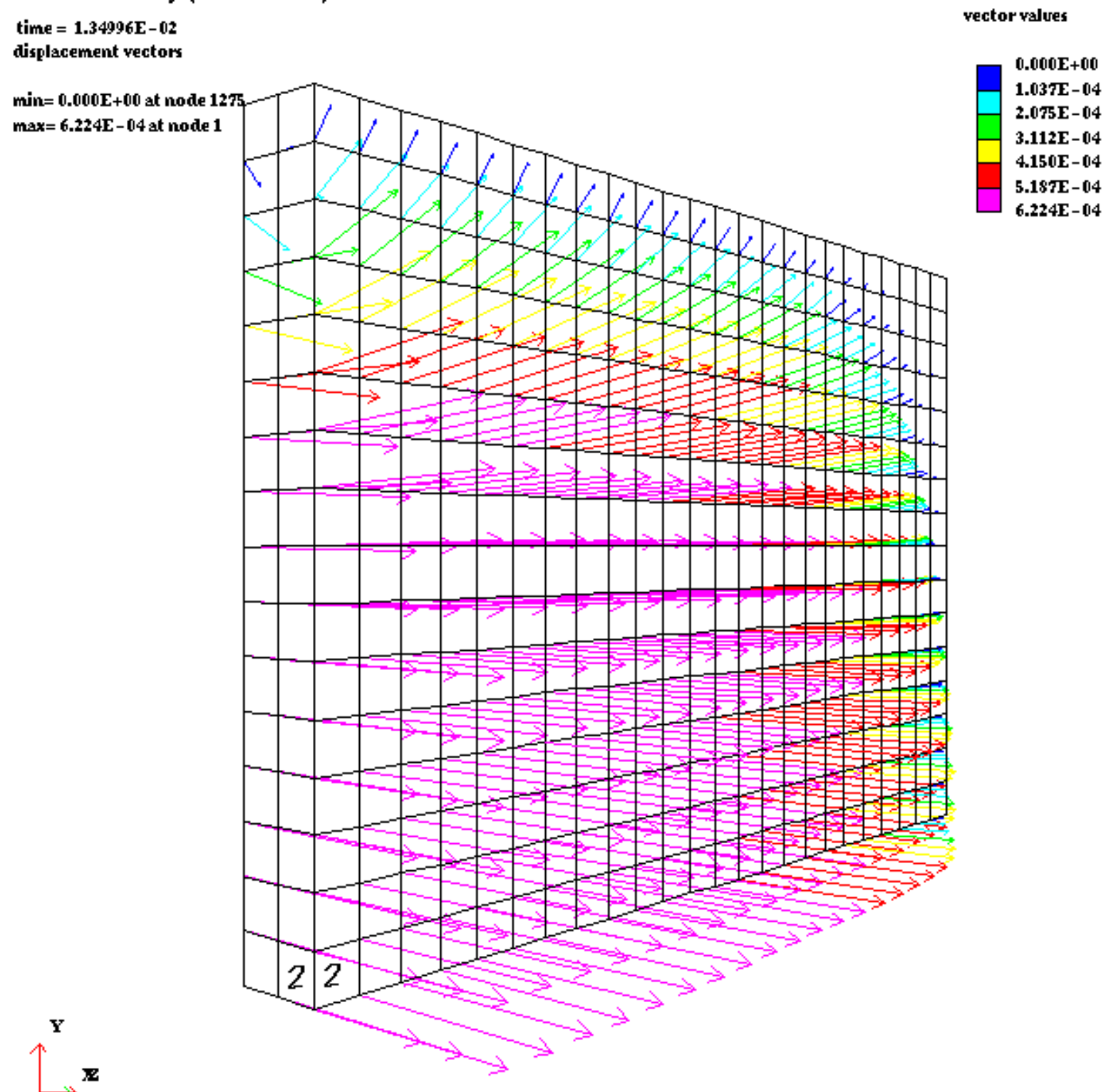

Figure 5.4 - Displacement Vectors at First Response 
The Tensile Damage Parameter (TDP), used with UMAT 43, allows the concrete to be modeled without damage. This is accomplished by setting the value to a very large number, in this case, $10^{12}$. When the damage increment, $\delta \mathrm{D}$ (Eq. 4.5), is calculated, the value is zero for all practical purposes. Fig. 5.5 shows a comparison of the plain concrete model with the undamaged concrete model $\left(\mathrm{TDP}=10^{12}\right)$. It can be seen that the undamaged concrete has a residual deflection less than that of the UMAT 43 concrete model, as is expected.

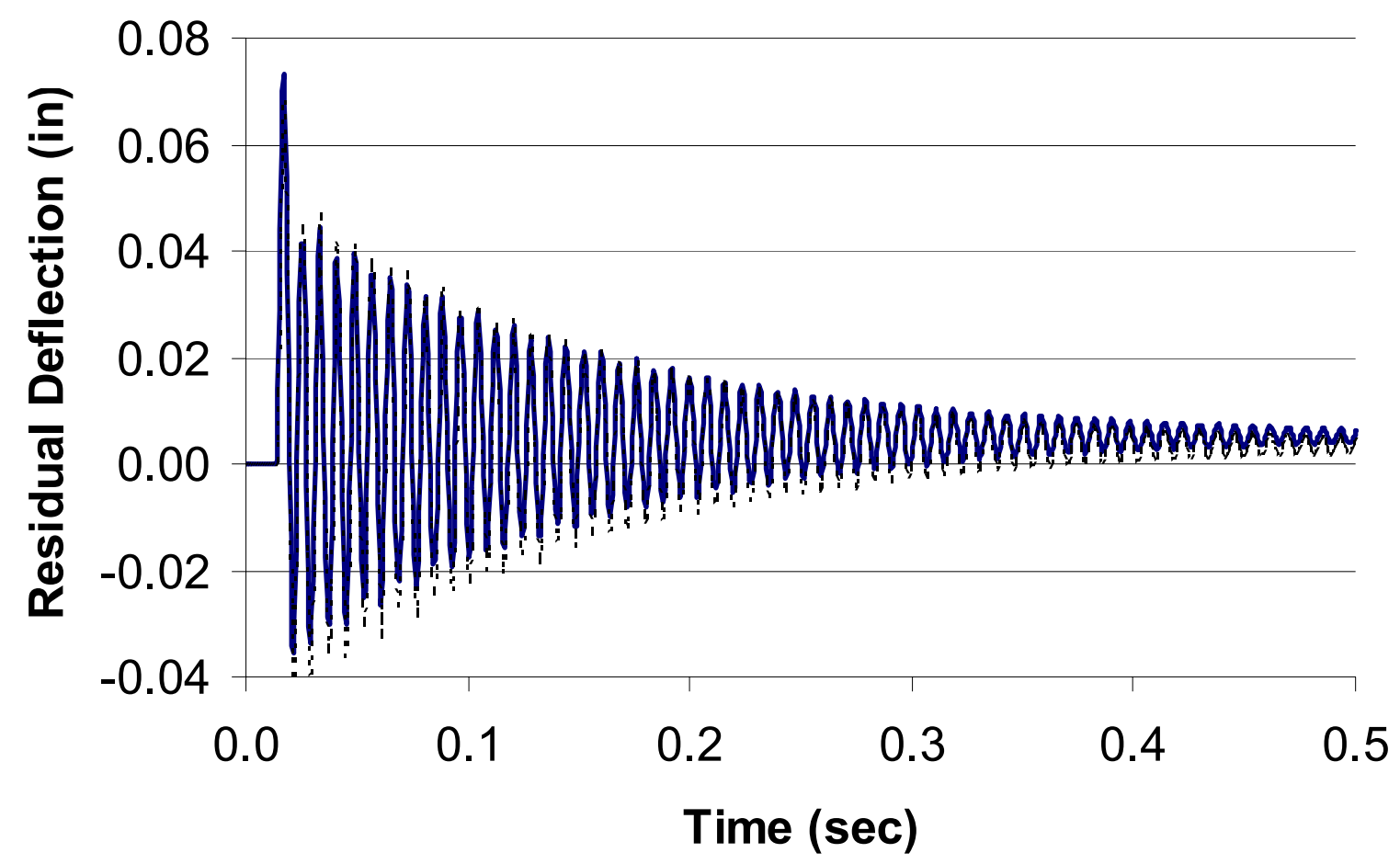

Concrete Only …... Concrete Undamaged

Figure 5.5 - Comparison of Concrete Wall and Concrete Wall with Undamaged Concrete 
The results of the concrete wall, reinforced with externally applied CFRP is shown in Fig. 5.6. This shows a greater residual deflection of the plain wall, but both deflections are relatively small. Increased airblast loads or decreased standoff distances may better show the benefits of external reinforcement.

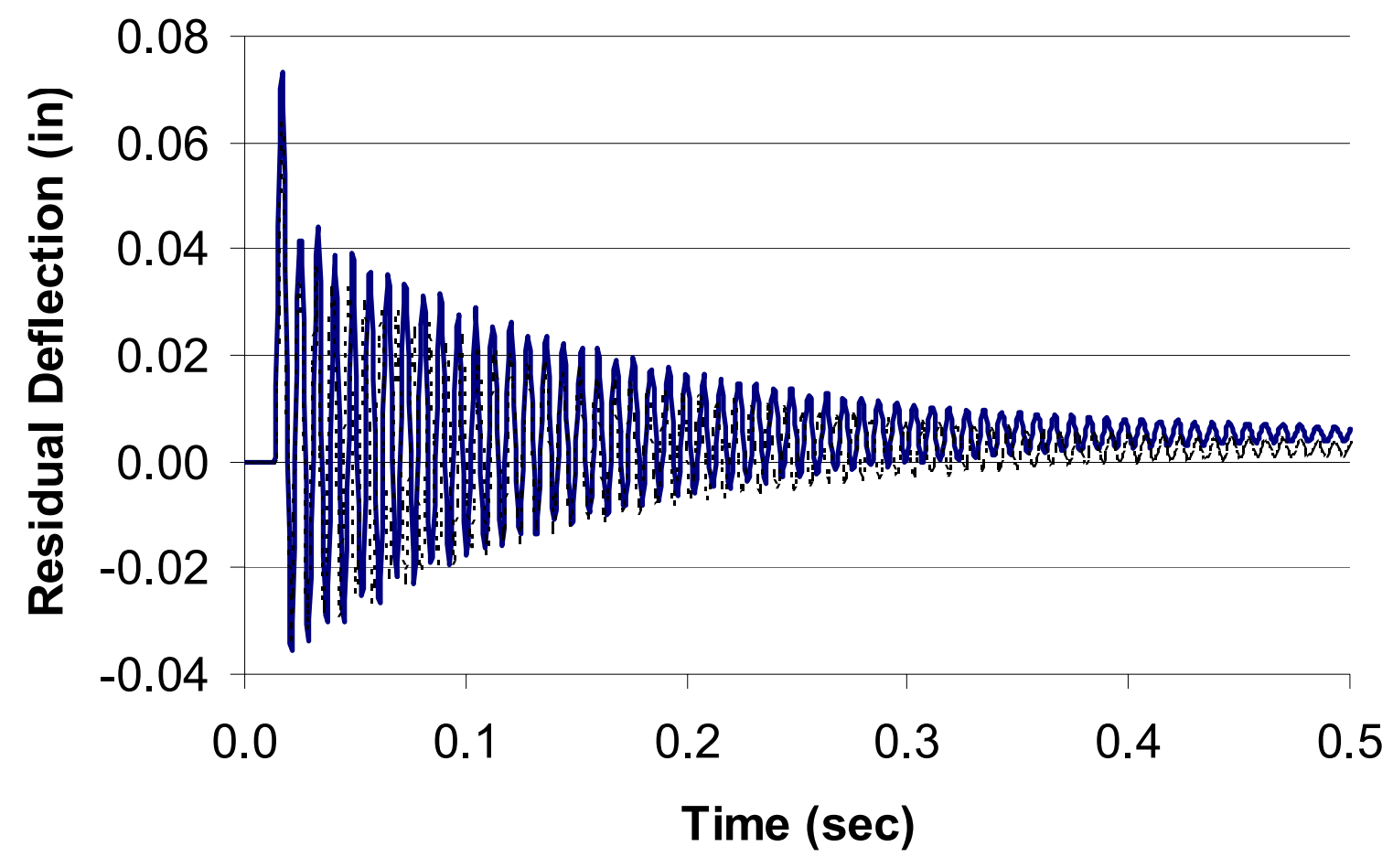

— Concrete Only ….... CBACK

Figure 5.6 - Comparison of Plain Concrete Wall and Concrete Wall with Composite on the Back 
The mean values of residual deflection for all three concrete wall models are shown in Fig. 5.7. This shows that the CFRP reinforced concrete is better than concrete that does not sustain tensile damage.
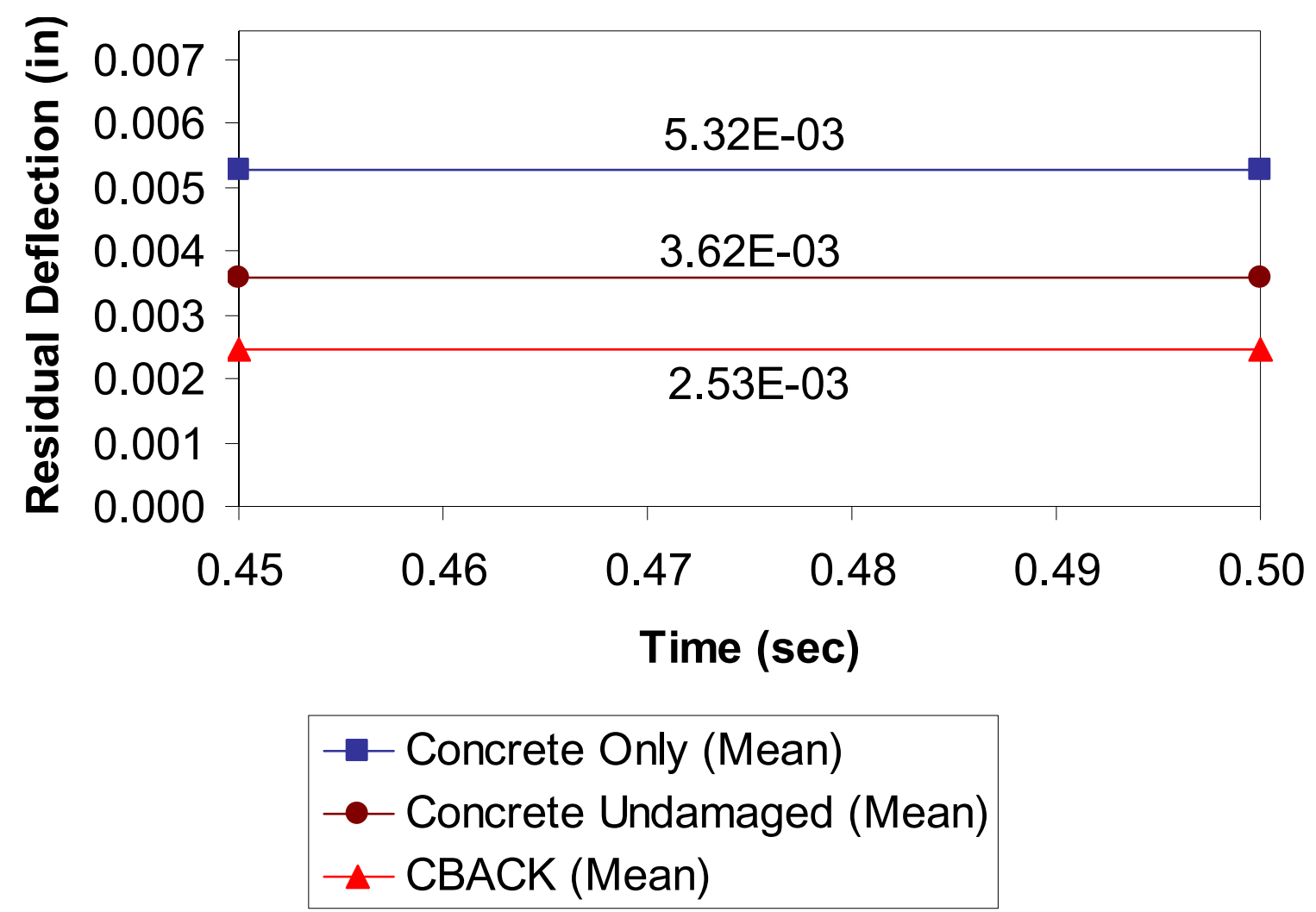

Figure 5.7 - Mean Residual Deflection Value of All Three Concrete Wall Curves 


\section{CHAPTER 6}

\section{Conclusions and Recommendations}

\subsection{Conclusions}

The UMAT43 damage model, developed from a two-invariant geologic cap model, was shown to correlate well to the available experimental data. Comparisons were made for three and four point bending tests of statically and dynamically loaded beams.

The concrete wall models show an increase in blast resistance when adding a layer of CFRP to the back of a plain wall. The strengthening effect was small because of a small bomb and large standoff distance. Therefore, it is also apparent from the research that increasing the standoff distance reduces the effects of the blast loads.

Many beams with external reinforcement have been tested experimentally under quasi-static load. All of these beams could be modeled using the proposed damage model. These models will require large amounts of CPU time due to the complexity of the geometry and the number of sliding interfaces. More simplistic representations of the model need to be developed to allow for solving in a realistic amount of time. 


\subsection{Recommendations:}

Time and budget restraints of this study limited the amount of models that could be investigated. Areas that could be explored further.

- Modeling of remaining five beams tested by Faza

- With a steel plate bonded to the bottom

- Wrapped in CFRP in four configurations

- Study the effect of placing the composite on the front (outside) of wall

- Effects of different composite layups on walls subject to airblast loads

- Larger amounts of TNT for larger airblast loads

- Change standoff distances to change airblast loads

- Modeling of adhesive layer between concrete and composite 


\section{CHAPTER 7}

\section{References}

Aboudi, Jacob, 1991, Mechanics of Composite Materials: A Unified Micromechanical Approach, Studies in Applied Mechanics 29, Elsevier Science Publishing Company, Inc., New York, NY.

Bachmann, Hugo and Walter Ammann, 1987, Vibrations in Structures: Induced by Man and Machines, International Association for Bridge and Structural Engineering, Zurich, Switzerland.

Baker, Wilfred E., 1973, Explosions in Air, University of Texas Press, Austin, Texas.

Barbero, Ever J., Julio F. Davalos, Sam A. Kiger and James S. Shore, 1997, "Reinforcement with Advanced Composite Materials for Blast Loads," Structures Congress - Building to Last, Proceedings of the 15th Structures Congress, Part 1 (of 2), April 13-16, pp. 663-667.

Barbero, Ever J., 1999, Introduction to Composite Materials Design, Taylor \& Francis, Philadelphia, PA.

Barzegar, Fariborz and Srinivas Maddipudi, 1994, "Generating Reinforcement in FE Modeling of Concrete Structures," Journal of Structural Engineering, Vol. 120, No. 5, May, pp. 1656-1662.

Beards, C. F., 1983, Structural Vibration Analysis: Modeling, Analysis and Damping of Vibrating Structures, Ellis Horwood Ltd., West Sussex, England.

Beshara, F. B. A. and K. S. Virdi, 1992, "Prediction of Dynamic Response of Blast-Loaded Reinforced Concrete Structures," Computers \& Structures, Vol. 44, No. 1/2, pp. 297-313.

Bounds, William, ed., 1998, Concrete and Blast Effects, American Concrete Institute, Committee 370, Short Duration Dynamic and Vibratory Load Effects.

Bulson, P. S., ed., 1989, Structures Under Shock and Impact, Proceedings of the First International Conference, Cambridge, Massachusetts, USA, July, Elsevier Science Publishers, Amsterdam, The Netherlands.

Chen, W. F. and G. Y. Baladi, 1985, Soil Plasticity: Theory and Implementation, Developments in Geotechnical Engineering; 38, Elsevier Science Publishing Company, Inc., New York, NY.

CONWEP, 1992, Conventional Weapons Effects Computer Program, Version 2.00, US Army Engineer Waterways Experimental Station, Vicksburg, MS, USA 
Crawford, John E., L. Javier Malvar, James W. Wesevich, Joseph Valancius and Aaron D. Reynolds, 1997, ACI Structural Journal, Vol. 94, No. 4, July-August, pp. 371-377.

Cummins, Toney K., Paul F. Mlakar and James S. Shore, 1997, “Advanced Composite Materials (ACM) and Structural Hardening," Structures Congress - Building to Last, Proceedings of the 15th Structures Congress, Part 1 (of 2), April 13-16, pp. 658-662.

de Borst, René and A. H. van den Boogaard, 1994, "Finite-Element Modeling of Deformation and Cracking in Early-Age Concrete," Journal of Engineering Mechanics, Vol. 120, No. 12, December, pp. 2519-2534.

Faza, Salem S., Hota V. S. GangaRao and Ever J. Barbero, 1995, "Fiber Composite Wrap for Rehabilitation of Concrete Structures," Proceedings Repair and Rehabilitation of the Infrastructure of the Americas, August 29-31, 1994, University of Puerto Rico, Mayaguez, Puerto Rico, April, pp. 181-92.

Hallquist, John O., 1993, LS-DYNA3D Theoretical Manual, Livermore Software Technology Corporation, Livermore, CA, LSTC Report 1018, Rev. 2, July.

Hota, V. S. GangaRao and P. V. Vijay, 1998, "Bending Behavior of Concrete Beams Wrapped with Concrete Fabric," Journal of Structural Engineering, Vol. 124, No. 1, January, pp. 3-10.

Hranac, Kelly Carter, 2001, "Composite Blastproofing Systems Move From R\&D to the Marketplace,” High-Performance Composites, Vol. 9, No. 1, January/February.

Janson, J. and J. Hult, 1977, "Damage Mechanics and Fracture Mechanics: A Combined Approach," Journal de Mecanique Appliquee, Vol. 1, pp. 69-84.

Jerome, David Mark, 1996, Dynamic Response of Concrete Beams Externally Reinforced with Carbon Fiber-Reinforces Plastic, Doctoral Dissertation, UMI Dissertation Services, UMI No. 9703552.

Kingery, Charles N. and Gerald Bulmash, 1984, "Airblast Parameters from TNT Spherical Air Burst and Hemispherical Surface Burst," ARBRL-TR-02555, April.

Kornhauser, Murray, 1964, Structural Effects of Impact, Spartan Books, Baltimore, MD.

LSTC, 1995, LS-INGRID Grahical Interface User Manual, Livermore Software Technology Corporation, Livermore, CA, Rev. 3.4M, January.

LSTC, 1996, LS-DYNA3D User's Manual (Nonlinear Dynamic Analysis of Structures in Three Dimensions), Livermore Software Technology Corporation, Livermore, CA, LSTC Report 1007, Rev. 3, Version LS-DYNA3D 936, January 1. 
Malvar, L. Javier, John E. Crawford, Don A. Simons and James W. Wesevich, 1995, “A Concrete Material Model for DYNA3D," Proceedings of Engineering Mechanics, Vol. 1, Proceedings of the 10th Conference on Engineering Mechanics, Part 1 (of 2), May 21-24, Boulder, CO, pp. 142-146.

Malvar, L. Javier, John E. Crawford, Don A. Simons and James W. Wesevich, 1997, "Plasticity concrete material model for DYNA3D," International Journal of Impact Engineering, Vol. 19, No. 9-10, October-November, pp. 847-873.

Marzouk, H. M. and Zhiwei Chen, 1993, "Finite Element Analysis of High-Strength Concrete Slabs," ACI Structural Journal, Vol. 90, No. 5, September-October, pp. 505-513.

Miyamoto, Ayaho, Michael William King and Manabu Fujii, 1994, "Integrated Analytical Procedure for Concrete Slabs Under Impact Loads," Journal of Structural Engineering, Vol. 120, No. 6, June, pp. 1685-1702.

Murray, Yvonne D. and Brett A. Lewis, 1995, Numerical Simulation of Damage in Concrete, Technical Report DNA-TR-94-190, Aptek, Inc., pp. D-3.

Nashif, Ahid D., David I. G. Jones and John P. Henderson, 1985, Vibration Damping, John Wiley \& Sons, Inc., New York.

National Research Council, 1995, Protecting Buildings From Bomb Damage, Transfer of Blast-Effects Mitigation Technologies from Military to Civilian Applications, Board on Infrastructure and the Constructed Environment Commission on Engineering and Technical Systems, Committee on Feasibility of Applying Blast-Mitigating Technologies and Design Methodologies from Military Facilities to Civilian Buildings, National Academy Press Washington, D. C.

Prendergast, John, 1995, “Oklahoma City Aftermath,” Civil Engineering, Vol. 65, No. 10, October, pp. 42-45.

Reddy, J. N.,1997, Mechanics of Laminated Composite Plates: Theory and Analysis, CRC Press, Inc.

Ross, C. Allen, M. R. Purcell and Elisabetta L. Jerome, 1997, "Blast Response of Concrete Beams and Slabs Externally Reinforced with Fiber Reinforced Plastics (FRP)," Structures Congress - Building to Last, Proceedings of the 15th Structures Congress, Part 1 (of 2), April 13-16, pp. 673-677.

Schwer, Leonard E. and Yvonne D. Murray, 1994, "A Three-Invariant Smooth Cap Model with Mixed Hardening," International Journal for Numerical and Analytical Methods in Geomechanics, Vol. 18, pp. 657-688. 
Shin, Young S. and Jonas A. Zukas, eds., 1996, Structures Under Extreme Loading Conditions, American Society of Mechanical Engineers, Pressure Vessels and Piping Conference, Montreal, Quebec, Canada, July 21-26.

Simo, Juan C., Jiann-Wen Ju, Karl S. Pister and Robert L. Taylor, 1988, “Assessment of Cap Model: Consistent Return Algorithms and Rate-Dependent Extension," Journal of Engineering Mechanics, Vol. 114, No. 2, February, pp. 191-218.

Steidel, Robert F., Jr., 1989, An Introduction to Mechanical Vibrations, 3rd Ed., John Wiley \& Sons, Inc.

Taylor, R., D. R. H. Maher and B. Hayes, 1966, "Effect of the Arrangement of Reinforcement on the Behavior of Reinforced Concrete Slabs," Magazine of Concrete Research, Vol. 18, No. 55, June, pp. 85-94.

TM 5-855-1, 1986, Fundamentals of Protective Design for Conventional Weapons, U. S. Department of the Army, Washington, DC, November.

TM 5-1300, 1990, Structures to Resist the Effects of Accidental Explosions Manual, U. S. Department of the Army, Washington, DC, November. 
Appendix A:

\section{T\&P.BAS Program}




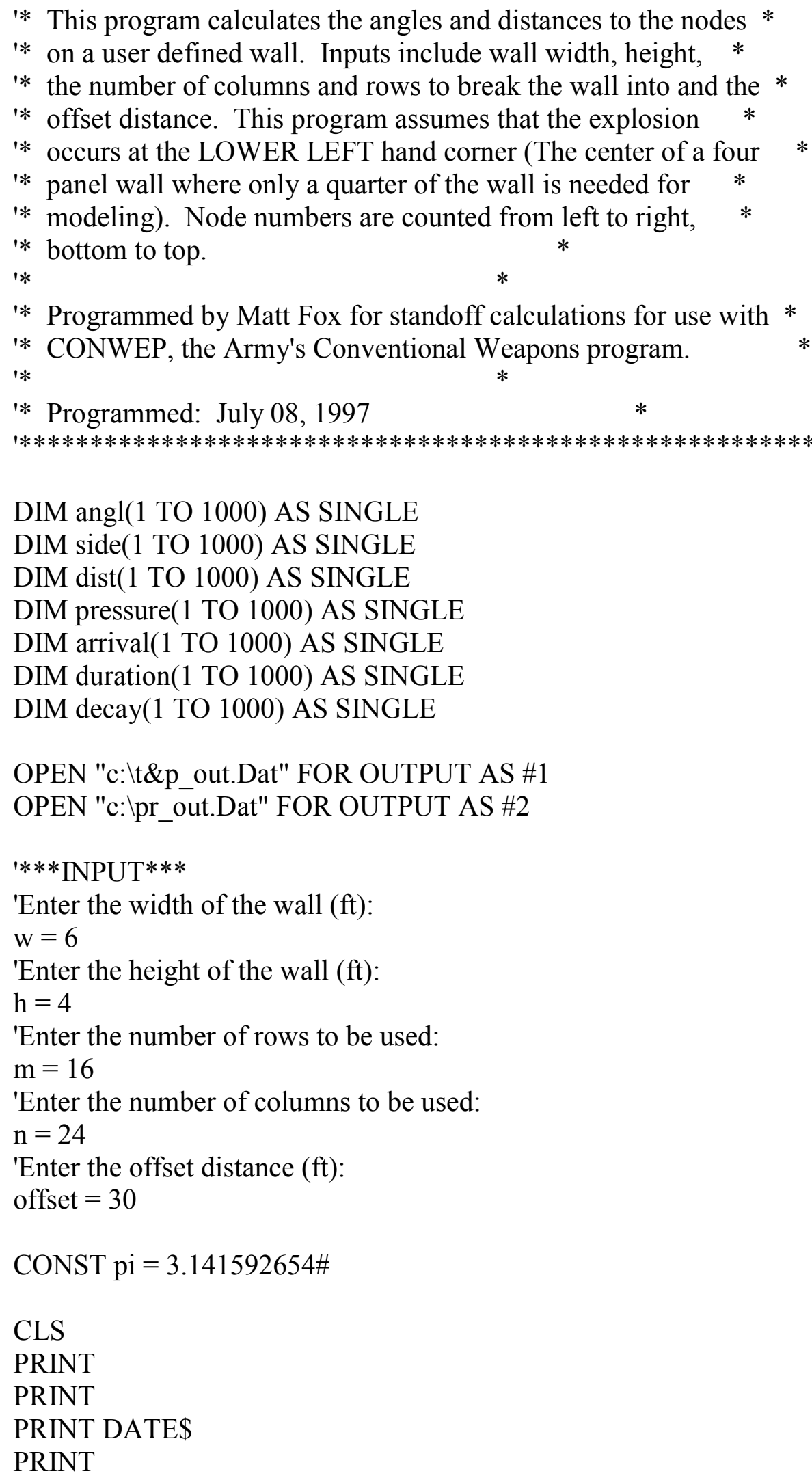

'Enter the width of the wall (ft):

$\mathrm{w}=6$

'Enter the height of the wall (ft):

$\mathrm{h}=4$

'Enter the number of rows to be used:

$\mathrm{m}=16$

'Enter the number of columns to be used:

$\mathrm{n}=24$

'Enter the offset distance $(\mathrm{ft})$ :

offset $=30$

CONST pi $=3.141592654 \#$

\section{CLS}

PRINT

PRINT

PRINT DATES

PRINT 
PRINT "node distance(ft) pressure(psi) arrival(msec) duration(msec) decay"

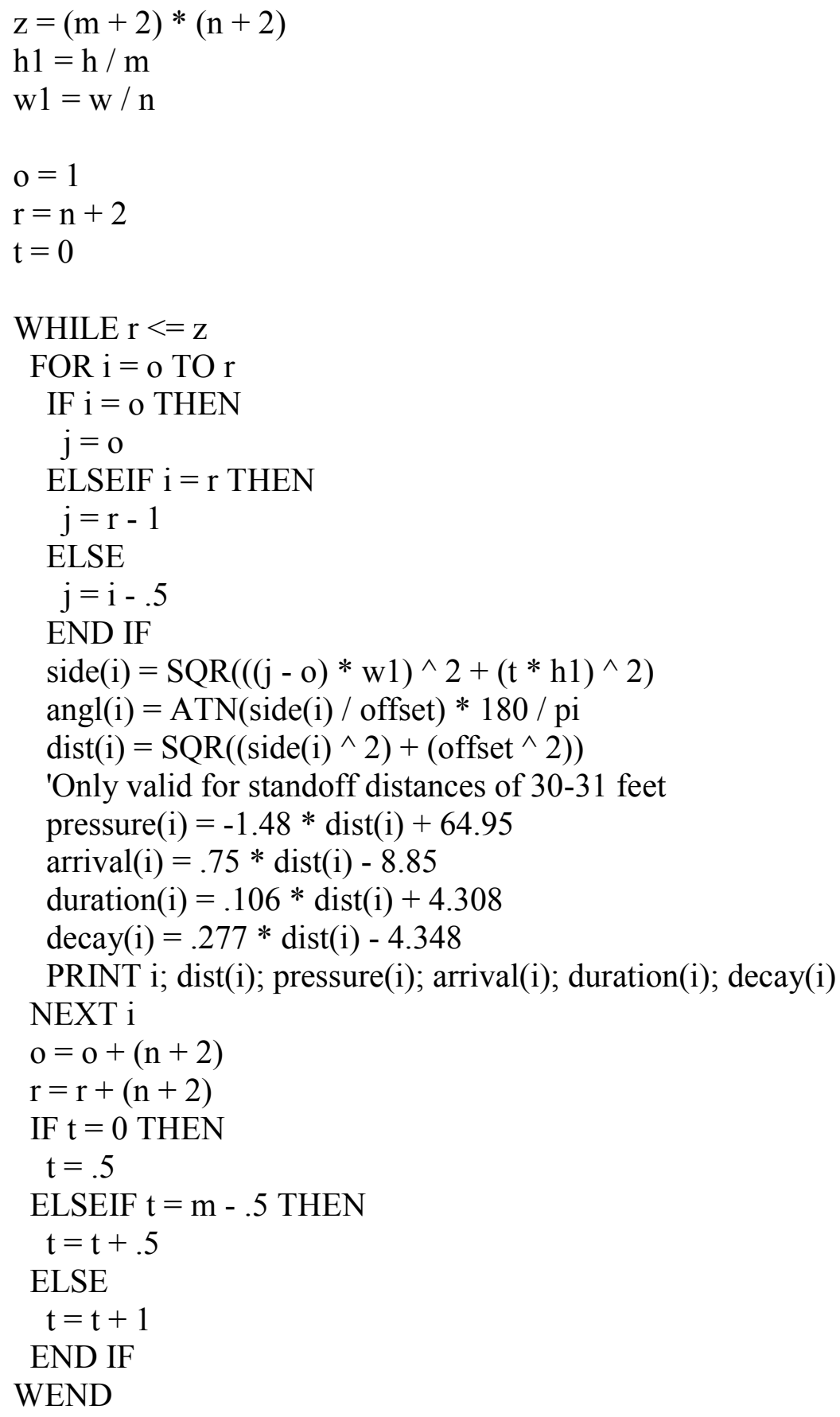

LOCATE 25,2

PRINT "Press any key when you are ready to continue." SLEEP 


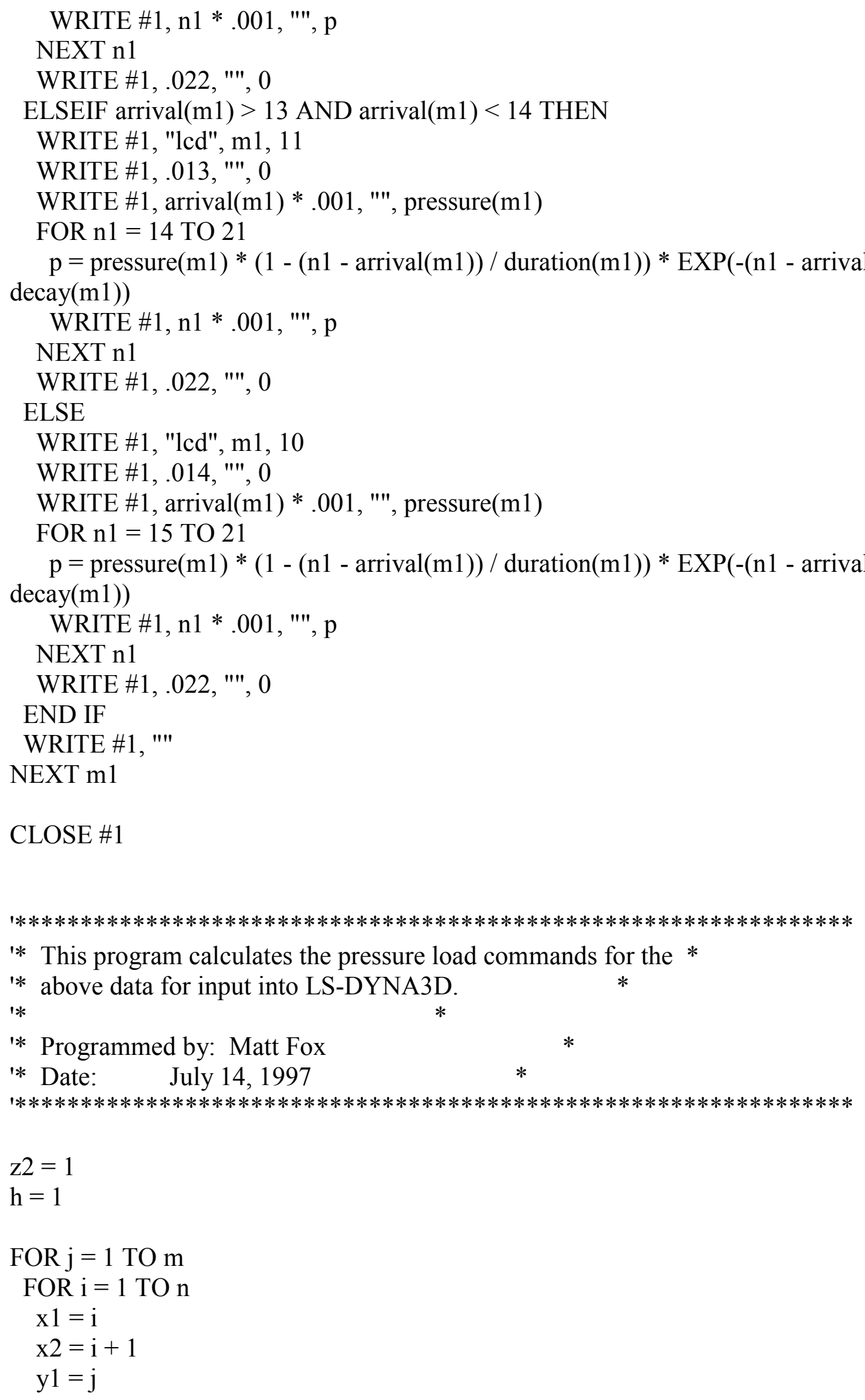




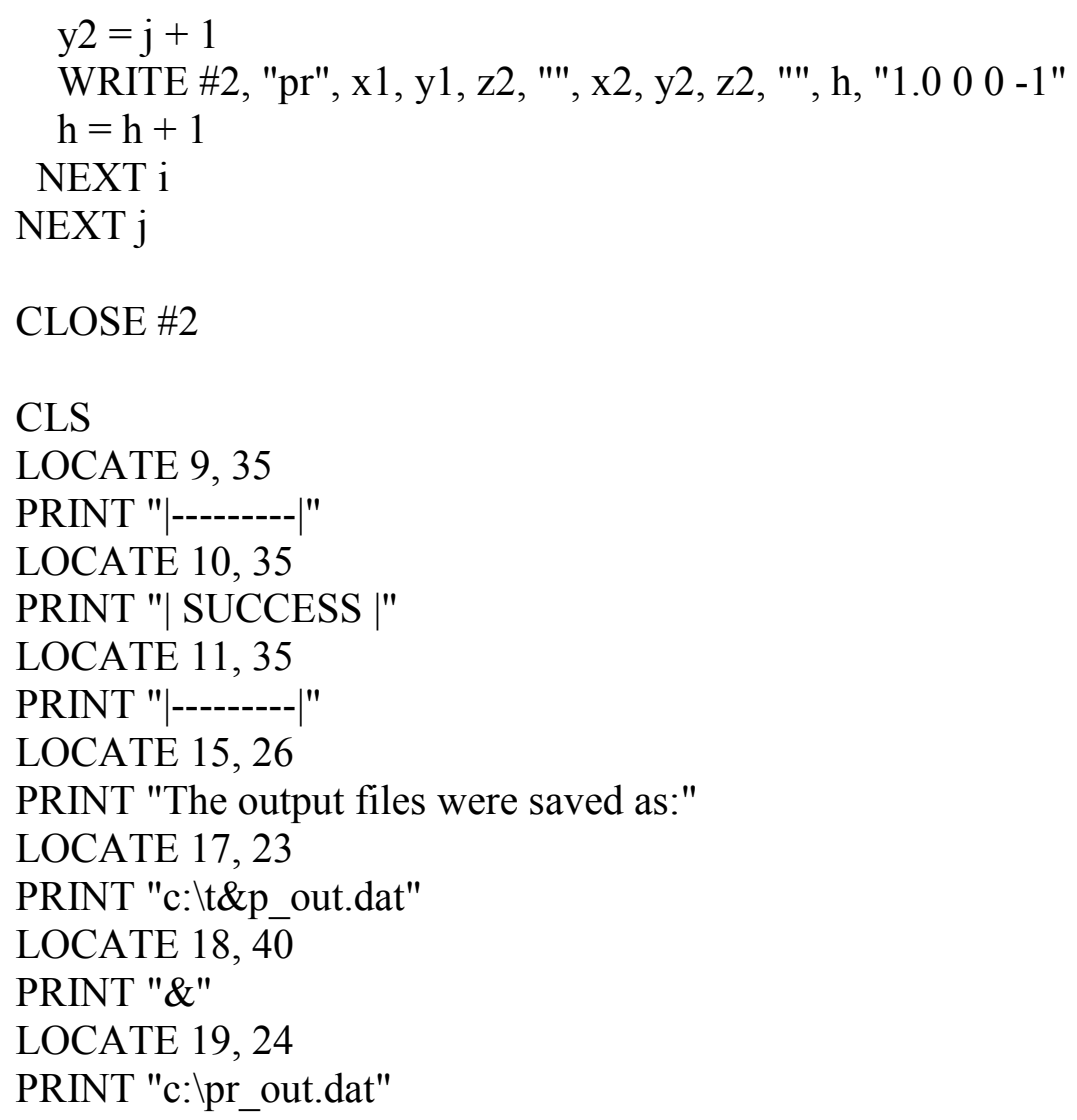


Appendix B:

\section{T\&P.BAS Output Files}




\section{Input load curves for the blast loading of the concrete wall.}

\begin{tabular}{|c|c|c|c|c|}
\hline lcd 111 & .01418 .06375 & .0175 .084029 & $.02 \quad .7868857$ & \\
\hline .0130 & $.015 \quad 12.08244$ & .0183 .023638 & .021 .1597122 & $\operatorname{lcd} 2210$ \\
\hline 1.365039E-02 20.54922 & .0167 .869045 & .0191 .626567 & .0220 & .0140 \\
\hline .01417 .93532 & .0174 .932854 & .02 .7000523 & & $1.400847 \mathrm{E}-0219.84261$ \\
\hline .01511 .98265 & .0182 .914008 & .021 .104181 & lcd 1711 & .01513 .52645 \\
\hline .0167 .79319 & $.019 \quad 1.549581$ & .0220 & .0130 & .0168 .976992 \\
\hline .0174 .876517 & .02 .648248 & & $1.386189 \mathrm{E}-0220.13186$ & .0175 .764073 \\
\hline .0182 .873268 & $.0217 .143895 \mathrm{E}-02$ & lcd 1211 & .01419 .09793 & $.018 \quad 3.522077$ \\
\hline .0191 .521069 & .0220 & .0130 & .01512 .89013 & .0191 .981083 \\
\hline .02 .6291468 & & $1.375328 \mathrm{E}-0220.34619$ & .0168 .486432 & $.02 \quad .9425589$ \\
\hline $.0215 .944407 \mathrm{E}-02$ & $\operatorname{lcd} 711$ & .01418 .50014 & .0175 .394141 & .021 .2610986 \\
\hline \multirow{2}{*}{.0220} & .0130 & .01512 .42234 & .0183 .249889 & .0220 \\
\hline & $1.368318 \mathrm{E}-0220.48452$ & .0168 .128133 & .0191 .786604 & \\
\hline $\operatorname{lcd} 211$ & .01418 .11512 & .0175 .125839 & $.02 \quad .8087563$ & lcd 2310 \\
\hline .0130 & .01512 .12238 & .0183 .054036 & .021 .1738194 & .0140 \\
\hline $1.365195 \mathrm{E}-0220.54614$ & .0167 .899437 & .0191 .647979 & .0220 & $1.404228 \mathrm{E}-0219.77589$ \\
\hline .01417 .94388 & .0174 .955446 & .02 .7145186 & & .01513 .67393 \\
\hline .01511 .9893 & .0182 .930363 & .021 .1133773 & lcd 1811 & .0169 .091207 \\
\hline .0167 .798241 & .0191 .561042 & .0220 & .0130 & .0175 .850622 \\
\hline .0174 .880266 & .02 .6559395 & & 1.388819E-02 20.07996 & .0183 .586106 \\
\hline $.018 \quad 2.875977$ & $.0217 .628096 \mathrm{E}-02$ & lcd 1311 & .01419 .24285 & .0192 .027125 \\
\hline .0191 .522963 & .0220 & .0130 & .01513 .00391 & $.02 \quad .9744919$ \\
\hline .02 .6304144 & & $1.377194 \mathrm{E}-02 \quad 20.30938$ & .0168 .57388 & .021 .2821607 \\
\hline $.0216 .023879 \mathrm{E}-02$ & lcd 811 & .01418 .60272 & .0175 .459869 & .0220 \\
\hline \multirow{2}{*}{.0220} & .0130 & .01512 .50244 & $.018 \quad 3.298071$ & \\
\hline & .013694120 .46298 & .0168 .189341 & .0191 .82088 & $\operatorname{lcd} 2410$ \\
\hline lcd 311 & .01418 .17504 & .0175 .171557 & $.02 \quad .8322067$ & .0140 \\
\hline .0130 & .01512 .16899 & .0183 .087313 & .021 .1889971 & $1.407758 \mathrm{E}-0219.70624$ \\
\hline 1.365508E-02 20.53998 & .0167 .934918 & .0191 .671453 & .0220 & $.015 \quad 13.82813$ \\
\hline .01417 .96101 & .0174 .981837 & .02 .7304056 & & .0169 .210825 \\
\hline .01512 .0026 & .0182 .949481 & .021 .1235027 & lcd 1911 & .0175 .941433 \\
\hline .0167 .808347 & .0191 .57445 & .0220 & .0130 & .0183 .653425 \\
\hline .0174 .887768 & .02 .6649468 & & .01391620 .02508 & .0192 .07565 \\
\hline .0182 .881399 & $.0218 .195993 \mathrm{E}-02$ & lcd 1411 & .01419 .39614 & $.02 \quad 1.008248$ \\
\hline .0191 .526755 & .0220 & .0130 & $.015 \quad 13.12442$ & .021 .3045171 \\
\hline .02 .6329525 & & $1.379213 \mathrm{E}-02 \quad 20.26953$ & .0168 .666631 & .0220 \\
\hline $.0216 .183044 \mathrm{E}-02$ & $\operatorname{lcd} 911$ & .01418 .71381 & .0175 .529686 & \\
\hline \multirow[t]{2}{*}{.0220} & .0130 & .01512 .58927 & .0183 .349336 & lcd 2511 \\
\hline & $1.370657 \mathrm{E}-02 \quad 20.43837$ & .0168 .255757 & .0191 .857421 & .0130 \\
\hline $\operatorname{lcd} 411$ & .01418 .24351 & .0175 .22122 & $.02 \quad .8572704$ & $1.365195 \mathrm{E}-0220.54614$ \\
\hline .0130 & .01512 .22229 & .0183 .123507 & .021 .2052766 & .01417 .94388 \\
\hline $1.365976 \mathrm{E}-0220.53073$ & .0167 .975517 & .0191 .697021 & .0220 & .01511 .9893 \\
\hline .01417 .9867 & .0175 .012055 & $.02 \quad .7477434$ & & .0167 .798241 \\
\hline $.015 \quad 12.02255$ & .0182 .971388 & .021 .1345831 & $\operatorname{lcd} 2011$ & .0174 .880266 \\
\hline .0167 .823513 & .0191 .589828 & .0220 & .0130 & $.018 \quad 2.875977$ \\
\hline .0174 .899029 & .02 .6752895 & & 1.394533E-02 19.96722 & .0191 .522963 \\
\hline .0182 .88954 & $.0218 .849228 \mathrm{E}-02$ & lcd 1511 & .01419 .55782 & .02 .6304144 \\
\hline .0191 .53245 & .0220 & .0130 & .01513 .25169 & $.0216 .023879 \mathrm{E}-02$ \\
\hline .02 .636766 & & $1.381386 \mathrm{E}-02 \quad 20.22665$ & .0168 .764729 & .0220 \\
\hline $.021 \quad .0642235$ & lcd 1011 & .01418 .83339 & .0175 .603644 & \\
\hline \multirow[t]{2}{*}{.0220} & .0130 & .01512 .68281 & $.018 \quad 3.403738$ & $\operatorname{lcd} 2611$ \\
\hline & $1.372059 \mathrm{E}-0220.41069$ & .0168 .327393 & .0191 .896277 & .0130 \\
\hline lcd 511 & .01418 .32052 & .0175 .274849 & $.02 \quad .8839925$ & $1.365352 \mathrm{E}-0220.54306$ \\
\hline .0130 & $.015 \quad 12.28227$ & .0183 .162643 & .021 .2226968 & .01417 .95244 \\
\hline 1.366601E-02 20.5184 & .0168 .021238 & .0191 .724712 & .0220 & .01511 .99595 \\
\hline .01418 .02095 & .0175 .046111 & $.02 \quad .7665591$ & & .0167 .803293 \\
\hline $.015 \quad 12.04917$ & .0182 .996099 & .021 .1466432 & $\operatorname{lcd} 2111$ & .0174 .884017 \\
\hline .0167 .843744 & .0191 .607193 & .0220 & .0130 & .0182 .878688 \\
\hline .0174 .914054 & .02 .6869845 & & $1.397615 \mathrm{E}-0219.90639$ & .0191 .524858 \\
\hline .0182 .900406 & $.0219 .589331 \mathrm{E}-02$ & lcd 1611 & .01419 .7278 & .02 .631683 \\
\hline .0191 .540056 & .0220 & .0130 & $.015 \quad 13.38571$ & $.0216 .103424 \mathrm{E}-02$ \\
\hline $.02 \quad 6418617$ & & $1.383711 \mathrm{E}-0220.18076$ & .0168 .868177 & .0220 \\
\hline $.0216 .742378 \mathrm{E}-02$ & $\operatorname{lcd} 1111$ & .01418 .96143 & .0175 .681762 & \\
\hline \multirow[t]{2}{*}{.0220} & .0130 & .01512 .7831 & .0183 .461305 & $\operatorname{lcd} 2711$ \\
\hline & $1.373616 \mathrm{E}-0220.37997$ & .0168 .404279 & .0191 .937484 & .0130 \\
\hline lcd 611 & .01418 .40606 & .0175 .332479 & $.02 \quad .9124082$ & 1.365664E-02 20.5369 \\
\hline .0130 & .01512 .34895 & .0183 .204759 & .021 .2412915 & .01417 .96957 \\
\hline $1.367382 \mathrm{E}-0220.503$ & .0168 .072101 & .0191 .754561 & .0220 & .01512 .00925 \\
\hline
\end{tabular}




\begin{tabular}{|c|c|c|c|c|}
\hline .0167 .813401 & $.0218 .277393 \mathrm{E}-02$ & $1.379368 \mathrm{E}-0220.26646$ & .0183 .352194 & $1.365508 \mathrm{E}-0220.53998$ \\
\hline $.017 \quad 4.891521$ & .0220 & .01418 .72236 & .0191 .859459 & .01417 .96101 \\
\hline $.018 \quad 2.884112$ & & .01512 .59595 & $.02 \quad .8586707$ & .01512 .0026 \\
\hline .0191 .528652 & lcd 3311 & .0168 .26087 & .021 .2061877 & .0167 .808347 \\
\hline .02 .6342227 & .0130 & .0175 .225045 & .0220 & .0174 .887768 \\
\hline $.0216 .262738 \mathrm{E}-02$ & 1.370813E-02 20.43529 & .0183 .126297 & & .0182 .881399 \\
\hline \multirow[t]{2}{*}{.0220} & .01418 .25206 & .0191 .698993 & lcd 4411 & .0191 .526755 \\
\hline & .01512 .22895 & .02 .7490823 & .0130 & .02 .6329525 \\
\hline $\operatorname{lcd} 2811$ & .0167 .98059 & .021 .1354401 & $1.394687 \mathrm{E}-02 \quad 19.96417$ & $.0216 .183044 \mathrm{E}-02$ \\
\hline .0130 & .0175 .015832 & .0220 & .01419 .56631 & .0220 \\
\hline $1.366133 \mathrm{E}-02 \quad 20.52765$ & $.018 \quad 2.974128$ & & $.015 \quad 13.25839$ & \\
\hline .01417 .99526 & .0191 .591753 & $\operatorname{lcd} 3911$ & .0168 .769894 & lcd 5011 \\
\hline $.015 \quad 12.02921$ & .02 .6765849 & .0130 & .0175 .607541 & .0130 \\
\hline .0167 .828571 & $.0218 .931133 \mathrm{E}-02$ & $1.381541 \mathrm{E}-0220.22359$ & .0183 .406607 & 1.365664E-02 20.5369 \\
\hline .0174 .902785 & .0220 & .01418 .84192 & .0191 .898329 & .01417 .96957 \\
\hline .0182 .892256 & & .01512 .6895 & $.02 \quad .8854055$ & $.015 \quad 12.00925$ \\
\hline .0191 .534351 & lcd 3411 & .0168 .332513 & .021 .2236197 & .0167 .813401 \\
\hline .02 .638039 & .0130 & .0175 .278685 & .0220 & .0174 .891521 \\
\hline $.0216 .502267 \mathrm{E}-02$ & $1.372215 \mathrm{E}-0220.40762$ & .0183 .165444 & & $.018 \quad 2.884112$ \\
\hline \multirow{2}{*}{.0220} & .01418 .32907 & .0191 .726695 & lcd 4511 & .0191 .528652 \\
\hline & .01512 .28894 & .02 .7679085 & .0130 & .02 .6342227 \\
\hline $\operatorname{lcd} 2911$ & .0168 .026319 & .021 .1475096 & 1.397769E-02 19.90335 & $.0216 .262738 \mathrm{E}-02$ \\
\hline .0130 & .0175 .049897 & .0220 & .01419 .73629 & .0220 \\
\hline $1.366757 \mathrm{E}-02 \quad 20.51532$ & $.018 \quad 2.998847$ & & $.015 \quad 13.39241$ & \\
\hline .01418 .0295 & .0191 .609125 & $\operatorname{lcd} 4011$ & .0168 .873352 & $\operatorname{lcd} 5111$ \\
\hline .01512 .05581 & .02 .6882868 & .0130 & .0175 .685673 & .0130 \\
\hline .0167 .8488 & $.0219 .671837 \mathrm{E}-02$ & 1.383866E-02 20.1777 & .0183 .46419 & $1.365976 \mathrm{E}-0220.53073$ \\
\hline .0174 .91781 & .0220 & .01418 .96996 & .0191 .939551 & .01417 .9867 \\
\hline .0182 .903123 & & $.015 \quad 12.78979$ & $.02 \quad .9138359$ & $.015 \quad 12.02255$ \\
\hline .0191 .541958 & lcd 3511 & .0168 .409406 & .021 .2422276 & .0167 .823513 \\
\hline .02 .6431366 & .0130 & .0175 .336326 & .0220 & .0174 .899029 \\
\hline $.0216 .822488 \mathrm{E}-02$ & 1.373772E-02 20.3769 & $.018 \quad 3.207572$ & & .0182 .88954 \\
\hline \multirow[t]{2}{*}{.0220} & .01418 .41461 & .0191 .756557 & $\operatorname{lcd} 4610$ & .0191 .53245 \\
\hline & .01512 .35562 & .02 .7882463 & .0140 & .02 .636766 \\
\hline lcd 3011 & .0168 .07719 & .021 .1605883 & $1.401001 \mathrm{E}-02 \quad 19.83957$ & .021 .0642235 \\
\hline .0130 & .0175 .087825 & .0220 & .01513 .53316 & .0220 \\
\hline $1.367538 \mathrm{E}-02 \quad 20.49992$ & $.018 \quad 3.026397$ & & .0168 .982184 & \\
\hline .01418 .07231 & .0191 .628509 & $\operatorname{lcd} 4111$ & $.017 \quad 5.768004$ & lcd 5211 \\
\hline $.015 \quad 12.08909$ & .02 .7013633 & .0130 & $.018 \quad 3.524983$ & .0130 \\
\hline .0167 .874107 & .021 .1050134 & $1.386344 \mathrm{E}-02 \quad 20.12881$ & .0191 .98317 & $1.366445 \mathrm{E}-0220.52148$ \\
\hline .0174 .936615 & .0220 & .01419 .10645 & $.02 \quad .9440043$ & .01418 .01238 \\
\hline .0182 .916731 & & .01512 .89682 & .021 .2620501 & $.015 \quad 12.04251$ \\
\hline $.019 \quad 1.551488$ & lcd 3611 & .0168 .491571 & .0220 & .0167 .838683 \\
\hline .02 .6495275 & .0130 & .0175 .398002 & & .0174 .910295 \\
\hline $.0217 .224395 \mathrm{E}-02$ & $1.375483 \mathrm{E}-0220.34312$ & $.018 \quad 3.252716$ & $\operatorname{lcd} 4710$ & $.018 \quad 2.897687$ \\
\hline \multirow[t]{2}{*}{.0220} & .01418 .50868 & $.019 \quad 1.788614$ & .0140 & .0191 .538152 \\
\hline & $.015 \quad 12.42901$ & $.02 \quad .8101297$ & $1.404382 \mathrm{E}-02 \quad 19.77286$ & .02 .6405861 \\
\hline $\operatorname{lcd} 3111$ & .0168 .133226 & .021 .1747068 & .01513 .68063 & $.0216 .662238 \mathrm{E}-02$ \\
\hline .0130 & .0175 .129642 & .0220 & .0169 .096398 & .0220 \\
\hline $1.368474 \mathrm{E}-02 \quad 20.48145$ & .0183 .056803 & & .0175 .85456 & \\
\hline .01418 .12368 & .0191 .64993 & $\operatorname{lcd} 4211$ & $.018 \quad 3.589022$ & lcd 5311 \\
\hline $.015 \quad 12.12903$ & .02 .7158376 & .0130 & .0192 .029225 & .0130 \\
\hline .0167 .904501 & $.021 \quad .114217$ & $1.388974 \mathrm{E}-02 \quad 20.07691$ & $.02 \quad .9759506$ & $1.367069 \mathrm{E}-0220.50916$ \\
\hline .0174 .959212 & .0220 & .01419 .25136 & .021 .2831249 & .01418 .04663 \\
\hline $.018 \quad 2.933091$ & & .01513 .0106 & .0220 & $.015 \quad 12.06913$ \\
\hline .0191 .562954 & $\operatorname{lcd} 3711$ & .0168 .579025 & & .0167 .858924 \\
\hline .02 .6572233 & .0130 & .0175 .463739 & $\operatorname{lcd} 4810$ & .0174 .925332 \\
\hline $.0217 .708977 \mathrm{E}-02$ & 1.377349E-02 20.30631 & .0183 .30091 & .0140 & .0182 .908565 \\
\hline \multirow[t]{2}{*}{.0220} & .01418 .61127 & .0191 .822901 & $1.407911 \mathrm{E}-0219.70322$ & .0191 .545768 \\
\hline & $.015 \quad 12.50912$ & $.02 \quad .8335918$ & $.015 \quad 13.83483$ & .02 .6456914 \\
\hline $\operatorname{lcd} 3211$ & .0168 .194447 & .021 .1898952 & .0169 .216028 & $.0216 .983096 \mathrm{E}-02$ \\
\hline .0130 & $.017 \quad 5.175373$ & .0220 & .0175 .945387 & .0220 \\
\hline $1.369566 \mathrm{E}-0220.4599$ & .0183 .090093 & & .0183 .65636 & \\
\hline .01418 .1836 & .0191 .673415 & $\operatorname{lcd} 4311$ & .0192 .077769 & lcd 5411 \\
\hline $.015 \quad 12.17565$ & $.02 \quad .7317348$ & .0130 & $.02 \quad 1.009724$ & .0130 \\
\hline .0167 .93999 & .021 .124351 & $1.391755 \mathrm{E}-02 \quad 20.02203$ & .021 .3054966 & .013678520 .49376 \\
\hline .0174 .985611 & .0220 & .01419 .40466 & .0220 & .01418 .08944 \\
\hline .0182 .952216 & & .01513 .13112 & & $.015 \quad 12.10241$ \\
\hline .0191 .576369 & $\operatorname{lcd} 3811$ & .0168 .671791 & lcd 4911 & .0167 .884238 \\
\hline .02 .6662366 & .0130 & $.017 \quad 5.533574$ & .0130 & .0174 .944146 \\
\hline
\end{tabular}




\begin{tabular}{|c|c|c|c|c|}
\hline $.018 \quad 2.922182$ & & $.015 \quad 12.9102$ & .021 .2639529 & .01512 .06247 \\
\hline .0191 .555308 & lcd 6011 & .0168 .501853 & .0220 & .0167 .853862 \\
\hline .02 .6520901 & .0130 & .0175 .405725 & & .0174 .921572 \\
\hline $.0217 .385682 \mathrm{E}-02$ & $1.375794 \mathrm{E}-02 \quad 20.33699$ & .0183 .258374 & $\operatorname{lcd} 7110$ & $.018 \quad 2.905844$ \\
\hline \multirow[t]{2}{*}{.0220} & $.014 \quad 18.52578$ & .0191 .792636 & .0140 & .0191 .543863 \\
\hline & $.015 \quad 12.44236$ & .02 .8128787 & $1.404689 \mathrm{E}-02 \quad 19.7668$ & .02. .0444139 \\
\hline lcd 5511 & .0168 .143422 & .021 .1764837 & $.015 \quad 13.69404$ & $.0216 .902776 \mathrm{E}-02$ \\
\hline .0130 & .0175 .137255 & .0220 & .0169 .106795 & .0220 \\
\hline $1.368786 \mathrm{E}-02 \quad 20.47529$ & .0183 .062341 & & .0175 .862447 & \\
\hline .01418 .1408 & .0191 .653835 & lcd 6611 & .0183 .594864 & lcd 7711 \\
\hline $.015 \quad 12.14235$ & .02 .7184789 & .0130 & .0192 .033431 & .0130 \\
\hline .0167 .914639 & .021 .1158988 & $1.389283 \mathrm{E}-02 \quad 20.07081$ & .02 .9788729 & $1.367538 \mathrm{E}-02 \quad 20.49992$ \\
\hline .0174 .966751 & .0220 & .01419 .2684 & .021 .2850569 & .01418 .07231 \\
\hline .0182 .938551 & & $.015 \quad 13.02399$ & .0220 & $.015 \quad 12.08909$ \\
\hline .0191 .566783 & lcd 6111 & .0168 .589324 & & .0167 .874107 \\
\hline .02 .6597948 & .0130 & .0175 .471487 & lcd 7210 & .0174 .936615 \\
\hline $.0217 .871049 \mathrm{E}-02$ & .013776620 .30018 & .0183 .306596 & .0140 & $.018 \quad 2.916731$ \\
\hline \multirow[t]{2}{*}{.0220} & .01418 .62836 & .0191 .826951 & $1.408218 \mathrm{E}-02 \quad 19.69717$ & .0191 .551488 \\
\hline & $.015 \quad 12.52247$ & .02 .8363666 & .01513 .84824 & .02 .6495275 \\
\hline $\operatorname{lcd} 5611$ & .0168 .204659 & .021 .191695 & .0169 .226443 & $.0217 .224395 \mathrm{E}-02$ \\
\hline .0130 & .0175 .183007 & .0220 & $.017 \quad 5.953302$ & .0220 \\
\hline $1.369878 \mathrm{E}-02 \quad 20.45375$ & .0183 .095654 & & .0183 .662235 & \\
\hline .01418 .20071 & .0191 .677341 & lcd 6711 & .0192 .082009 & lcd 7811 \\
\hline $.015 \quad 12.18897$ & .02 .7343953 & .0130 & $.02 \quad 1.012679$ & .0130 \\
\hline .0167 .950136 & .021 .1260497 & $1.392064 \mathrm{E}-02 \quad 20.01594$ & .021 .3074585 & $1.368318 \mathrm{E}-02 \quad 20.48452$ \\
\hline .0174 .993161 & .0220 & .01419 .42168 & .0220 & .01418 .11512 \\
\hline .0182 .957689 & & .01513 .14452 & & $.015 \quad 12.12238$ \\
\hline .0191 .58021 & lcd 6211 & .0168 .682112 & lcd 7311 & .0167 .899437 \\
\hline .02 .668819 & .0130 & .0175 .54135 & .0130 & .0174 .955446 \\
\hline $.0218 .440416 \mathrm{E}-02$ & $1.379679 \mathrm{E}-02 \quad 20.26034$ & .0183 .357909 & $1.365976 \mathrm{E}-02 \quad 20.53073$ & $.018 \quad 2.930363$ \\
\hline \multirow[t]{2}{*}{.0220} & .01418 .73943 & .0191 .863538 & .01417 .9867 & .0191 .561042 \\
\hline & .01512 .6093 & .02 .861473 & $.015 \quad 12.02255$ & .02 .6559395 \\
\hline lcd 5711 & .0168 .271092 & .021. 2080119 & .0167 .823513 & $.0217 .628096 \mathrm{E}-02$ \\
\hline .0130 & $.017 \quad 5.232695$ & .0220 & .0174 .899029 & .0220 \\
\hline $1.371124 \mathrm{E}-02 \quad 20.42914$ & .0183 .131876 & & .0182 .88954 & \\
\hline .01418 .26918 & .0191 .702939 & lcd 6811 & .0191 .53245 & lcd 7911 \\
\hline $.015 \quad 12.24228$ & .02 .7517613 & .0130 & .02 .636766 & .0130 \\
\hline .0167 .99075 & .021 .1371554 & $1.394995 \mathrm{E}-02 \quad 19.95809$ & .021 .0642235 & $1.369254 \mathrm{E}-02 \quad 20.46605$ \\
\hline .0175 .023398 & .0220 & .01419 .58332 & .0220 & .01418 .16648 \\
\hline .0182 .979616 & & .01513 .27179 & & $.015 \quad 12.16233$ \\
\hline .0191 .595608 & lcd 6311 & .0168 .780231 & lcd 7411 & .0167 .929847 \\
\hline .02. 6791806 & .0130 & .0175 .615342 & .0130 & .0174 .978065 \\
\hline $.0219 .095298 \mathrm{E}-02$ & $1.381851 \mathrm{E}-02 \quad 20.21747$ & .0183 .412351 & $1.366133 \mathrm{E}-02 \quad 20.52765$ & $.018 \quad 2.946748$ \\
\hline \multirow[t]{2}{*}{.0220} & .01418 .85901 & .0191 .902437 & .01417 .99526 & .0191 .572532 \\
\hline & $.015 \quad 12.70287$ & .02 .8882353 & $.015 \quad 12.02921$ & .02 .6636575 \\
\hline lcd 5811 & .0168 .342762 & .021 .2254686 & .0167 .828571 & $.0218 .114646 \mathrm{E}-02$ \\
\hline .0130 & .0175 .286363 & .0220 & .0174 .902785 & .0220 \\
\hline $1.372526 \mathrm{E}-02 \quad 20.40147$ & .0183 .171052 & & .0182 .892256 & \\
\hline $.014 \quad 18.34618$ & .0191 .730667 & lcd 6911 & .0191 .534351 & lcd 8011 \\
\hline $.015 \quad 12.30227$ & .02 .7706112 & .0130 & .02 .638039 & .0130 \\
\hline .0168 .03649 & .021 .1492452 & $1.398077 \mathrm{E}-02 \quad 19.89727$ & $.0216 .502267 \mathrm{E}-02$ & $1.370345 \mathrm{E}-02 \quad 20.44452$ \\
\hline .0175 .057478 & .0220 & .01419 .75327 & .0220 & .01418 .22639 \\
\hline .0183 .004352 & & .01513 .40581 & & .01512 .20896 \\
\hline .0191 .612996 & lcd 6411 & .0168 .883706 & $\operatorname{lcd} 7511$ & .0167 .965364 \\
\hline .02 .6908967 & .0130 & .0175 .6935 & .0130 & .0175 .004496 \\
\hline $.0219 .837247 \mathrm{E}-02$ & $1.384176 \mathrm{E}-02 \quad 20.17159$ & .0183 .469964 & $1.366445 \mathrm{E}-02 \quad 20.52148$ & .0182 .965906 \\
\hline \multirow[t]{2}{*}{.0220} & .01418 .98703 & .0191 .94369 & .01418 .01238 & .0191 .585979 \\
\hline & $.015 \quad 12.80316$ & .02 .9166947 & .01512 .04251 & .02.6726992 \\
\hline lcd 5911 & .0168 .41967 & .021. 2441026 & .0167 .838683 & $.0218 .685508 \mathrm{E}-02$ \\
\hline .0130 & .0175 .344026 & .0220 & .0174 .910295 & .0220 \\
\hline $1.374083 \mathrm{E}-02 \quad 20.37075$ & .0183 .213204 & & $.018 \quad 2.897687$ & \\
\hline .01418 .43172 & .0191 .760553 & lcd 7010 & .0191 .538152 & lcd 8111 \\
\hline .01512 .36896 & .02 .7909716 & .0140 & .02 .6405861 & .0130 \\
\hline .0168 .087374 & .021 .1623441 & 1.401309E-02 19.83351 & $.0216 .662238 \mathrm{E}-02$ & $1.371592 \mathrm{E}-0220.41992$ \\
\hline $.017 \quad 5.095421$ & .0220 & .01513 .54657 & .0220 & .01418 .29486 \\
\hline .0183 .031917 & & .0168 .992559 & & $.015 \quad 12.26228$ \\
\hline .0191 .632396 & $\operatorname{lcd} 6511$ & .0175 .77586 & lcd 7611 & .0168 .005994 \\
\hline .02 .7039881 & .0130 & .0183 .53079 & .0130 & .0175 .034753 \\
\hline .021 .1066808 & $1.386654 \mathrm{E}-02 \quad 20.1227$ & .0191 .987342 & $1.366913 \mathrm{E}-02 \quad 20.51224$ & $.018 \quad 2.987855$ \\
\hline .0220 & .01419 .12351 & .02 .946894 & .01418 .03807 & .0191 .601397 \\
\hline
\end{tabular}




\begin{tabular}{|c|c|c|c|c|}
\hline .02 .6830795 & .0130 & .0175 .627048 & .0130 & .0174 .993161 \\
\hline $.0219 .342036 \mathrm{E}-02$ & $1.382316 \mathrm{E}-0220.20829$ & $.018 \quad 3.420974$ & $1.366757 \mathrm{E}-0220.51532$ & .0182 .957689 \\
\hline \multirow[t]{2}{*}{.0220} & .01418 .88462 & .0191 .908605 & .01418 .0295 & .0191 .58021 \\
\hline & $.015 \quad 12.72293$ & $.02 \quad .8924854$ & .01512 .05581 & .02 .668819 \\
\hline $\operatorname{lcd} 8211$ & .0168 .358133 & .021 .2282468 & .0167 .8488 & $.0218 .440416 \mathrm{E}-02$ \\
\hline .0130 & .0175 .297882 & .0220 & .0174 .91781 & .0220 \\
\hline 1.372994E-02 20.39226 & $.018 \quad 3.179468$ & & .0182 .903123 & \\
\hline .01418 .37184 & .0191 .73663 & $\operatorname{lcd} 9311$ & .0191 .541958 & $\operatorname{lcd} 10411$ \\
\hline $.015 \quad 12.32227$ & .02 .7746695 & .0130 & .02 .6431366 & .0130 \\
\hline .0168 .051745 & .021 .1518528 & $1.398539 \mathrm{E}-02 \quad 19.88816$ & $.0216 .822488 \mathrm{E}-02$ & $1.370969 \mathrm{E}-02 \quad 20.43221$ \\
\hline .0175 .06885 & .0220 & .01419 .77875 & .0220 & .01418 .26062 \\
\hline .0183 .01261 & & .01513 .42591 & & $.015 \quad 12.23562$ \\
\hline .0191 .618806 & lcd 8811 & .0168 .899242 & lcd 9911 & .0167 .985672 \\
\hline .02 .6948151 & .0130 & .0175 .705246 & .0130 & .0175 .019616 \\
\hline .021. 1008572 & $1.384641 E-0220.16242$ & $.018 \quad 3.478632$ & $1.367069 \mathrm{E}-0220.50916$ & $.018 \quad 2.976873$ \\
\hline \multirow[t]{2}{*}{.0220} & .01419 .01262 & .0191 .949904 & .01418 .04663 & .0191 .593681 \\
\hline & $.015 \quad 12.82323$ & $.02 \quad .9209887$ & .01512 .06913 & .02 .6778827 \\
\hline $\operatorname{lcd} 8311$ & .0168 .435064 & .021 .2469203 & .0167 .858924 & $.0219 .013201 \mathrm{E}-02$ \\
\hline .0130 & $.017 \quad 5.355577$ & .0220 & $.017 \quad 4.925332$ & .0220 \\
\hline .013745520 .36154 & $.018 \quad 3.221655$ & & .0182 .908565 & \\
\hline .01418 .45738 & .0191 .766551 & $\operatorname{lcd} 9410$ & .0191 .545768 & lcd 10511 \\
\hline $.015 \quad 12.38898$ & $.02 \quad .7950634$ & .0140 & .02 .6456914 & .0130 \\
\hline .0168 .102655 & .021 .1649815 & $.0140177 \quad 19.8244$ & $.0216 .983096 \mathrm{E}-02$ & $1.372215 \mathrm{E}-02 \quad 20.40762$ \\
\hline .0175 .106823 & .0220 & .01513 .56667 & .0220 & .01418 .32907 \\
\hline .0183 .040206 & & .0169 .008122 & & $.015 \quad 12.28894$ \\
\hline .0191 .638234 & lcd 8911 & .0175 .787648 & lcd 10011 & .0168 .026319 \\
\hline .02 .7079319 & .0130 & .0183 .539505 & .0130 & .0175 .049897 \\
\hline .021. 1091872 & $1.387118 \mathrm{E}-0220.11354$ & .0191 .993604 & $1.367538 \mathrm{E}-0220.49992$ & $.018 \quad 2.998847$ \\
\hline \multirow[t]{2}{*}{.0220} & .01419 .14908 & .02 .9512336 & .01418 .07231 & .0191 .609125 \\
\hline & $.015 \quad 12.93028$ & $.021 \quad .2668117$ & .01512 .08909 & .02 .6882868 \\
\hline lcd 8411 & $.016 \quad 8.517274$ & .0220 & .0167 .874107 & $.0219 .671837 \mathrm{E}-02$ \\
\hline .0130 & $.017 \quad 5.417312$ & & .0174 .936615 & .0220 \\
\hline $1.376261 \mathrm{E}-02 \quad 20.32778$ & $.018 \quad 3.266865$ & $\operatorname{lcd} 9510$ & $.018 \quad 2.916731$ & \\
\hline .01418 .55142 & .0191 .798673 & .0140 & .0191 .551488 & lcd 10611 \\
\hline .01512 .46238 & $.02 \quad .8170071$ & $.0140515 \quad 19.75771$ & .02 .6495275 & .0130 \\
\hline .0168 .158721 & .021 .1791535 & .01513 .71416 & $.0217 .224395 \mathrm{E}-02$ & $1.373616 \mathrm{E}-02 \quad 20.37997$ \\
\hline .0175 .14868 & .0220 & .0169 .122391 & .0220 & .01418 .40606 \\
\hline .0183 .070657 & & .0175 .87428 & & $.015 \quad 12.34895$ \\
\hline .0191 .659699 & $\operatorname{lcd} 9011$ & $.018 \quad 3.603631$ & lcd 10111 & .0168 .072101 \\
\hline .02 .7224472 & .0130 & .0192 .039746 & .0130 & .0175 .084029 \\
\hline .021 .1184272 & $1.389747 \mathrm{E}-0220.06166$ & .02 .9832615 & $1.368162 \mathrm{E}-0220.4876$ & .0183 .023638 \\
\hline \multirow[t]{2}{*}{.0220} & .01419 .29395 & .021 .2879598 & .01418 .10656 & .0191 .626567 \\
\hline & .01513 .04407 & .0220 & .01512 .11572 & .02 .7000523 \\
\hline $\operatorname{lcd} 8511$ & .0168 .604776 & & .0167 .894368 & .021 .104181 \\
\hline .0130 & .0175 .483114 & $\operatorname{lcd} 9610$ & .0174 .951677 & .0220 \\
\hline $1.378126 \mathrm{E}-02 \quad 20.29098$ & $.018 \quad 3.31513$ & .0140 & $.018 \quad 2.927634$ & \\
\hline .01418 .654 & $.019 \quad 1.83303$ & $1.408678 \mathrm{E}-02 \quad 19.68809$ & $.019 \quad 1.559129$ & lcd 10711 \\
\hline $.015 \quad 12.54251$ & .02 .8405338 & .01513 .86836 & .02 .654655 & .0130 \\
\hline .0168 .219981 & .021. 1943992 & .0169 .242067 & $.0217 .547182 \mathrm{E}-02$ & 1.375172E-02 20.34926 \\
\hline .0175 .194462 & .0220 & .0175 .965179 & .0220 & .01418 .49158 \\
\hline .0183 .104 & & $.018 \quad 3.671052$ & & $.015 \quad 12.41567$ \\
\hline .0191 .683236 & $\operatorname{lcd} 9111$ & .0192 .088376 & lcd 10211 & .0168 .123035 \\
\hline .02 .7383915 & .0130 & .021 .017118 & .0130 & .0175 .122034 \\
\hline .021 .1286025 & 1.392527E-02 20.0068 & .021 .3104062 & $1.368942 \mathrm{E}-0220.47221$ & .0183 .051268 \\
\hline \multirow[t]{2}{*}{.0220} & .01419 .44721 & .0220 & .01418 .14937 & .0191 .646029 \\
\hline & .01513 .16461 & & .01512 .14902 & $.02 \quad .7131997$ \\
\hline $\operatorname{lcd} 8611$ & .0168 .697589 & lcd 9711 & .0167 .91971 & $.021 \quad .1125379$ \\
\hline .0130 & $.017 \quad 5.553013$ & .0130 & .0174 .970523 & .0220 \\
\hline 1.380144E-02 20.25115 & .0183 .366485 & $1.366601 \mathrm{E}-0220.5184$ & $.018 \quad 2.941284$ & \\
\hline .01418 .76506 & .0191 .86966 & .01418 .02095 & .0191 .568699 & lcd 10811 \\
\hline .01512 .62935 & $.02 \quad .8656798$ & $.015 \quad 12.04917$ & .02 .6610822 & .0130 \\
\hline .0168 .286442 & .021 .2107516 & .0167 .843744 & $.0217 .952218 \mathrm{E}-02$ & 1.376883E-02 20.31551 \\
\hline .0175 .244184 & .0220 & .0174 .914054 & .0220 & .01418 .58562 \\
\hline .0183 .140258 & & .0182 .900406 & & $.015 \quad 12.48909$ \\
\hline .0191 .708868 & $\operatorname{lcd} 9211$ & .0191 .540056 & lcd 10311 & .0168 .179133 \\
\hline .02 .7557885 & .0130 & .02 .6418617 & .0130 & .0175 .163929 \\
\hline .021. 1397353 & $1.395458 \mathrm{E}-0219.94896$ & $.0216 .742378 \mathrm{E}-02$ & $1.369878 \mathrm{E}-0220.45375$ & .0183 .081759 \\
\hline \multirow[t]{2}{*}{.0220} & .01419 .60883 & .0220 & .01418 .20071 & .0191 .667532 \\
\hline & $.015 \quad 13.29189$ & & .01512 .18897 & .02 .72775 \\
\hline $\operatorname{lcd} 8711$ & .0168 .79574 & $\operatorname{lcd} 9811$ & .0167 .950136 & .021 .1218083 \\
\hline
\end{tabular}




\begin{tabular}{|c|c|c|c|c|}
\hline \multirow[t]{2}{*}{.0220} & .01419 .32803 & .021 .2918386 & .01418 .14937 & .0191 .636287 \\
\hline & .01513 .07085 & .0220 & $.015 \quad 12.14902$ & .02 .7066163 \\
\hline lcd 10911 & .0168 .625389 & & .0167 .91971 & .021 .1083509 \\
\hline .0130 & .0175 .498629 & lcd 12010 & .0174 .970523 & .0220 \\
\hline $1.378747 \mathrm{E}-02 \quad 20.27872$ & $.018 \quad 3.326521$ & .0140 & $.018 \quad 2.941284$ & \\
\hline .01418 .68818 & .0191 .841149 & 1.409291E-02 19.67599 & .0191 .568699 & lcd 13111 \\
\hline $.015 \quad 12.56922$ & .02 .8461014 & $.015 \quad 13.89517$ & .02 .6610822 & .0130 \\
\hline .0168 .240417 & .021 .1980148 & .0169 .262897 & $.0217 .952218 \mathrm{E}-02$ & .013759520 .33392 \\
\hline .0175 .209745 & .0220 & .0175 .981019 & .0220 & .01418 .53433 \\
\hline .0183 .11514 & & .0183 .682815 & & .01512 .44903 \\
\hline .0191 .691107 & lcd 11511 & .0192 .096872 & lcd 12611 & .0168 .148523 \\
\hline .02 .74373 & .0130 & .021 .023043 & .0130 & .0175 .141064 \\
\hline .021 .1320154 & 1.393144E-02 19.99462 & $.021 \quad .3143443$ & 1.369722E-02 20.45683 & .0183 .065114 \\
\hline \multirow[t]{2}{*}{.0220} & .01419 .48125 & .0220 & .01418 .19216 & .0191 .65579 \\
\hline & $.015 \quad 13.1914$ & & $.015 \quad 12.18231$ & $.02 \quad .7198014$ \\
\hline lcd 11011 & .0168 .718239 & lcd 12111 & .0167 .945063 & .021 .1167412 \\
\hline .0130 & .0175 .568579 & .0130 & .0174 .989386 & .0220 \\
\hline $1.380765 \mathrm{E}-0220.2389$ & .0183 .377933 & $1.367382 \mathrm{E}-0220.503$ & .0182 .954952 & \\
\hline .01418 .79923 & .0191 .877836 & .01418 .06375 & .0191 .578289 & lcd 13211 \\
\hline $.015 \quad 12.65608$ & $.02 \quad .8713011$ & .01512 .08244 & .02 .6675274 & .0130 \\
\hline .0168 .306913 & $.021 \quad .2144151$ & .0167 .869045 & $.0218 .358869 \mathrm{E}-02$ & .013776620 .30018 \\
\hline .0175 .259511 & .0220 & .0174 .932854 & .0220 & .01418 .62836 \\
\hline .0183 .151444 & & .0182 .914008 & & $.015 \quad 12.52247$ \\
\hline .0191 .716783 & lcd 11611 & .0191 .549581 & lcd 12711 & .0168 .204659 \\
\hline .02 .7611678 & .0130 & .02 .648248 & .0130 & .0175 .183007 \\
\hline .021 .143184 & $1.396074 \mathrm{E}-0219.93679$ & $.0217 .143895 \mathrm{E}-02$ & $1.370657 \mathrm{E}-0220.43837$ & .0183 .095654 \\
\hline \multirow[t]{2}{*}{.0220} & .01419 .64283 & .0220 & .01418 .24351 & .0191 .677341 \\
\hline & .01513 .31869 & & .01512 .22229 & $.02 \quad .7343953$ \\
\hline lcd 11111 & .0168 .816424 & lcd 12211 & .0167 .975517 & .021 .1260497 \\
\hline .0130 & .0175 .642665 & .0130 & .0175 .012055 & .0220 \\
\hline $1.382936 \mathrm{E}-02 \quad 20.19605$ & .0183 .43248 & $1.367538 \mathrm{E}-0220.49992$ & .0182 .971388 & \\
\hline .01418 .91876 & .0191 .916839 & .01418 .07231 & .0191 .589828 & $\operatorname{lcd} 13311$ \\
\hline $.015 \quad 12.74967$ & .02 .8981622 & .01512 .08909 & .02 .6752895 & .0130 \\
\hline .0168 .378634 & .021 .2319602 & .0167 .874107 & $.0218 .849228 \mathrm{E}-02$ & $1.379523 \mathrm{E}-0220.2634$ \\
\hline .0175 .31325 & .0220 & .0174 .936615 & .0220 & .01418 .73089 \\
\hline .0183 .190699 & & .0182 .916731 & & .01512 .60262 \\
\hline .0191 .74459 & lcd 11711 & .0191 .551488 & lcd 12811 & .0168 .265981 \\
\hline .02 .780091 & .0130 & .02 .6495275 & .0130 & .0175 .22887 \\
\hline .021 .1553389 & $1.399155 \mathrm{E}-02 \quad 19.87601$ & $.0217 .224395 \mathrm{E}-02$ & 1.371748E-02 20.41684 & .0183 .129086 \\
\hline \multirow[t]{2}{*}{.0220} & .01419 .81272 & .0220 & .01418 .30341 & .0191 .700966 \\
\hline & $.015 \quad 13.45273$ & & $.015 \quad 12.26894$ & .02 .7504214 \\
\hline lcd 11211 & .0168 .919971 & lcd 12311 & .0168 .011073 & $.021 \quad .1362974$ \\
\hline .0130 & .0175 .720923 & .0130 & .0175 .038537 & .0220 \\
\hline .013852620 .15019 & .0183 .490203 & .013678520 .49376 & .0182 .990601 & \\
\hline .01419 .04675 & .0191 .958204 & .01418 .08944 & .0191 .603328 & lcd 13411 \\
\hline .01512 .84999 & .02 .9267262 & $.015 \quad 12.10241$ & .02 .6843799 & .0130 \\
\hline .0168 .455606 & .021 .2506877 & .0167 .884238 & $.0219 .424365 \mathrm{E}-02$ & $1.381541 \mathrm{E}-0220.22359$ \\
\hline .0175 .370995 & .0220 & .0174 .944146 & .0220 & .01418 .84192 \\
\hline .0183 .23294 & & .0182 .922182 & & .01512 .6895 \\
\hline .0191 .774563 & lcd 11810 & .0191 .555308 & lcd 12911 & .0168 .332513 \\
\hline .02 .8005317 & .0140 & .02 .6520901 & .0130 & .0175 .278685 \\
\hline .021 .1685087 & $1.402385 \mathrm{E}-0219.81227$ & $.0217 .385682 \mathrm{E}-02$ & 1.372994E-02 20.39226 & .0183 .165444 \\
\hline \multirow[t]{2}{*}{.0220} & $.015 \quad 13.59349$ & .0220 & .01418 .37184 & .0191 .726695 \\
\hline & .0169 .028882 & & $.015 \quad 12.32227$ & .02 .7679085 \\
\hline lcd 11311 & .0175 .803375 & lcd 12411 & .0168 .051745 & .021 .1475096 \\
\hline .0130 & .0183 .551137 & .0130 & .0175 .06885 & .0220 \\
\hline 1.387737E-02 20.10133 & .0192 .001966 & $1.368318 \mathrm{E}-0220.48452$ & .0183 .01261 & \\
\hline .01419 .18319 & $.02 \quad .9570307$ & .01418 .11512 & .0191 .618806 & lcd 13511 \\
\hline .01512 .95705 & .021 .2706332 & .01512 .12238 & .02 .6948151 & .0130 \\
\hline .0168 .537852 & .0220 & .0167 .899437 & .021 .1008572 & $1.383711 \mathrm{E}-0220.18076$ \\
\hline .0175 .432778 & & .0174 .955446 & .0220 & .01418 .96143 \\
\hline $.018 \quad 3.278202$ & lcd 11910 & .0182 .930363 & & $.015 \quad 12.7831$ \\
\hline .0191 .806738 & .0140 & .0191 .561042 & lcd 13011 & .0168 .404279 \\
\hline .02 .822524 & $1.405764 \mathrm{E}-02 \quad 19.7456$ & .02 .6559395 & .0130 & .0175 .332479 \\
\hline .021 .1827238 & $.015 \quad 13.74098$ & $.0217 .628096 \mathrm{E}-02$ & 1.374394E-02 20.36461 & .0183 .204759 \\
\hline \multirow[t]{2}{*}{.0220} & .0169 .143189 & .0220 & .01418 .44883 & .0191 .754561 \\
\hline & .0175 .890065 & & $.015 \quad 12.38231$ & .02 .7868857 \\
\hline lcd 11411 & .0183 .615328 & lcd 12511 & .0168 .09756 & .021 .1597122 \\
\hline .0130 & .0192 .048174 & .0130 & .0175 .103021 & .0220 \\
\hline $1.390365 \mathrm{E}-0220.04946$ & .02 .9891221 & 1.368942E-02 20.47221 & .0183 .037442 & \\
\hline
\end{tabular}




\begin{tabular}{|c|c|c|c|c|}
\hline lcd 13611 & .0168 .945881 & lcd 14711 & .0168 .041574 & .021 .141458 \\
\hline .0130 & .0175 .740525 & .0130 & .0175 .061267 & .0220 \\
\hline $1.386035 \mathrm{E}-02 \quad 20.13491$ & .0183 .504679 & $1.368786 \mathrm{E}-0220.47529$ & .0183 .007103 & \\
\hline .01419 .0894 & .0191 .968591 & .01418 .1408 & .0191 .614931 & lcd 15811 \\
\hline $.015 \quad 12.88344$ & $.02 \quad .9339115$ & $.015 \quad 12.14235$ & .02 .6922017 & .0130 \\
\hline .0168 .481294 & .021 .2554098 & .0167 .914639 & $.0219 .919976 \mathrm{E}-02$ & $1.382471 \mathrm{E}-0220.20523$ \\
\hline .0175 .390282 & .0220 & .0174 .966751 & .0220 & .01418 .89316 \\
\hline $.018 \quad 3.247062$ & & .0182 .938551 & & $.015 \quad 12.72961$ \\
\hline .0191 .784596 & $\operatorname{lcd} 14210$ & .0191 .566783 & $\operatorname{lcd} 15311$ & .0168 .363259 \\
\hline $.02 \quad .8073837$ & .0140 & .02 .6597948 & .0130 & .0175 .301723 \\
\hline $.021 \quad .1729327$ & $1.403153 \mathrm{E}-02 \quad 19.79711$ & $.0217 .871049 \mathrm{E}-02$ & $1.373928 \mathrm{E}-0220.37383$ & $.018 \quad 3.182275$ \\
\hline \multirow[t]{2}{*}{.0220} & .01513 .62701 & .0220 & .01418 .42316 & .0191 .738619 \\
\hline & .0169 .054844 & & .01512 .36229 & $.02 \quad .7760242$ \\
\hline lcd 13711 & .0175 .82305 & $\operatorname{lcd} 14811$ & .0168 .082282 & .021 .1527236 \\
\hline .0130 & .0183 .565694 & .0130 & .0175 .091623 & .0220 \\
\hline .013885120 .08607 & .0192 .012435 & $1.369254 \mathrm{E}-02 \quad 20.46605$ & .0183 .029156 & \\
\hline .01419 .2258 & .02 .9642935 & .01418 .16648 & .0191 .630452 & $\operatorname{lcd} 15911$ \\
\hline $.015 \quad 12.99051$ & .021 .2754249 & $.015 \quad 12.16233$ & .02 .7026752 & .0130 \\
\hline .0168 .563581 & .0220 & .0167 .929847 & .021 .1058466 & $1.384641 \mathrm{E}-0220.16242$ \\
\hline $.017 \quad 5.452122$ & & .0174 .978065 & .0220 & .01419 .01262 \\
\hline .0183 .292388 & $\operatorname{lcd} 14310$ & .0182 .946748 & & $.015 \quad 12.82323$ \\
\hline .0191 .816833 & .0140 & .0191 .572532 & lcd 15411 & .0168 .435064 \\
\hline .02 .8294355 & $1.406531 \mathrm{E}-02 \quad 19.73046$ & .02 .6636575 & .0130 & .0175 .355577 \\
\hline .021 .1872008 & $.015 \quad 13.7745$ & $.0218 .114646 \mathrm{E}-02$ & $1.375328 \mathrm{E}-0220.34619$ & $.018 \quad 3.221655$ \\
\hline \multirow[t]{2}{*}{.0220} & .0169 .169195 & .0220 & .01418 .50014 & $.019 \quad 1.766551$ \\
\hline & .0175 .90981 & & $.015 \quad 12.42234$ & $.02 \quad .7950634$ \\
\hline lcd 13811 & .0183 .629966 & $\operatorname{lcd} 14911$ & .0168 .128133 & .021 .1649815 \\
\hline .0130 & .0192 .058727 & .0130 & $.017 \quad 5.125839$ & .0220 \\
\hline $1.391137 \mathrm{E}-02 \quad 20.03422$ & .02 .9964641 & $1.369878 \mathrm{E}-02 \quad 20.45375$ & .0183 .054036 & \\
\hline .01419 .37061 & .021 .296702 & .01418 .20071 & .0191 .647979 & lcd 16011 \\
\hline .01513 .10434 & .0220 & $.015 \quad 12.18897$ & .02 .7145186 & .0130 \\
\hline .0168 .651167 & & .0167 .950136 & .021 .1133773 & $1.386963 \mathrm{E}-0220.11659$ \\
\hline .0175 .518038 & $\operatorname{lcd} 14410$ & .0174 .993161 & .0220 & .01419 .14056 \\
\hline $.018 \quad 3.340778$ & .0140 & .0182 .957689 & & $.015 \quad 12.92359$ \\
\hline .0191 .851315 & 1.410057E-02 19.66088 & .0191 .58021 & lcd 15511 & .0168 .512135 \\
\hline $.02 \quad .8530779$ & .01513 .92869 & .02 .668819 & .0130 & .0175 .41345 \\
\hline .021 .2025493 & .0169 .288949 & $.0218 .440416 \mathrm{E}-02$ & $1.376883 \mathrm{E}-02 \quad 20.31551$ & $.018 \quad 3.264035$ \\
\hline \multirow[t]{2}{*}{.0220} & .0176 .000835 & .0220 & .01418 .58562 & .0191 .79666 \\
\hline & .0183 .697536 & & .01512 .48909 & $.02 \quad .8156303$ \\
\hline lcd 13911 & .0192 .10751 & $\operatorname{lcd} 15011$ & .0168 .179133 & .021 .1782629 \\
\hline .0130 & .021 .030467 & .0130 & $.017 \quad 5.163929$ & .0220 \\
\hline $1.393916 \mathrm{E}-02 \quad 19.97939$ & .021 .3192822 & $1.370657 \mathrm{E}-02 \quad 20.43837$ & $.018 \quad 3.081759$ & \\
\hline .01419 .52379 & .0220 & .01418 .24351 & .0191 .667532 & $\operatorname{lcd} 16111$ \\
\hline .01513 .2249 & & $.015 \quad 12.22229$ & .02 .72775 & .0130 \\
\hline $.016 \quad 8.744061$ & $\operatorname{lcd} 14511$ & .0167 .975517 & .021 .1218083 & $1.389438 \mathrm{E}-0220.06776$ \\
\hline .0175 .588052 & .0130 & .0175 .012055 & .0220 & .01419 .27691 \\
\hline .0183 .392261 & $1.368318 \mathrm{E}-02 \quad 20.48452$ & $.018 \quad 2.971388$ & & $.015 \quad 13.03068$ \\
\hline .0191 .888073 & .01418 .11512 & .0191 .589828 & lcd 15611 & .0168 .594473 \\
\hline $.02 \quad .8783444$ & $.015 \quad 12.12238$ & .02 .6752895 & .0130 & .0175 .475361 \\
\hline .021 .2190094 & .0167 .899437 & $.0218 .849228 \mathrm{E}-02$ & 1.378592E-02 20.28179 & $.018 \quad 3.309439$ \\
\hline \multirow[t]{2}{*}{.0220} & .0174 .955446 & .0220 & .01418 .67963 & .0191 .828976 \\
\hline & .0182 .930363 & & $.015 \quad 12.56254$ & $.02 \quad .8377544$ \\
\hline lcd 14011 & .0191 .561042 & $\operatorname{lcd} 15111$ & .0168 .235309 & .021 .1925954 \\
\hline .0130 & .02 .6559395 & .0130 & $.017 \quad 5.205924$ & .0220 \\
\hline $1.396845 \mathrm{E}-02 \quad 19.92159$ & $.0217 .628096 \mathrm{E}-02$ & $1.371592 \mathrm{E}-02 \quad 20.41992$ & $.018 \quad 3.112354$ & \\
\hline .01419 .68532 & .0220 & .01418 .29486 & .0191 .689138 & lcd 16211 \\
\hline .01513 .35219 & & $.015 \quad 12.26228$ & $.02 \quad .7423945$ & .0130 \\
\hline .0168 .842293 & lcd 14611 & .0168 .005994 & .021 .1311614 & $1.392064 \mathrm{E}-0220.01594$ \\
\hline .0175 .662203 & .0130 & .0175 .034753 & .0220 & .01419 .42168 \\
\hline .0183 .446882 & $1.368474 \mathrm{E}-0220.48145$ & .0182 .987855 & & $.015 \quad 13.14452$ \\
\hline .0191 .927151 & .01418 .12368 & .0191 .601397 & lcd 15711 & .0168 .682112 \\
\hline $.02 \quad .9052755$ & $.015 \quad 12.12903$ & .02 .6830795 & .0130 & .0175 .54135 \\
\hline .021 .2366172 & .0167 .904501 & $.0219 .342036 \mathrm{E}-02$ & $1.380455 \mathrm{E}-0220.24502$ & .0183 .357909 \\
\hline \multirow[t]{2}{*}{.0220} & .0174 .959212 & .0220 & .01418 .78214 & .0191 .863538 \\
\hline & $.018 \quad 2.933091$ & & $.015 \quad 12.64271$ & .02 .861473 \\
\hline lcd 14111 & $.019 \quad 1.562954$ & $\operatorname{lcd} 15211$ & .0168 .296675 & .021 .2080119 \\
\hline .0130 & .02 .6572233 & .0130 & .0175 .251844 & .0220 \\
\hline $1.399924 \mathrm{E}-02 \quad 19.86082$ & $.0217 .708977 \mathrm{E}-02$ & $1.372682 \mathrm{E}-0220.3984$ & $.018 \quad 3.145849$ & \\
\hline .01419 .85515 & .0220 & .01418 .35473 & .0191 .712823 & $\operatorname{lcd} 16311$ \\
\hline .01513 .48623 & & .01512 .30894 & .02 .7584761 & .0130 \\
\hline
\end{tabular}




\begin{tabular}{|c|c|c|c|c|}
\hline 1.394841E-02 19.96113 & .0220 & .01418 .30341 & .0191 .68127 & lcd 18511 \\
\hline .01419 .57482 & & $.015 \quad 12.26894$ & $.02 \quad .7370585$ & .0130 \\
\hline $.015 \quad 13.26509$ & lcd 16911 & .0168 .011073 & .021 .1277508 & $1.390519 \mathrm{E}-0220.04642$ \\
\hline .0168 .775065 & .0130 & .0175 .038537 & .0220 & .01419 .33655 \\
\hline .0175 .611443 & .013694120 .46298 & .0182 .990601 & & .01513 .07755 \\
\hline .0183 .40948 & .01418 .17504 & .0191 .603328 & lcd 18011 & .0168 .630543 \\
\hline .0191 .900383 & .01512 .16899 & .02 .6843799 & .0130 & .0175 .502509 \\
\hline .02 .8868206 & .0167 .934918 & $.0219 .424365 \mathrm{E}-02$ & $1.379679 \mathrm{E}-0220.26034$ & .0183 .32937 \\
\hline .021 .2245442 & .0174 .981837 & .0220 & .01418 .73943 & .0191 .84318 \\
\hline \multirow[t]{2}{*}{.0220} & $.018 \quad 2.949481$ & & .01512 .6093 & .02 .847495 \\
\hline & .0191 .57445 & lcd 17511 & .0168 .271092 & .021 .1989202 \\
\hline lcd 16411 & .02 .6649468 & .0130 & .0175 .232695 & .0220 \\
\hline .0130 & $.0218 .195993 \mathrm{E}-02$ & 1.372682E-02 20.3984 & .0183 .131876 & \\
\hline 1.397769E-02 19.90335 & .0220 & .01418 .35473 & .0191 .702939 & lcd 18611 \\
\hline .01419 .73629 & & $.015 \quad 12.30894$ & .02 .7517613 & .0130 \\
\hline .01513 .39241 & lcd 17011 & .0168 .041574 & .021 .1371554 & $1.393144 \mathrm{E}-0219.99462$ \\
\hline .0168 .873352 & .0130 & .0175 .061267 & .0220 & .01419 .48125 \\
\hline .0175 .685673 & $1.369566 \mathrm{E}-0220.4599$ & .0183 .007103 & & .01513 .1914 \\
\hline .0183 .46419 & .01418 .1836 & .0191 .614931 & lcd 18111 & .0168 .718239 \\
\hline .0191 .939551 & .01512 .17565 & .02 .6922017 & .0130 & .0175 .568579 \\
\hline .02 .9138359 & .0167 .93999 & $.0219 .919976 \mathrm{E}-02$ & $1.381541 \mathrm{E}-0220.22359$ & $.018 \quad 3.377933$ \\
\hline .021 .2422276 & .0174 .985611 & .0220 & .01418 .84192 & .0191 .877836 \\
\hline \multirow[t]{2}{*}{.0220} & .0182 .952216 & & .01512 .6895 & $.02 \quad .8713011$ \\
\hline & .0191 .576369 & lcd 17611 & .0168 .332513 & .021 .2144151 \\
\hline lcd 16510 & .02 .6662366 & .0130 & $.017 \quad 5.278685$ & .0220 \\
\hline .0140 & $.0218 .277393 \mathrm{E}-02$ & 1.373772E-02 20.3769 & $.018 \quad 3.165444$ & \\
\hline 1.400847E-02 19.84261 & .0220 & .01418 .41461 & .0191 .726695 & lcd 18711 \\
\hline .01513 .52645 & & .01512 .35562 & .02 .7679085 & .0130 \\
\hline .0168 .976992 & lcd 17111 & .0168 .07719 & .021 .1475096 & $.0139592 \quad 19.93983$ \\
\hline .0175 .764073 & .0130 & .0175 .087825 & .0220 & .01419 .63433 \\
\hline $.018 \quad 3.522077$ & $1.369878 \mathrm{E}-0220.45375$ & .0183 .026397 & & $.015 \quad 13.31199$ \\
\hline .0191 .981083 & .01418 .20071 & .0191 .628509 & lcd 18211 & .0168 .811256 \\
\hline .02 .9425589 & .01512 .18897 & .02 .7013633 & .0130 & .0175 .638762 \\
\hline .021 .2610986 & .0167 .950136 & .021 .1050134 & $1.383556 \mathrm{E}-0220.18382$ & $.018 \quad 3.429604$ \\
\hline \multirow[t]{2}{*}{.0220} & .0174 .993161 & .0220 & .01418 .9529 & .0191 .914781 \\
\hline & $.018 \quad 2.957689$ & & $.015 \quad 12.77641$ & .02 .8967427 \\
\hline lcd 16610 & .0191 .58021 & lcd 17711 & .0168 .399149 & .021 .2310314 \\
\hline .0140 & .02 .668819 & .0130 & .0175 .328632 & .0220 \\
\hline $1.404075 \mathrm{E}-02 \quad 19.77892$ & $.0218 .440416 \mathrm{E}-02$ & $1.375017 \mathrm{E}-02 \quad 20.35233$ & $.018 \quad 3.201945$ & \\
\hline .01513 .66723 & .0220 & .01418 .48303 & .0191 .752566 & lcd 18811 \\
\hline .0169 .086009 & & .01512 .40899 & .02 .7855253 & .0130 \\
\hline .0175 .84668 & lcd 17211 & .0168 .117937 & .021 .1588362 & $1.398847 \mathrm{E}-0219.88208$ \\
\hline .0183 .583187 & .0130 & .0175 .118227 & .0220 & .01419 .79574 \\
\hline .0192 .025024 & $1.370345 \mathrm{E}-0220.44452$ & .0183 .0485 & & $.015 \quad 13.43932$ \\
\hline $.02 \quad .9730324$ & .01418 .22639 & .0191 .644078 & lcd 18311 & .0168 .909608 \\
\hline .021. 2811962 & .01512 .20896 & $.02 \quad .7118808$ & .0130 & .0175 .713085 \\
\hline \multirow[t]{2}{*}{.0220} & .0167 .965364 & .021 .1116988 & $1.385725 \mathrm{E}-0220.14103$ & $.018 \quad 3.484417$ \\
\hline & .0175 .004496 & .0220 & .01419 .07234 & .0191 .954053 \\
\hline $\operatorname{lcd} 16710$ & .0182 .965906 & & .01512 .87006 & $.02 \quad .9238565$ \\
\hline .0140 & .0191 .585979 & $\operatorname{lcd} 17811$ & .0168 .471017 & .021 .248803 \\
\hline $1.407451 \mathrm{E}-0219.71229$ & .02 .6726992 & .0130 & .0175 .382565 & .0220 \\
\hline .01513 .81472 & $.0218 .685508 \mathrm{E}-02$ & $1.376416 \mathrm{E}-02 \quad 20.32471$ & $.018 \quad 3.24141$ & \\
\hline .0169 .200415 & .0220 & .01418 .55998 & .0191 .78058 & lcd 18910 \\
\hline .0175 .933523 & & $.015 \quad 12.46906$ & .02 .8046405 & .0140 \\
\hline .0183 .647556 & $\operatorname{lcd} 17311$ & .0168 .163826 & .021 .171161 & $1.401924 \mathrm{E}-0219.82137$ \\
\hline .0192 .071415 & .0130 & .0175 .152493 & .0220 & $.015 \quad 13.57338$ \\
\hline .021 .005298 & 1.370969E-02 20.43221 & $.018 \quad 3.073432$ & & .0169 .013311 \\
\hline .021 3025593 & .01418 .26062 & .0191 .661657 & lcd 18411 & .0175 .791579 \\
\hline \multirow[t]{2}{*}{.0220} & $.015 \quad 12.23562$ & $.02 \quad .7237723$ & .0130 & $.018 \quad 3.542412$ \\
\hline & .0167 .985672 & .021 .1192717 & $1.388046 \mathrm{E}-0220.09522$ & .0191 .995694 \\
\hline lcd 16810 & .0175 .019616 & .0220 & .01419 .20022 & .02 .952682 \\
\hline .0140 & $.018 \quad 2.976873$ & & .01512 .97043 & .021 .2677662 \\
\hline 1.410976E-02 19.64274 & .0191 .593681 & lcd 17911 & .0168 .548137 & .0220 \\
\hline .01513 .96892 & .02 .6778827 & .0130 & .0175 .44051 & \\
\hline .0169 .320225 & $.0219 .013201 \mathrm{E}-02$ & .013779720 .29405 & $.018 \quad 3.283872$ & $\operatorname{lcd} 19010$ \\
\hline $.017 \quad 6.024635$ & .0220 & .01418 .64545 & .0191 .810772 & .0140 \\
\hline $.018 \quad 3.715227$ & & $.015 \quad 12.53583$ & .02 .8252852 & $.0140515 \quad 19.75771$ \\
\hline .0192 .120302 & lcd 17411 & .0168 .214873 & .021 .1845119 & $.015 \quad 13.71416$ \\
\hline .021 .0394 & .0130 & .0175 .190642 & .0220 & .0169 .122391 \\
\hline $.021 \quad .3252292$ & $1.371748 \mathrm{E}-0220.41684$ & .0183 .101217 & & .0175 .87428 \\
\hline
\end{tabular}




\begin{tabular}{|c|c|c|c|c|}
\hline .0183 .603631 & .0130 & .0175 .14868 & .0220 & $.015 \quad 13.49294$ \\
\hline .0192 .039746 & $1.371592 \mathrm{E}-02 \quad 20.41992$ & .0183 .070657 & & .0168 .951068 \\
\hline .02 .9832615 & .01418 .29486 & .019 1.659699 & lcd 20711 & .0175 .744451 \\
\hline .021 .2879598 & $.015 \quad 12.26228$ & .02 .7224472 & .0130 & .0183 .507579 \\
\hline \multirow[t]{2}{*}{.0220} & .0168 .005994 & .021 .1184272 & $1.386963 \mathrm{E}-02 \quad 20.11659$ & .0191 .970672 \\
\hline & .0175 .034753 & .0220 & .01419 .14056 & .02 .9353516 \\
\hline lcd 19110 & .0182 .987855 & & $.015 \quad 12.92359$ & .021 .2563567 \\
\hline .0140 & .0191 .601397 & lcd 20211 & .0168 .512135 & .0220 \\
\hline 1.408524E-02 19.69112 & .02 .6830795 & .0130 & .0175 .41345 & \\
\hline $.015 \quad 13.86165$ & $.0219 .342036 \mathrm{E}-02$ & .0137766 20.30018 & $.018 \quad 3.264035$ & $\operatorname{lcd} 21310$ \\
\hline .0169 .236857 & .0220 & .01418 .62836 & .0191 .79666 & .0140 \\
\hline .0175 .961219 & & .01512 .52247 & .02 .8156303 & $1.403153 \mathrm{E}-02 \quad 19.79711$ \\
\hline .0183 .668112 & lcd 19711 & .0168 .204659 & .021 .1782629 & .01513 .62701 \\
\hline .0192 .086252 & .0130 & .0175 .183007 & .0220 & .0169 .054844 \\
\hline .021 .015637 & $1.372215 \mathrm{E}-02 \quad 20.40762$ & .0183 .095654 & & .0175 .82305 \\
\hline .021 .3094226 & .01418 .32907 & .0191 .677341 & $\operatorname{lcd} 20811$ & .0183 .565694 \\
\hline \multirow[t]{2}{*}{.0220} & $.015 \quad 12.28894$ & .02 .7343953 & .0130 & .0192 .012435 \\
\hline & .0168 .026319 & .021 .1260497 & $1.389283 \mathrm{E}-02 \quad 20.07081$ & .02 .9642935 \\
\hline lcd 19210 & .0175 .049897 & .0220 & .01419 .2684 & .021 .2754249 \\
\hline .0140 & $.018 \quad 2.998847$ & & $.015 \quad 13.02399$ & .0220 \\
\hline $1.412047 \mathrm{E}-02 \quad 19.6216$ & .0191 .609125 & lcd 20311 & .0168 .589324 & \\
\hline . & .02 .6882868 & .0130 & $.017 \quad 5.471487$ & $\operatorname{lcd} 21410$ \\
\hline .0169 .356724 & $.0219 .671837 \mathrm{E}-02$ & $1.379213 \mathrm{E}-02 \quad 20.26953$ & .0183 .306596 & .0140 \\
\hline $.017 \quad 6.052425$ & .0220 & .01418 .71381 & .0191 .826951 & $1.406377 \mathrm{E}-02 \quad 19.73348$ \\
\hline .0183 .735895 & & $.015 \quad 12.58927$ & .02 .8363666 & $.015 \quad 13.7678$ \\
\hline .0192 .135257 & lcd 19811 & .0168 .255757 & .021. 191695 & .0169 .163997 \\
\hline $.02 \quad 1.049852$ & .0130 & .0175 .22122 & .0220 & .0175 .905862 \\
\hline .021 .3321959 & $1.372994 \mathrm{E}-02 \quad 20.39226$ & .0183 .123507 & & .0183 .627039 \\
\hline \multirow[t]{2}{*}{.0220} & .01418 .37184 & .0191 .697021 & lcd 20911 & .0192 .056617 \\
\hline & $.015 \quad 12.32227$ & .02 .7477434 & .0130 & .02 .9949952 \\
\hline lcd 19311 & .0168 .051745 & .021 .1345831 & $1.391755 \mathrm{E}-02 \quad 20.02203$ & .021 .2957287 \\
\hline .0130 & .0175 .06885 & .0220 & .01419 .40466 & .0220 \\
\hline $1.370657 \mathrm{E}-02 \quad 20.43837$ & .0183 .01261 & & $.015 \quad 13.13112$ & \\
\hline .01418 .24351 & .0191 .618806 & lcd 20411 & .0168 .671791 & lcd 21510 \\
\hline $.015 \quad 12.22229$ & .02 .6948151 & .0130 & $.017 \quad 5.533574$ & .0140 \\
\hline .0167 .975517 & .021. 1008572 & .013809220 .23584 & .0183 .352194 & .014097519 .66693 \\
\hline $.017 \quad 5.012055$ & .0220 & .01418 .80777 & .0191 .859459 & $.015 \quad 13.91528$ \\
\hline $.018 \quad 2.971388$ & & .01512 .66276 & .02 .8586707 & .0169 .278524 \\
\hline .0191 .589828 & lcd 19911 & .0168 .312033 & .021. 2061877 & .0175 .992904 \\
\hline .02 .6752895 & .0130 & .0175 .263344 & .0220 & .0183 .691644 \\
\hline $.0218 .849228 \mathrm{E}-02$ & $1.373928 \mathrm{E}-02 \quad 20.37383$ & .0183 .154243 & & .0192 .103251 \\
\hline \multirow[t]{2}{*}{.0220} & .01418 .42316 & .0191 .718764 & $\operatorname{lcd} 21011$ & $.02 \quad 1.027495$ \\
\hline & $.015 \quad 12.36229$ & .02 .7625146 & .0130 & .021 .3173045 \\
\hline lcd 19411 & .0168 .082282 & .021 .1440479 & $1.394379 \mathrm{E}-02 \quad 19.97026$ & .0220 \\
\hline .0130 & .0175 .091623 & .0220 & .01419 .5493 & \\
\hline $1.370813 \mathrm{E}-02 \quad 20.43529$ & .0183 .029156 & & $.015 \quad 13.24499$ & $\operatorname{lcd} 21610$ \\
\hline .01418 .25206 & .0191 .630452 & $\operatorname{lcd} 20511$ & .0168 .75956 & .0140 \\
\hline $.015 \quad 12.22895$ & .02 .7026752 & .0130 & .0175 .599743 & $1.413271 \mathrm{E}-02 \quad 19.59744$ \\
\hline .0167 .98059 & .021. 1058466 & $1.382781 \mathrm{E}-02 \quad 20.19911$ & .0183 .400866 & $.015 \quad 14.06947$ \\
\hline .0175 .015832 & .0220 & .01418 .91022 & .0191 .894224 & .0169 .398463 \\
\hline $.018 \quad 2.974128$ & & $.015 \quad 12.74298$ & .02 .8825789 & $.017 \quad 6.084225$ \\
\hline .0191 .591753 & lcd 20011 & .0168 .373506 & .021 2217737 & .0183 .759561 \\
\hline .02 .6765849 & .0130 & .0175 .309404 & .0220 & .0192 .152393 \\
\hline $.0218 .931133 \mathrm{E}-02$ & $1.375017 \mathrm{E}-02 \quad 20.35233$ & .0183 .187889 & & $.02 \quad 1.061841$ \\
\hline \multirow[t]{2}{*}{.0220} & .01418 .48303 & .0191 .742598 & $\operatorname{lcd} 21111$ & .021 .3401971 \\
\hline & $.015 \quad 12.40899$ & .02 .7787338 & .0130 & .0220 \\
\hline lcd 19511 & .0168 .117937 & .021 .1544659 & $1.397153 \mathrm{E}-02 \quad 19.91551$ & \\
\hline .0130 & .0175 .118227 & .0220 & .01419 .70231 & $\operatorname{lcd} 21711$ \\
\hline $1.371124 \mathrm{E}-02 \quad 20.42914$ & .0183 .0485 & & .01513 .3656 & .0130 \\
\hline .01418 .26918 & .0191 .644078 & $\operatorname{lcd} 20611$ & .0168 .852643 & $1.372059 \mathrm{E}-02 \quad 20.41069$ \\
\hline $.015 \quad 12.24228$ & .02 .7118808 & .0130 & .0175 .670023 & .01418 .32052 \\
\hline .0167 .99075 & .021 .1116988 & $1.384796 \mathrm{E}-02 \quad 20.15936$ & .0183 .452647 & $.015 \quad 12.28227$ \\
\hline .0175 .023398 & .0220 & .01419 .02116 & .0191 .931281 & .0168 .021238 \\
\hline $.018 \quad 2.979616$ & & $.015 \quad 12.82992$ & .02 .9081258 & .0175 .046111 \\
\hline .0191 .595608 & lcd 20111 & .0168 .440201 & .021.2384846 & .0182 .996099 \\
\hline .02. 6791806 & .0130 & .0175 .359431 & .0220 & .0191 .607193 \\
\hline $.0219 .095298 \mathrm{E}-02$ & $1.376261 \mathrm{E}-02 \quad 20.32778$ & .0183 .224476 & & .02 .6869845 \\
\hline \multirow[t]{2}{*}{.0220} & .01418 .55142 & .0191 .768554 & $\operatorname{lcd} 21210$ & $.0219 .589331 \mathrm{E}-02$ \\
\hline & $.015 \quad 12.46238$ & .02 .7964298 & .0140 & .0220 \\
\hline lcd 19611 & .0168 .158721 & .021. 1658626 & $1.400078 \mathrm{E}-02 \quad 19.85779$ & \\
\hline
\end{tabular}




\begin{tabular}{|c|c|c|c|c|}
\hline $\operatorname{lcd} 21811$ & .0168 .128133 & .021 .1518528 & $1.395766 \mathrm{E}-02 \quad 19.94288$ & .0220 \\
\hline .0130 & .0175 .125839 & .0220 & .01419 .62582 & \\
\hline $1.372215 \mathrm{E}-0220.40762$ & .0183 .054036 & & .01513 .30529 & $\operatorname{lcd} 24010$ \\
\hline .01418 .32907 & .0191 .647979 & $\operatorname{lcd} 22911$ & .0168 .806078 & .0140 \\
\hline $.015 \quad 12.28894$ & .02 .7145186 & .0130 & .0175 .634853 & $1.414648 \mathrm{E}-0219.57028$ \\
\hline $.016 \quad 8.026319$ & .021 .1133773 & $1.384176 \mathrm{E}-0220.17159$ & $.018 \quad 3.426723$ & $.015 \quad 14.12979$ \\
\hline .0175 .049897 & .0220 & .01418 .98703 & .0191 .912719 & .0169 .445442 \\
\hline .0182 .998847 & & .01512 .80316 & .02 .8953215 & .0176 .12004 \\
\hline .0191 .609125 & $\operatorname{lcd} 22411$ & .0168 .41967 & .021 .2301017 & $.018 \quad 3.786236$ \\
\hline .02 .6882868 & .0130 & .0175 .344026 & .0220 & .0192 .171726 \\
\hline $.0219 .671837 \mathrm{E}-02$ & $1.376416 \mathrm{E}-02 \quad 20.32471$ & .0183 .213204 & & $.02 \quad 1.075381$ \\
\hline \multirow[t]{2}{*}{.0220} & .01418 .55998 & .0191 .760553 & $\operatorname{lcd} 23511$ & $.021 \quad 3492469$ \\
\hline & .01512 .46906 & .02 .7909716 & .0130 & .0220 \\
\hline $\operatorname{lcd} 21911$ & .0168 .163826 & .021 .1623441 & 1.398539E-02 19.88816 & \\
\hline .0130 & .0175 .152493 & .0220 & .01419 .77875 & $\operatorname{lcd} 24111$ \\
\hline $1.372526 \mathrm{E}-02 \quad 20.40147$ & $.018 \quad 3.073432$ & & $.015 \quad 13.42591$ & .0130 \\
\hline .01418 .34618 & .0191 .661657 & $\operatorname{lcd} 23011$ & .0168 .899242 & $1.373616 \mathrm{E}-0220.37997$ \\
\hline $.015 \quad 12.30227$ & $.02 \quad .7237723$ & .0130 & .0175 .705246 & .01418 .40606 \\
\hline .0168 .03649 & .021 .1192717 & $1.386189 \mathrm{E}-0220.13186$ & .0183 .478632 & $.015 \quad 12.34895$ \\
\hline .0175 .057478 & .0220 & .01419 .09793 & .0191 .949904 & .0168 .072101 \\
\hline .0183 .004352 & & $.015 \quad 12.89013$ & $.02 \quad .9209887$ & .0175 .084029 \\
\hline .0191 .612996 & $\operatorname{lcd} 22511$ & .0168 .486432 & .021 .2469203 & .0183 .023638 \\
\hline .02 .6908967 & .0130 & .0175 .394141 & .0220 & .0191 .626567 \\
\hline $.0219 .837247 \mathrm{E}-02$ & .013776620 .30018 & $.018 \quad 3.249889$ & & .02 .7000523 \\
\hline \multirow[t]{2}{*}{.0220} & .01418 .62836 & .0191 .786604 & $\operatorname{lcd} 23610$ & .021 .104181 \\
\hline & $.015 \quad 12.52247$ & .02 .8087563 & .0140 & .0220 \\
\hline $\operatorname{lcd} 22011$ & .0168 .204659 & .021 .1738194 & $1.401462 \mathrm{E}-02 \quad 19.83047$ & \\
\hline .0130 & .0175 .183007 & .0220 & .01513 .55326 & $\operatorname{lcd} 24211$ \\
\hline 1.372994E-02 20.39226 & $.018 \quad 3.095654$ & & .0168 .997743 & .0130 \\
\hline .01418 .37184 & .0191 .677341 & $\operatorname{lcd} 23111$ & $.017 \quad 5.779786$ & 1.373772E-02 20.3769 \\
\hline $.015 \quad 12.32227$ & .02 .7343953 & .0130 & .0183 .533692 & .01418 .41461 \\
\hline .0168 .051745 & .021 .1260497 & $1.388355 \mathrm{E}-0220.08912$ & .0191 .989427 & $.015 \quad 12.35562$ \\
\hline .0175 .06885 & .0220 & .01419 .21728 & $.02 \quad .948339$ & .0168 .07719 \\
\hline .0183 .01261 & & $.015 \quad 12.98382$ & .021 .2649046 & .0175 .087825 \\
\hline .0191 .618806 & $\operatorname{lcd} 22611$ & .0168 .558434 & .0220 & $.018 \quad 3.026397$ \\
\hline .02 .6948151 & .0130 & .0175 .448253 & & .0191 .628509 \\
\hline .021 .1008572 & $1.379058 \mathrm{E}-0220.27259$ & .0183 .28955 & $\operatorname{lcd} 23710$ & .02 .7013633 \\
\hline \multirow[t]{2}{*}{.0220} & .01418 .70527 & .0191 .814813 & .0140 & .021 .1050134 \\
\hline & .01512 .58258 & .02 .828052 & $1.404536 \mathrm{E}-02 \quad 19.76983$ & .0220 \\
\hline $\operatorname{lcd} 22111$ & .0168 .250642 & .021 .1863043 & $.015 \quad 13.68734$ & \\
\hline .0130 & .0175 .217393 & .0220 & .0169 .101602 & $\operatorname{lcd} 24311$ \\
\hline 1.373616E-02 20.37997 & $.018 \quad 3.120717$ & & .0175 .858507 & .0130 \\
\hline .01418 .40606 & .0191 .695048 & $\operatorname{lcd} 23211$ & $.018 \quad 3.591945$ & $1.374083 \mathrm{E}-0220.37075$ \\
\hline .01512 .34895 & .02 .7464046 & .0130 & .0192 .031329 & .01418 .43172 \\
\hline .0168 .072101 & .021 .1337264 & $1.390674 \mathrm{E}-02 \quad 20.04337$ & $.02 \quad .9774125$ & $.015 \quad 12.36896$ \\
\hline .0175 .084029 & .0220 & .01419 .34506 & .021 .2840913 & .0168 .087374 \\
\hline .0183 .023638 & & .01513 .08425 & .0220 & .0175 .095421 \\
\hline .0191 .626567 & $\operatorname{lcd} 22711$ & .0168 .635697 & & $.018 \quad 3.031917$ \\
\hline .02 .7000523 & .0130 & .0175 .506389 & $\operatorname{lcd} 23810$ & .0191 .632396 \\
\hline .021 .104181 & .013806120 .24196 & $.018 \quad 3.33222$ & .0140 & .02 .7039881 \\
\hline \multirow[t]{2}{*}{.0220} & .01418 .79069 & $.019 \quad 1.845212$ & $1.407758 \mathrm{E}-02 \quad 19.70624$ & .021 .1066808 \\
\hline & .01512 .6494 & $.02 \quad .8488894$ & .01513 .82813 & .0220 \\
\hline $\operatorname{lcd} 22211$ & .0168 .301795 & .021 .1998264 & .0169 .210825 & \\
\hline .0130 & .0175 .255678 & .0220 & .0175 .941433 & $\operatorname{lcd} 24411$ \\
\hline 1.374394E-02 20.36461 & $.018 \quad 3.148647$ & & .0183 .653425 & .0130 \\
\hline .01418 .44883 & .0191 .714803 & $\operatorname{lcd} 23311$ & .0192 .07565 & .013745520 .36154 \\
\hline $.015 \quad 12.38231$ & $.02 \quad .7598219$ & .0130 & .021 .008248 & .01418 .45738 \\
\hline .0168 .09756 & .021 .1423208 & $1.393144 \mathrm{E}-02 \quad 19.99462$ & .021 .3045171 & $.015 \quad 12.38898$ \\
\hline .0175 .103021 & .0220 & .01419 .48125 & .0220 & .0168 .102655 \\
\hline .0183 .037442 & & $.015 \quad 13.1914$ & & .0175 .106823 \\
\hline .0191 .636287 & lcd 22811 & .0168 .718239 & $\operatorname{lcd} 23910$ & .0183 .040206 \\
\hline .02 .7066163 & .0130 & .0175 .568579 & .0140 & .0191 .638234 \\
\hline $.021 \quad 1083509$ & $1.382316 \mathrm{E}-0220.20829$ & $.018 \quad 3.377933$ & 1.411129E-02 19.63972 & $.02 \quad .7079319$ \\
\hline \multirow[t]{2}{*}{.0220} & .01418 .88462 & .0191 .877836 & $.015 \quad 13.97562$ & .021 .1091872 \\
\hline & $.015 \quad 12.72293$ & $.02 \quad .8713011$ & .0169 .325433 & .0220 \\
\hline $\operatorname{lcd} 22311$ & .0168 .358133 & .021 .2144151 & .0176 .028599 & \\
\hline .0130 & .0175 .297882 & .0220 & $.018 \quad 3.718175$ & $\operatorname{lcd} 24511$ \\
\hline 1.375328E-02 20.34619 & .0183 .179468 & & .0192 .122434 & .0130 \\
\hline .01418 .50014 & .0191 .73663 & $\operatorname{lcd} 23411$ & .021 .04089 & $1.375172 \mathrm{E}-0220.34926$ \\
\hline $.015 \quad 12.42234$ & .02 .7746695 & .0130 & .021 .3262218 & .01418 .49158 \\
\hline
\end{tabular}




\begin{tabular}{|c|c|c|c|c|}
\hline .01512 .41567 & $.02 \quad .7598219$ & .0130 & .02 .9920558 & .01512 .44236 \\
\hline .0168 .123035 & .021 .1423208 & $1.392218 \mathrm{E}-0220.01289$ & .021 .2937814 & .0168 .143422 \\
\hline .0175 .122034 & .0220 & .01419 .4302 & .0220 & .0175 .137255 \\
\hline .0183 .051268 & & $.015 \quad 13.15122$ & & .0183 .062341 \\
\hline .0191 .646029 & $\operatorname{lcd} 25111$ & .0168 .687272 & lcd 26210 & .0191 .653835 \\
\hline .02 .7131997 & .0130 & .0175 .545238 & .0140 & $.02 \quad .7184789$ \\
\hline .021 .1125379 & $1.382161 \mathrm{E}-0220.21135$ & .0183 .360768 & 1.409291E-02 19.67599 & .021 .1158988 \\
\hline \multirow[t]{2}{*}{.0220} & .01418 .87608 & .0191 .865579 & $.015 \quad 13.89517$ & .0220 \\
\hline & $.015 \quad 12.71624$ & $.02 \quad .8628749$ & .0169 .262897 & \\
\hline $\operatorname{lcd} 24611$ & .0168 .353008 & .021 .2089247 & .0175 .981019 & lcd 26811 \\
\hline .0130 & .0175 .294041 & .0220 & .0183 .682815 & .0130 \\
\hline .013759520 .33392 & .0183 .176661 & & .0192 .096872 & $1.376261 \mathrm{E}-0220.32778$ \\
\hline .01418 .53433 & .0191 .734641 & $\operatorname{lcd} 25711$ & $.02 \quad 1.023043$ & .01418 .55142 \\
\hline $.015 \quad 12.44903$ & .02 .7733158 & .0130 & .021 .3143443 & $.015 \quad 12.46238$ \\
\hline .0168 .148523 & .021 .1509828 & $1.394687 \mathrm{E}-02 \quad 19.96417$ & .0220 & .0168 .158721 \\
\hline .0175 .141064 & .0220 & .01419 .56631 & & .0175 .14868 \\
\hline .0183 .065114 & & $.015 \quad 13.25839$ & $\operatorname{lcd} 26310$ & $.018 \quad 3.070657$ \\
\hline .0191 .65579 & $\operatorname{lcd} 25211$ & .0168 .769894 & .0140 & .0191 .659699 \\
\hline .02 .7198014 & .0130 & .0175 .607541 & 1.412659E-02 19.60952 & $.02 \quad .7224472$ \\
\hline .021. 1167412 & $1.383866 \mathrm{E}-0220.1777$ & .0183 .406607 & .01514 .04265 & .021 .1184272 \\
\hline \multirow[t]{2}{*}{.0220} & .01418 .96996 & .0191 .898329 & .0169 .377587 & .0220 \\
\hline & $.015 \quad 12.78979$ & .02 .8854055 & $.017 \quad 6.068318$ & \\
\hline $\operatorname{lcd} 24711$ & .0168 .409406 & .021 .2236197 & $.018 \quad 3.747721$ & lcd 26911 \\
\hline .0130 & .0175 .336326 & .0220 & .0192 .143818 & .0130 \\
\hline 1.376883E-02 20.31551 & $.018 \quad 3.207572$ & & $.02 \quad 1.05584$ & $1.376883 \mathrm{E}-0220.31551$ \\
\hline .01418 .58562 & .0191 .756557 & $\operatorname{lcd} 25811$ & .021 .3361908 & .01418 .58562 \\
\hline .01512 .48909 & .02 .7882463 & .0130 & .0220 & $.015 \quad 12.48909$ \\
\hline .0168 .179133 & .021 .1605883 & $1.397307 \mathrm{E}-02 \quad 19.91247$ & & .0168 .179133 \\
\hline .0175 .163929 & .0220 & .01419 .7108 & $\operatorname{lcd} 26410$ & .0175 .163929 \\
\hline .0183 .081759 & & .01513 .3723 & .0140 & $.018 \quad 3.081759$ \\
\hline .0191 .667532 & lcd 25311 & .0168 .857819 & $1.416176 \mathrm{E}-02 \quad 19.54013$ & .0191 .667532 \\
\hline .02 .72775 & .0130 & .0175 .673934 & .01514 .19681 & $.02 \quad .72775$ \\
\hline .021 .1218083 & $1.385725 \mathrm{E}-0220.14103$ & $.018 \quad 3.455531$ & .0169 .497675 & .021 .1218083 \\
\hline \multirow[t]{2}{*}{.0220} & .01419 .07234 & .0191 .933347 & $.017 \quad 6.159891$ & .0220 \\
\hline & .01512 .87006 & .02 .9095521 & $.018 \quad 3.815942$ & \\
\hline $\operatorname{lcd} 24811$ & .0168 .471017 & .021 .2394193 & .0192 .193276 & $\operatorname{lcd} 27011$ \\
\hline .0130 & .0175 .382565 & .0220 & $.02 \quad 1.090492$ & .0130 \\
\hline $.0137797 \quad 20.29405$ & $.018 \quad 3.24141$ & & .021 .3593629 & .013776620 .30018 \\
\hline .01418 .64545 & .0191 .78058 & $\operatorname{lcd} 25910$ & .0220 & .01418 .62836 \\
\hline $.015 \quad 12.53583$ & .02 .8046405 & .0140 & & $.015 \quad 12.52247$ \\
\hline .0168 .214873 & .021 .171161 & $1.400078 \mathrm{E}-02 \quad 19.85779$ & $\operatorname{lcd} 26511$ & .0168 .204659 \\
\hline .0175 .190642 & .0220 & $.015 \quad 13.49294$ & .0130 & .0175 .183007 \\
\hline $.018 \quad 3.101217$ & & .0168 .951068 & $1.375328 \mathrm{E}-0220.34619$ & .0183 .095654 \\
\hline .0191 .68127 & $\operatorname{lcd} 25411$ & $.017 \quad 5.744451$ & .01418 .50014 & .0191 .677341 \\
\hline .02 .7370585 & .0130 & $.018 \quad 3.507579$ & $.015 \quad 12.42234$ & $.02 \quad .7343953$ \\
\hline .021. 1277508 & $1.387737 \mathrm{E}-0220.10133$ & .0191 .970672 & .0168 .128133 & .021 .1260497 \\
\hline \multirow[t]{2}{*}{.0220} & .01419 .18319 & .02 .9353516 & $.017 \quad 5.125839$ & .0220 \\
\hline & .01512 .95705 & .021 .2563567 & .0183 .054036 & \\
\hline $\operatorname{lcd} 24911$ & .0168 .537852 & .0220 & .0191 .647979 & $\operatorname{lcd} 27111$ \\
\hline .0130 & .0175 .432778 & & .02 .7145186 & .0130 \\
\hline 1.379213E-02 20.26953 & .0183 .278202 & $\operatorname{lcd} 26010$ & .021 .1133773 & $1.378592 \mathrm{E}-0220.28179$ \\
\hline .01418 .71381 & .0191 .806738 & .0140 & .0220 & .01418 .67963 \\
\hline $.015 \quad 12.58927$ & $.02 \quad .822524$ & $1.402999 \mathrm{E}-0219.80014$ & & $.015 \quad 12.56254$ \\
\hline .0168 .255757 & .021 .1827238 & .01513 .6203 & lcd 26611 & .0168 .235309 \\
\hline .0175 .22122 & .0220 & .0169 .049648 & .0130 & .0175 .205924 \\
\hline .0183 .123507 & & .0175 .819112 & $1.375483 \mathrm{E}-0220.34312$ & .0183 .112354 \\
\hline .0191 .697021 & $\operatorname{lcd} 25511$ & .0183 .56278 & .01418 .50868 & .0191 .689138 \\
\hline .02 .7477434 & .0130 & .0192 .010339 & .01512 .42901 & .02 .7423945 \\
\hline .021 .1345831 & $1.389901 \mathrm{E}-0220.05861$ & $.02 \quad .9628389$ & .0168 .133226 & .021 .1311614 \\
\hline \multirow[t]{2}{*}{.0220} & .01419 .30247 & .021 .2744649 & .0175 .129642 & .0220 \\
\hline & .01513 .05076 & .0220 & .0183 .056803 & \\
\hline $\operatorname{lcd} 25011$ & .0168 .609927 & & .0191 .64993 & $\operatorname{lcd} 27211$ \\
\hline .0130 & .0175 .48699 & $\operatorname{lcd} 26110$ & .02 .7158376 & .0130 \\
\hline .013806120 .24196 & $.018 \quad 3.317975$ & .0140 & .021 .114217 & $1.379679 \mathrm{E}-0220.26034$ \\
\hline .01418 .79069 & .0191 .835058 & $.0140607 \quad 19.73954$ & .0220 & .01418 .73943 \\
\hline .01512 .6494 & $.02 \quad .8419241$ & $.015 \quad 13.75438$ & & .01512 .6093 \\
\hline .0168 .301795 & .021 .1953018 & .0169 .153585 & $\operatorname{lcd} 26711$ & .0168 .271092 \\
\hline .0175 .255678 & .0220 & .0175 .897958 & .0130 & .0175 .232695 \\
\hline .0183 .148647 & & $.018 \quad 3.621179$ & 1.375794E-02 20.33699 & .0183 .131876 \\
\hline .0191 .714803 & lcd 25611 & .0192 .052392 & .01418 .52578 & .0191 .702939 \\
\hline
\end{tabular}




\begin{tabular}{|c|c|c|c|c|}
\hline $.02 \quad .7517613$ & .0130 & .0183 .539505 & $.015 \quad 12.50244$ & .02 .7504214 \\
\hline .021 .1371554 & $1.389438 \mathrm{E}-02 \quad 20.06776$ & .0191 .993604 & .0168 .189341 & .021 .1362974 \\
\hline \multirow[t]{2}{*}{.0220} & .01419 .27691 & .02 .9512336 & .0175 .171557 & .0220 \\
\hline & .01513 .03068 & .021 .2668117 & .0183 .087313 & \\
\hline $\operatorname{lcd} 27311$ & .0168 .594473 & .0220 & .0191 .671453 & lcd 29511 \\
\hline .0130 & .0175 .475361 & & .02 .7304056 & .0130 \\
\hline $.0138092 \quad 20.23584$ & .0183 .309439 & $\operatorname{lcd} 28410$ & .021 .1235027 & $1.380455 \mathrm{E}-02 \quad 20.24502$ \\
\hline .01418 .80777 & .0191 .828976 & .0140 & .0220 & $.014 \quad 18.78214$ \\
\hline $.015 \quad 12.66276$ & .02 .8377544 & $1.404689 \mathrm{E}-02 \quad 19.7668$ & & $.015 \quad 12.64271$ \\
\hline .0168 .312033 & .021. 1925954 & $.015 \quad 13.69404$ & $\operatorname{lcd} 29011$ & .0168 .296675 \\
\hline .0175 .263344 & .0220 & .0169 .106795 & .0130 & $.017 \quad 5.251844$ \\
\hline .0183 .154243 & & .0175 .862447 & $1.377349 \mathrm{E}-02 \quad 20.30631$ & .0183 .145849 \\
\hline .0191 .718764 & $\operatorname{lcd} 27911$ & .0183 .594864 & .01418 .61127 & .0191 .712823 \\
\hline .02 .7625146 & .0130 & .0192 .033431 & $.015 \quad 12.50912$ & .02 .7584761 \\
\hline .021 .1440479 & .01391620 .02508 & .02 .9788729 & .0168 .194447 & .021 .141458 \\
\hline \multirow[t]{2}{*}{.0220} & $.014 \quad 19.39614$ & .021 .2850569 & .0175 .175373 & .0220 \\
\hline & $.015 \quad 13.12442$ & .0220 & .0183 .090093 & \\
\hline $\operatorname{lcd} 27411$ & .0168 .666631 & & .0191 .673415 & $\operatorname{lcd} 29611$ \\
\hline .0130 & .0175 .529686 & $\operatorname{lcd} 28510$ & $.02 \quad .7317348$ & .0130 \\
\hline $1.382316 \mathrm{E}-02 \quad 20.20829$ & .0183 .349336 & .0140 & .021. 124351 & $1.381541 \mathrm{E}-02 \quad 20.22359$ \\
\hline .01418 .88462 & .0191 .857421 & $1.407758 \mathrm{E}-02 \quad 19.70624$ & .0220 & $.014 \quad 18.84192$ \\
\hline $.015 \quad 12.72293$ & .02 .8572704 & $.015 \quad 13.82813$ & & $.015 \quad 12.6895$ \\
\hline .0168 .358133 & .021.2052766 & .0169 .210825 & lcd 29111 & .0168 .332513 \\
\hline .0175 .297882 & .0220 & .0175 .941433 & .0130 & $.017 \quad 5.278685$ \\
\hline .0183 .179468 & & .0183 .653425 & $.0137766 \quad 20.30018$ & .0183 .165444 \\
\hline .0191 .73663 & lcd 28011 & .0192 .07565 & .01418 .62836 & .0191 .726695 \\
\hline .02 .7746695 & .0130 & $.02 \quad 1.008248$ & $.015 \quad 12.52247$ & .02 .7679085 \\
\hline .021. 1518528 & $1.393916 \mathrm{E}-02 \quad 19.97939$ & $.021 \quad .3045171$ & .0168 .204659 & .021. 1475096 \\
\hline \multirow[t]{2}{*}{.0220} & .01419 .52379 & .0220 & .0175 .183007 & .0220 \\
\hline & $.015 \quad 13.2249$ & & .0183 .095654 & \\
\hline $\operatorname{lcd} 27511$ & .0168 .744061 & lcd 28610 & .0191 .677341 & lcd 29711 \\
\hline .0130 & .0175 .588052 & .0140 & .02 .7343953 & .0130 \\
\hline $1.383866 \mathrm{E}-02 \quad 20.1777$ & .0183 .392261 & $1.410976 \mathrm{E}-02 \quad 19.64274$ & .021.1260497 & $1.382781 \mathrm{E}-02 \quad 20.19911$ \\
\hline ( & .0191 .888073 & $.015 \quad 13.96892$ & .0220 & .01418 .91022 \\
\hline $.015 \quad 12.78979$ & .02 .8783444 & .0169 .320225 & & $.015 \quad 12.74298$ \\
\hline .0168 .409406 & .021. 2190094 & $.017 \quad 6.024635$ & lcd 29211 & .0168 .373506 \\
\hline .0175 .336326 & .0220 & $.018 \quad 3.715227$ & .0130 & $.017 \quad 5.309404$ \\
\hline .0183 .207572 & & .0192 .120302 & $1.378126 \mathrm{E}-02 \quad 20.29098$ & .0183 .187889 \\
\hline .0191 .756557 & $\operatorname{lcd} 28111$ & .021 .0394 & .01418 .654 & .0191 .742598 \\
\hline .02 .7882463 & .0130 & .021 .3252292 & $.015 \quad 12.54251$ & .02 .7787338 \\
\hline .021.1605883 & $1.396383 \mathrm{E}-02 \quad 19.93071$ & .0220 & .0168 .219981 & .021 .1544659 \\
\hline \multirow[t]{2}{*}{.0220} & .01419 .65983 & & .0175 .194462 & .0220 \\
\hline & $.015 \quad 13.3321$ & $\operatorname{lcd} 28710$ & .0183 .104 & \\
\hline $\operatorname{lcd} 27611$ & .0168 .826775 & .0140 & .0191 .683236 & lcd 29811 \\
\hline .0130 & .0175 .650481 & $1.414342 \mathrm{E}-02 \quad 19.57632$ & .02 .7383915 & .0130 \\
\hline .013855720 .14408 & .0183 .43824 & $.015 \quad 14.11638$ & .021 .1286025 & $1.384176 \mathrm{E}-02 \quad 20.17159$ \\
\hline .01419 .06381 & .0191 .920963 & .0169 .434998 & .0220 & .01418 .98703 \\
\hline $.015 \quad 12.86337$ & .02 .9010063 & .0176 .112075 & & .01512 .80316 \\
\hline .0168 .465878 & $.021 \quad 2338217$ & .0183 .780302 & lcd 29311 & .0168 .41967 \\
\hline .0175 .378706 & .0220 & .0192 .167424 & .0130 & .0175 .344026 \\
\hline .0183 .238585 & & $.02 \quad 1.072367$ & $1.378747 \mathrm{E}-02 \quad 20.27872$ & $.018 \quad 3.213204$ \\
\hline .0191 .778573 & $\operatorname{lcd} 28211$ & .021 .3472308 & $.014 \quad 18.68818$ & .0191 .760553 \\
\hline .02 .8032699 & .0130 & .0220 & $.015 \quad 12.56922$ & .02 .7909716 \\
\hline .021 .170276 & $1.399001 \mathrm{E}-02 \quad 19.87904$ & & .0168 .240417 & .021. 1623441 \\
\hline \multirow[t]{2}{*}{.0220} & .01419 .80423 & lcd 28810 & .0175 .209745 & .0220 \\
\hline & $.015 \quad 13.44602$ & .0140 & .0183 .11514 & \\
\hline $\operatorname{lcd} 27711$ & .0168 .914789 & $1.417856 \mathrm{E}-02 \quad 19.50698$ & .0191 .691107 & lcd 29911 \\
\hline .0130 & .0175 .717003 & $.015 \quad 14.27052$ & $.02 \quad .74373$ & .0130 \\
\hline $1.387427 \mathrm{E}-02 \quad 20.10743$ & .0183 .48731 & .0169 .555163 & .021 .1320154 & $1.385725 \mathrm{E}-02 \quad 20.14103$ \\
\hline .01419 .16613 & .0191 .956128 & .0176 .203788 & .0220 & .01419 .07234 \\
\hline .01512 .94366 & .02 .9252908 & .0183 .848694 & & .01512 .87006 \\
\hline .0168 .527562 & .021. 2497449 & .0192 .217063 & lcd 29411 & .0168 .471017 \\
\hline .0175 .425044 & .0220 & .021 .107194 & .0130 & .0175 .382565 \\
\hline .0183 .272532 & & $.021 \quad .3705634$ & $1.379523 \mathrm{E}-02 \quad 20.2634$ & .0183 .24141 \\
\hline .0191 .802704 & $\operatorname{lcd} 28310$ & .0220 & $.014 \quad 18.73089$ & .0191 .78058 \\
\hline .02 .8197639 & .0140 & & $.015 \quad 12.60262$ & .02 .8046405 \\
\hline .021. 1809372 & .014017719 .8244 & $\operatorname{lcd} 28911$ & .0168 .265981 & .021 .171161 \\
\hline \multirow[t]{2}{*}{.0220} & .01513 .56667 & .0130 & .0175 .22887 & .0220 \\
\hline & .0169 .008122 & $1.377194 \mathrm{E}-02 \quad 20.30938$ & .0183 .129086 & \\
\hline $\operatorname{lcd} 27811$ & .0175 .787648 & .01418 .60272 & .0191 .700966 & lcd 30011 \\
\hline
\end{tabular}




\begin{tabular}{|c|c|c|c|c|}
\hline .0130 & .0175 .697416 & $.015 \quad 14.19681$ & .021. 1397353 & $1.386189 \mathrm{E}-02 \quad 20.13186$ \\
\hline $1.387427 \mathrm{E}-02 \quad 20.10743$ & .0183 .472853 & .0169 .497675 & .0220 & .01419 .09793 \\
\hline .01419 .16613 & .0191 .945761 & .0176 .159891 & & $.015 \quad 12.89013$ \\
\hline .01512 .94366 & .02 .9181259 & .0183 .815942 & $\operatorname{lcd} 31711$ & .0168 .486432 \\
\hline .0168 .527562 & .021. 2450416 & .0192 .193276 & - 0130 & .0175 .394141 \\
\hline $.017 \quad 5.425044$ & .0220 & .021 .090492 & $1.380765 \mathrm{E}-02 \quad 20.2389$ & .0183 .249889 \\
\hline .0183 .272532 & & .021 .3593629 & . 01418.79923 & .0191 .786604 \\
\hline .0191 .802704 & lcd 30610 & .0220 & $.015 \quad 12.65608$ & .02 .8087563 \\
\hline .02 .8197639 & .0140 & & .0168 .306913 & .021 .1738194 \\
\hline .021. 1809372 & $1.400847 \mathrm{E}-02 \quad 19.84261$ & $\operatorname{lcd} 31210$ & $.017 \quad 5.259511$ & .0220 \\
\hline \multirow[t]{2}{*}{.0220} & .01513 .52645 & .0140 & $.018 \quad 3.151444$ & \\
\hline & .0168 .976992 & $1.419687 \mathrm{E}-02 \quad 19.47084$ & .019 1.716783 & $\operatorname{lcd} 32311$ \\
\hline $\operatorname{lcd} 30111$ & .0175 .764073 & $.015 \quad 14.35092$ & .02 .7611678 & .0130 \\
\hline .0130 & .0183 .522077 & .0169 .617929 & .021 .143184 & $1.387737 \mathrm{E}-02 \quad 20.10133$ \\
\hline $1.389283 \mathrm{E}-02 \quad 20.07081$ & .0191 .981083 & $.017 \quad 6.251759$ & .0220 & $.014 \quad 19.18319$ \\
\hline .01419 .2684 & .02 .9425589 & .0183 .884522 & & $.015 \quad 12.95705$ \\
\hline $.015 \quad 13.02399$ & .021. 2610986 & .0192 .243113 & $\operatorname{lcd} 31811$ & .0168 .537852 \\
\hline .0168 .589324 & .0220 & .021 .125511 & .0130 & .0175 .432778 \\
\hline $.017 \quad 5.471487$ & & .021 .3828713 & $1.381541 \mathrm{E}-02 \quad 20.22359$ & $.018 \quad 3.278202$ \\
\hline .0183 .306596 & $\operatorname{lcd} 30710$ & .0220 & .01418 .84192 & .0191 .806738 \\
\hline .0191 .826951 & .0140 & & $.015 \quad 12.6895$ & .02 .822524 \\
\hline .02 .8363666 & 1.403614E-02 19.78802 & $\operatorname{lcd} 31311$ & .0168 .332513 & .021 .1827238 \\
\hline .021. 191695 & .01513 .64711 & .0130 & $.017 \quad 5.278685$ & .0220 \\
\hline \multirow[t]{2}{*}{.0220} & .0169 .070423 & $1.379213 \mathrm{E}-02 \quad 20.26953$ & $.018 \quad 3.165444$ & \\
\hline & .0175 .834861 & .01418 .71381 & .019 1.726695 & $\operatorname{lcd} 32411$ \\
\hline $\operatorname{lcd} 30211$ & $.018 \quad 3.574436$ & $.015 \quad 12.58927$ & .02 .7679085 & .0130 \\
\hline .0130 & .0192 .018726 & .0168 .255757 & .021. 1475096 & $1.389438 \mathrm{E}-02 \quad 20.06776$ \\
\hline $1.391292 \mathrm{E}-02 \quad 20.03117$ & .02.9686593 & .0175 .22122 & .0220 & .01419 .27691 \\
\hline .01419 .37912 & .021 .2783073 & .0183 .123507 & & $.015 \quad 13.03068$ \\
\hline .01513 .11103 & .0220 & .0191 .697021 & $\operatorname{lcd} 31911$ & .0168 .594473 \\
\hline .0168 .656318 & & .02 .7477434 & .0130 & .0175 .475361 \\
\hline .0175 .521918 & lcd 30810 & .021 .1345831 & $1.382471 \mathrm{E}-02 \quad 20.20523$ & .0183 .309439 \\
\hline .0183 .343628 & .0140 & .0220 & .01418 .89316 & .0191 .828976 \\
\hline .0191 .853348 & $1.406531 \mathrm{E}-02 \quad 19.73046$ & & $.015 \quad 12.72961$ & .02 .8377544 \\
\hline .02 .8544738 & .01513 .7745 & lcd 31411 & .0168 .363259 & .021 .1925954 \\
\hline .021 .2034572 & .0169 .169195 & .0130 & .0175 .301723 & .0220 \\
\hline \multirow[t]{2}{*}{.0220} & .0175 .90981 & $1.379368 \mathrm{E}-02 \quad 20.26646$ & $.018 \quad 3.182275$ & \\
\hline & .0183 .629966 & .01418 .72236 & .019 1.738619 & $\operatorname{lcd} 32511$ \\
\hline $\operatorname{lcd} 30311$ & .0192 .058727 & .01512 .59595 & .02 .7760242 & .0130 \\
\hline .0130 & .02 .9964641 & .0168 .26087 & .021.1527236 & $1.391292 \mathrm{E}-02 \quad 20.03117$ \\
\hline $1.393453 \mathrm{E}-02 \quad 19.98853$ & .021.296702 & .0175 .225045 & .0220 & .01419 .37912 \\
\hline .01419 .49827 & .0220 & .0183 .126297 & & .01513 .11103 \\
\hline $.015 \quad 13.2048$ & & .0191 .698993 & $\operatorname{lcd} 32011$ & .0168 .656318 \\
\hline .0168 .728565 & lcd 30910 & .02 .7490823 & .0130 & .0175 .521918 \\
\hline .0175 .576365 & .0140 & .021 .1354401 & $1.383556 \mathrm{E}-02 \quad 20.18382$ & .0183 .343628 \\
\hline .0183 .383661 & $1.409597 \mathrm{E}-02 \quad 19.66995$ & .0220 & .01418 .9529 & .0191 .853348 \\
\hline .0191 .881928 & .01513 .90858 & & $.015 \quad 12.77641$ & .02 .8544738 \\
\hline .02 .8741159 & .0169 .273315 & $\operatorname{lcd} 31511$ & .0168 .399149 & .021. 2034572 \\
\hline .021 .2162506 & .0175 .988942 & .0130 & .0175 .328632 & .0220 \\
\hline \multirow[t]{2}{*}{.0220} & .0183 .6887 & $1.379679 \mathrm{E}-02 \quad 20.26034$ & $.018 \quad 3.201945$ & \\
\hline & .0192 .101124 & .01418 .73943 & .019 1.752566 & $\operatorname{lcd} 32611$ \\
\hline lcd 30411 & $.02 \quad 1.02601$ & $.015 \quad 12.6093$ & .02 .7855253 & .0130 \\
\hline .0130 & .021 .3163172 & .0168 .271092 & .021 .1588362 & $1.393299 \mathrm{E}-02 \quad 19.99157$ \\
\hline $1.395766 \mathrm{E}-02 \quad 19.94288$ & .0220 & .0175 .232695 & .0220 & .01419 .48977 \\
\hline .01419 .62582 & & .0183 .131876 & & .01513 .1981 \\
\hline $.015 \quad 13.30529$ & $\operatorname{lcd} 31010$ & .0191 .702939 & $\operatorname{lcd} 32111$ & .0168 .723405 \\
\hline .0168 .806078 & .0140 & .02 .7517613 & .0130 & .0175 .572474 \\
\hline .0175 .634853 & 1.412812E-02 19.6065 & .021 .1371554 & $1.384796 \mathrm{E}-02 \quad 20.15936$ & .0183 .380799 \\
\hline .0183 .426723 & $.015 \quad 14.04935$ & .0220 & .01419 .02116 & .0191 .879883 \\
\hline .0191 .912719 & .0169 .382804 & & $.015 \quad 12.82992$ & .02 .8727091 \\
\hline .02 .8953215 & .0176 .072292 & $\operatorname{lcd} 31611$ & .0168 .440201 & .021 .2153331 \\
\hline .021 .2301017 & .0183 .750679 & .0130 & .0175 .359431 & .0220 \\
\hline \multirow[t]{2}{*}{.0220} & .0192 .14596 & 1.380144E-02 20.25115 & .0183 .224476 & \\
\hline & $.02 \quad 1.057339$ & .01418 .76506 & .0191 .768554 & $\operatorname{lcd} 32711$ \\
\hline lcd 30511 & .021 .3371912 & $.015 \quad 12.62935$ & .02 .7964298 & .0130 \\
\hline .0130 & .0220 & .0168 .286442 & .021 .1658626 & $1.395458 \mathrm{E}-02 \quad 19.94896$ \\
\hline $1.398231 \mathrm{E}-02 \quad 19.89423$ & & .0175 .244184 & .0220 & .01419 .60883 \\
\hline .01419 .76177 & $\operatorname{lcd} 31110$ & .0183 .140258 & & $.015 \quad 13.29189$ \\
\hline .01513 .41251 & .0140 & .0191 .708868 & lcd 32211 & .0168 .79574 \\
\hline .0168 .888885 & $1.416176 \mathrm{E}-02 \quad 19.54013$ & .02 .7557885 & .0130 & .0175 .627048 \\
\hline
\end{tabular}




\begin{tabular}{|c|c|c|c|c|}
\hline .0183 .420974 & $.015 \quad 13.99573$ & & $.015 \quad 12.87006$ & .02 .8741159 \\
\hline .0191 .908605 & .0169 .341079 & lcd 33911 & .0168 .471017 & .021 .2162506 \\
\hline .02 .8924854 & .0176 .040511 & .0130 & .0175 .382565 & .0220 \\
\hline .021 .2282468 & .0183 .727033 & $1.381851 \mathrm{E}-02 \quad 20.21747$ & .0183 .24141 & \\
\hline \multirow[t]{2}{*}{.0220} & .0192 .128843 & .01418 .85901 & .0191 .78058 & $\operatorname{lcd} 35011$ \\
\hline & .021 .045368 & .01512 .70287 & .02 .8046405 & .0130 \\
\hline lcd 32811 & .021 .3292063 & .0168 .342762 & .021 .171161 & $1.395458 \mathrm{E}-02 \quad 19.94896$ \\
\hline .0130 & .0220 & $.017 \quad 5.286363$ & .0220 & .01419 .60883 \\
\hline $1.397769 \mathrm{E}-02 \quad 19.90335$ & & .0183 .171052 & & $.015 \quad 13.29189$ \\
\hline .01419 .73629 & lcd 33410 & .0191 .730667 & $\operatorname{lcd} 34511$ & .0168 .79574 \\
\hline .01513 .39241 & .0140 & .02 .7706112 & .0130 & .0175 .627048 \\
\hline .0168 .873352 & $.014148 \quad 19.56727$ & .021 .1492452 & $1.386963 \mathrm{E}-02 \quad 20.11659$ & .0183 .420974 \\
\hline .0175 .685673 & $.015 \quad 14.13649$ & .0220 & .01419 .14056 & .0191 .908605 \\
\hline .0183 .46419 & .0169 .450661 & & .01512 .92359 & $.02 \quad .8924854$ \\
\hline .0191 .939551 & .0176 .12402 & $\operatorname{lcd} 34011$ & .0168 .512135 & .021 .2282468 \\
\hline .02 .9138359 & .0183 .789202 & .0130 & $.017 \quad 5.41345$ & .0220 \\
\hline .021. 2422276 & .0192 .173877 & $1.382316 \mathrm{E}-02 \quad 20.20829$ & .0183 .264035 & \\
\hline \multirow[t]{2}{*}{.0220} & $.02 \quad 1.076888$ & .01418 .88462 & .0191 .79666 & $\operatorname{lcd} 35111$ \\
\hline & .021 .3502548 & .01512 .72293 & .02 .8156303 & .0130 \\
\hline lcd 32910 & .0220 & .0168 .358133 & .021 .1782629 & $1.397615 \mathrm{E}-02 \quad 19.90639$ \\
\hline .0140 & & $.017 \quad 5.297882$ & .0220 & $.014 \quad 19.7278$ \\
\hline $1.400232 \mathrm{E}-0219.85475$ & lcd 33510 & .0183 .179468 & & $.015 \quad 13.38571$ \\
\hline $.015 \quad 13.49964$ & .0140 & .0191 .73663 & $\operatorname{lcd} 34611$ & .0168 .868177 \\
\hline .0168 .956252 & $1.418161 \mathrm{E}-02 \quad 19.50095$ & .02 .7746695 & .0130 & .0175 .681762 \\
\hline $.017 \quad 5.748374$ & $.015 \quad 14.28392$ & .021 .1518528 & $1.388355 \mathrm{E}-02 \quad 20.08912$ & .0183 .461305 \\
\hline $.018 \quad 3.510477$ & .0169 .565622 & .0220 & $.014 \quad 19.21728$ & .0191 .937484 \\
\hline .0191 .972753 & .0176 .211779 & & $.015 \quad 12.98382$ & .02 .9124082 \\
\hline .02 .9367916 & .0183 .854659 & $\operatorname{lcd} 34111$ & .0168 .558434 & .021. 2412915 \\
\hline .021 .2573038 & .0192 .221398 & .0130 & .0175 .448253 & .0220 \\
\hline \multirow[t]{2}{*}{.0220} & $.02 \quad 1.11024$ & $1.382936 \mathrm{E}-02 \quad 20.19605$ & .0183 .28955 & \\
\hline & .021 .3726087 & .01418 .91876 & .0191 .814813 & $\operatorname{lcd} 35211$ \\
\hline $\operatorname{lcd} 33010$ & .0220 & .01512 .74967 & .02 .828052 & .0130 \\
\hline .0140 & & .0168 .378634 & .021 .1863043 & $1.399924 \mathrm{E}-02 \quad 19.86082$ \\
\hline $1.402846 \mathrm{E}-0219.80317$ & $\operatorname{lcd} 33610$ & .0175 .31325 & .0220 & .01419 .85515 \\
\hline .01513 .6136 & .0140 & .0183 .190699 & & .01513 .48623 \\
\hline .0169 .044459 & $1.421669 \mathrm{E}-02 \quad 19.43172$ & .0191 .74459 & $\operatorname{lcd} 34711$ & .0168 .945881 \\
\hline $.017 \quad 5.815179$ & $.015 \quad 14.43799$ & .02 .780091 & .0130 & .0175 .740525 \\
\hline .0183 .55987 & .0169 .685966 & .021 .1553389 & $1.389901 \mathrm{E}-02 \quad 20.05861$ & .0183 .504679 \\
\hline .0192 .008246 & .0176 .303811 & .0220 & $.014 \quad 19.30247$ & .0191 .968591 \\
\hline .02 .9613865 & .0183 .92344 & & .01513 .05076 & .02 .9339115 \\
\hline .021 .2735065 & .0192 .271446 & $\operatorname{lcd} 34211$ & .0168 .609927 & .021 .2554098 \\
\hline \multirow[t]{2}{*}{.0220} & $.02 \quad 1.145464$ & .0130 & .0175 .48699 & .0220 \\
\hline & .021 .3963062 & $1.383711 \mathrm{E}-0220.18076$ & .0183 .317975 & \\
\hline $\operatorname{lcd} 33110$ & .0220 & .01418 .96143 & .0191 .835058 & $\operatorname{lcd} 35310$ \\
\hline .0140 & & .01512 .7831 & .02 .8419241 & .0140 \\
\hline .014056119 .74862 & $\operatorname{lcd} 33711$ & .0168 .404279 & .021. 1953018 & $1.402385 \mathrm{E}-02 \quad 19.81227$ \\
\hline $.015 \quad 13.73427$ & .0130 & .0175 .332479 & .0220 & $.015 \quad 13.59349$ \\
\hline .0169 .13799 & $1.381386 \mathrm{E}-02 \quad 20.22665$ & .0183 .204759 & & .0169 .028882 \\
\hline .0175 .886119 & .01418 .83339 & .0191 .754561 & $\operatorname{lcd} 34811$ & .0175 .803375 \\
\hline .0183 .612403 & .01512 .68281 & .02 .7868857 & .0130 & .0183 .551137 \\
\hline .0192 .046067 & .0168 .327393 & .021 .1597122 & .01391620 .02508 & .0192 .001966 \\
\hline .02 .9876563 & .0175 .274849 & .0220 & $.014 \quad 19.39614$ & .02 .9570307 \\
\hline . 2908683 & .0183 .162643 & & $.015 \quad 13.12442$ & .021. 2706332 \\
\hline \multirow[t]{2}{*}{.0220} & .0191 .724712 & lcd 34311 & .0168 .666631 & .0220 \\
\hline & .02 .7665591 & .0130 & .0175 .529686 & \\
\hline $\operatorname{lcd} 33210$ & .021. 1466432 & $1.384641 \mathrm{E}-0220.16242$ & .0183 .349336 & $\operatorname{lcd} 35410$ \\
\hline .0140 & .0220 & .01419 .01262 & .0191 .857421 & .0140 \\
\hline $1.408524 \mathrm{E}-02 \quad 19.69112$ & & $.015 \quad 12.82323$ & .02 .8572704 & $1.404996 \mathrm{E}-02 \quad 19.76074$ \\
\hline .01513 .86165 & lcd 33811 & .0168 .435064 & .021. 2052766 & .01513 .70746 \\
\hline .0169 .236857 & .0130 & .0175 .355577 & .0220 & .0169 .117195 \\
\hline .0175 .961219 & $1.381541 \mathrm{E}-02 \quad 20.22359$ & .0183 .221655 & & .0175 .870337 \\
\hline .0183 .668112 & .01418 .84192 & .0191 .766551 & $\operatorname{lcd} 34911$ & .0183 .600709 \\
\hline .0192 .086252 & $.015 \quad 12.6895$ & .02 .7950634 & .0130 & .0192 .037641 \\
\hline $.02 \quad 1.015637$ & .0168 .332513 & .021 .1649815 & $1.393453 \mathrm{E}-02 \quad 19.98853$ & .02 .9817988 \\
\hline .021 .3094226 & $.017 \quad 5.278685$ & .0220 & $.014 \quad 19.49827$ & .021 .286992 \\
\hline \multirow[t]{2}{*}{.0220} & .0183 .165444 & & .01513 .2048 & .0220 \\
\hline & .0191 .726695 & $\operatorname{lcd} 34411$ & .0168 .728565 & \\
\hline $\operatorname{lcd} 33310$ & .02 .7679085 & .0130 & .0175 .576365 & lcd 35510 \\
\hline .0140 & .021. 1475096 & $1.385725 \mathrm{E}-02 \quad 20.14103$ & .0183 .383661 & .0140 \\
\hline $1.411588 \mathrm{E}-02 \quad 19.63066$ & .0220 & .01419 .07234 & .019 1.881928 & $1.407758 \mathrm{E}-02 \quad 19.70624$ \\
\hline
\end{tabular}




\begin{tabular}{|c|c|c|c|c|}
\hline .01513 .82813 & .0130 & .0175 .390282 & .0220 & .0169 .106795 \\
\hline .0169 .210825 & $1.383711 \mathrm{E}-0220.18076$ & .0183 .247062 & & .0175 .862447 \\
\hline .0175 .941433 & .01418 .96143 & .0191 .784596 & $\operatorname{lcd} 37211$ & .0183 .594864 \\
\hline $.018 \quad 3.653425$ & $.015 \quad 12.7831$ & $.02 \quad .8073837$ & .0130 & .0192 .033431 \\
\hline .0192 .07565 & .0168 .404279 & $.021 \quad .1729327$ & $1.393916 \mathrm{E}-02 \quad 19.97939$ & $.02 \quad .9788729$ \\
\hline .021 .008248 & .0175 .332479 & .0220 & .01419 .52379 & .021 .2850569 \\
\hline .021 .3045171 & .0183 .204759 & & .01513 .2249 & .0220 \\
\hline \multirow[t]{2}{*}{.0220} & .0191 .754561 & $\operatorname{lcd} 36711$ & .0168 .744061 & \\
\hline & .02 .7868857 & .0130 & .0175 .588052 & $\operatorname{lcd} 37810$ \\
\hline $\operatorname{lcd} 35610$ & .021 .1597122 & $1.386963 \mathrm{E}-0220.11659$ & $.018 \quad 3.392261$ & .0140 \\
\hline .0140 & .0220 & .01419 .14056 & .0191 .888073 & $1.407298 \mathrm{E}-0219.71532$ \\
\hline 1.410669E-02 19.64879 & & .01512 .92359 & $.02 \quad .8783444$ & $.015 \quad 13.80802$ \\
\hline $.015 \quad 13.95551$ & $\operatorname{lcd} 36211$ & .0168 .512135 & .021 .2190094 & .0169 .195211 \\
\hline .0169 .309797 & .0130 & .0175 .41345 & .0220 & .0175 .92957 \\
\hline $.017 \quad 6.016698$ & $1.383866 \mathrm{E}-02 \quad 20.1777$ & $.018 \quad 3.264035$ & & .0183 .644623 \\
\hline $.018 \quad 3.709327$ & .01418 .96996 & .0191 .79666 & lcd 37311 & .0192 .069299 \\
\hline .0192 .116035 & $.015 \quad 12.78979$ & .02 .8156303 & .0130 & $.02 \quad 1.003824$ \\
\hline .021 .036419 & .0168 .409406 & $.021 \quad .1782629$ & $1.395766 \mathrm{E}-02 \quad 19.94288$ & $.021 \quad .3015817$ \\
\hline .021 .3232441 & .0175 .336326 & .0220 & .01419 .62582 & .0220 \\
\hline \multirow[t]{2}{*}{.0220} & $.018 \quad 3.207572$ & & $.015 \quad 13.30529$ & \\
\hline & .0191 .756557 & lcd 36811 & .0168 .806078 & $\operatorname{lcd} 37910$ \\
\hline $\operatorname{lcd} 35710$ & .02 .7882463 & .0130 & .0175 .634853 & .0140 \\
\hline .0140 & .021 .1605883 & $1.388046 \mathrm{E}-0220.09522$ & .0183 .426723 & $1.410057 \mathrm{E}-0219.66088$ \\
\hline $.0141373 \quad 19.58839$ & .0220 & .01419 .20022 & .0191 .912719 & $.015 \quad 13.92869$ \\
\hline $.015 \quad 14.08957$ & & $.015 \quad 12.97043$ & $.02 \quad .8953215$ & .0169 .288949 \\
\hline .0169 .414116 & lcd 36311 & .0168 .548137 & .021 .2301017 & .0176 .000835 \\
\hline .0176 .096155 & .0130 & .0175 .44051 & .0220 & .0183 .697536 \\
\hline $.018 \quad 3.768444$ & $1.384176 \mathrm{E}-0220.17159$ & $.018 \quad 3.283872$ & & .0192 .10751 \\
\hline .0192 .158829 & .01418 .98703 & .0191 .810772 & $\operatorname{lcd} 37411$ & $.02 \quad 1.030467$ \\
\hline $.02 \quad 1.066347$ & .01512 .80316 & $.02 \quad .8252852$ & .0130 & .021 .3192822 \\
\hline .021 .3432072 & .0168 .41967 & .021 .1845119 & 1.397769E-02 19.90335 & .0220 \\
\hline \multirow[t]{2}{*}{.0220} & .0175 .344026 & .0220 & .01419 .73629 & \\
\hline & $.018 \quad 3.213204$ & & $.015 \quad 13.39241$ & $\operatorname{lcd} 38010$ \\
\hline $\operatorname{lcd} 35810$ & .0191 .760553 & $\operatorname{lcd} 36911$ & .0168 .873352 & .0140 \\
\hline .0140 & .02 .7909716 & .0130 & .0175 .685673 & $1.412965 \mathrm{E}-0219.60348$ \\
\hline $.0141694 \quad 19.52505$ & .021 .1623441 & $1.389283 \mathrm{E}-02 \quad 20.07081$ & $.018 \quad 3.46419$ & $.015 \quad 14.05606$ \\
\hline $.015 \quad 14.23031$ & .0220 & .01419 .2684 & .0191 .939551 & .0169 .388024 \\
\hline .0169 .523802 & & $.015 \quad 13.02399$ & $.02 \quad .9138359$ & $.017 \quad 6.07627$ \\
\hline .0176 .179836 & $\operatorname{lcd} 36411$ & $.016 \quad 8.589324$ & .021 .2422276 & $.018 \quad 3.753639$ \\
\hline $.018 \quad 3.830819$ & .0130 & $.017 \quad 5.471487$ & .0220 & .0192 .148104 \\
\hline .0192 .204078 & $1.384641 \mathrm{E}-0220.16242$ & .0183 .306596 & & $.02 \quad 1.058839$ \\
\hline $.02 \quad 1.098074$ & .01419 .01262 & .0191 .826951 & $\operatorname{lcd} 37511$ & .021 .3381926 \\
\hline .021 .3644446 & $.015 \quad 12.82323$ & .02 .8363666 & .0130 & .0220 \\
\hline \multirow[t]{2}{*}{.0220} & .0168 .435064 & .021 .191695 & 1.399924E-02 19.86082 & \\
\hline & $.017 \quad 5.355577$ & .0220 & .01419 .85515 & $\operatorname{lcd} 38110$ \\
\hline $\operatorname{lcd} 35910$ & .0183 .221655 & & $.015 \quad 13.48623$ & .0140 \\
\hline .0140 & .0191 .766551 & $\operatorname{lcd} 37011$ & .0168 .945881 & $1.416023 \mathrm{E}-0219.54314$ \\
\hline $1.420297 \mathrm{E}-02 \quad 19.4588$ & .02 .7950634 & .0130 & .0175 .740525 & $.015 \quad 14.19011$ \\
\hline $.015 \quad 14.37771$ & .021 .1649815 & $1.390674 \mathrm{E}-02 \quad 20.04337$ & $.018 \quad 3.504679$ & .0169 .492451 \\
\hline .0169 .638856 & .0220 & .01419 .34506 & .0191 .968591 & .0176 .155903 \\
\hline $.017 \quad 6.267764$ & & $.015 \quad 13.08425$ & $.02 \quad .9339115$ & $.018 \quad 3.812968$ \\
\hline .0183 .896483 & $\operatorname{lcd} 36511$ & .0168 .635697 & .021 .2554098 & .0192 .191118 \\
\hline .0192 .251817 & .0130 & .0175 .506389 & .0220 & $.02 \quad 1.088978$ \\
\hline $.02 \quad 1.131637$ & .013852620 .15019 & .0183 .33222 & & .021 .3583484 \\
\hline .021 .3869932 & .01419 .04675 & .0191 .845212 & $\operatorname{lcd} 37610$ & .0220 \\
\hline \multirow[t]{2}{*}{.0220} & .01512 .84999 & $.02 \quad .8488894$ & .0140 & \\
\hline & .0168 .455606 & .021 .1998264 & 1.402231E-02 19.8153 & lcd 38210 \\
\hline $\operatorname{lcd} 36010$ & .0175 .370995 & .0220 & $.015 \quad 13.58679$ & .0140 \\
\hline .0140 & .0183 .23294 & & .0169 .023694 & 1.419229E-02 19.47987 \\
\hline 1.423802E-02 19.38964 & .0191 .774563 & $\operatorname{lcd} 37111$ & .0175 .799444 & $.015 \quad 14.33082$ \\
\hline $.015 \quad 14.53174$ & $.02 \quad .8005317$ & .0130 & .0183 .548229 & .0169 .602231 \\
\hline .0169 .759289 & .021 .1685087 & $1.392218 \mathrm{E}-0220.01289$ & .0191 .999875 & $.017 \quad 6.239757$ \\
\hline .0176 .359966 & .0220 & .01419 .4302 & $.02 \quad .9555808$ & $.018 \quad 3.875554$ \\
\hline .0183 .965476 & & .01513 .15122 & .021 .2696771 & .0192 .23659 \\
\hline .0192 .302091 & $\operatorname{lcd} 36611$ & .0168 .687272 & .0220 & .021 .120922 \\
\hline .021 .167082 & .0130 & .0175 .545238 & & .021 .3797853 \\
\hline .021 .4108938 & $1.386035 \mathrm{E}-0220.13491$ & .0183 .360768 & lcd 37710 & .0220 \\
\hline \multirow[t]{2}{*}{.0220} & .01419 .0894 & .0191 .865579 & .0140 & \\
\hline & $.015 \quad 12.88344$ & $.02 \quad .8628749$ & 1.404689E-02 19.7668 & $\operatorname{lcd} 38310$ \\
\hline $\operatorname{lcd} 36111$ & .0168 .481294 & .021 .2089247 & .01513 .69404 & .0140 \\
\hline
\end{tabular}




$\begin{array}{ll}1.422584 \mathrm{E}-02 & 19.41368 \\ .015 & 14.47818 \\ .016 & 9.717388 \\ .017 & 6.327868 \\ .018 & 3.941442 \\ .019 & 2.284564 \\ .02 & 1.154714 \\ .021 & .4025437 \\ .022 & 0 \\ & \\ 1 \text { cd } 384 & 10 \\ .014 & 0 \\ 1.426085 \mathrm{E}-02 & 19.34459 \\ .015 & 14.63215 \\ .016 & 9.837912 \\ .017 & 6.420249 \\ .018 & 4.010657 \\ .019 & 2.335076 \\ .02 & 1.190391 \\ .021 & .42666 \\ .022 & 0\end{array}$


Input pressure loads for surfaces for the blast loading of the concrete wall.

pr $1111122221111.0000-1$ pr $2 \begin{array}{llllllllll}1 & 1 & 3 & 2 & 1 & 2 & 1.0 & 0 & 0 & -1\end{array}$ pr $311442131.0000-1$ pr $4 \begin{array}{llllllllll}1 & 1 & 5 & 2 & 4 & 1.0 & 0 & 0 & -1\end{array}$ pr $5 \begin{array}{lllllllllll}1 & 6 & 2 & 1 & 5 & 1.0 & 0 & 0 & -1\end{array}$ pr $6 \begin{array}{lllllllllll}1 & 1 & 2 & 1 & 6 & 1.0 & 0 & 0 & -1\end{array}$ pr $7 \begin{array}{llllllllll}1 & 1 & 8 & 2 & 1 & 7 & 1.0 & 0 & 0 & -1\end{array}$ pr $8 \begin{array}{llllllllll}1 & 1 & 9 & 2 & 1 & 8 & 1.0 & 0 & 0 & -1\end{array}$ pr $911102191.000-1$ pr $101111121101.0000-1$ pr $11111122211111.0000-1$ pr $1211113211121.0000-1$ pr $131111421131.0000-1$ pr $141111521141.0000-1$ pr $15111621151.0000-1$ pr $1611117211161.0000-1$ pr $171111821171.0000-1$ pr $1811119211181.0000-1$ pr $19112021191.0000-1$ pr $20112121201.0000-1$ pr $2111222212211.0000-1$ pr $2211123211221.0000-1$ pr $2311124211231.0000-1$ pr $241112521241.000-1$ pr $1212231251.0000-1$ pr $2213331261.000-1$ pr $3214431271.0000-1$ pr $4215531281.0000-1$ pr $5216331291.0000-1$ pr $621731301.000-1$ pr $72 \begin{array}{lllllllll} & 8 & 3 & 1 & 31 & 1.0 & 0 & 0 & -1\end{array}$ pr $8219331321.0000-1$ pr $92110313331.0000-1$ pr $102111311341.0000-1$ pr $112112311351.0000-1$ pr $122113311361.0000-1$ pr $132114311371.0000-1$ pr $14211531381.000-1$ pr $15211631391.000-1$ pr $16211731401.000-1$ pr $17211831411.0000-1$ pr $18211931421.0000-1$ pr $19212031431.000-1$ pr $20212131441.000-1$ pr $21212231451.0000-1$ pr $22212331461.000-1$ pr $2321124311471.0000-1$ pr $24212531481.000-1$ pr $1312241491.0000-1$ pr $2311341501.0000-1$ pr $3314441511.0000-1$ pr $4315441521.0000-1$ pr $531641531.0000-1$ pr $63177411541.0000-1$ pr $7318841551.0000-1$ pr $831941561.000-1$ pr $9311041571.000-1$ pr $10311141581.000-1$ pr $11311241591.000-1$ pr $12311341601.000-1$ pr $13311441611.000-1$ pr $14311541621.000-1$ pr $15311641631.000-1$ pr $16311741641.000-1$ pr $17311841651.000-1$ pr $18311941661.000-1$ pr $19312041671.000-1$ pr $20312141681.000-1$ pr $21312241691.000-1$ pr $22312341701.000-1$ pr $23312441711.000-1$ pr $24312541721.000-1$ pr $141251731.000-1$ pr $2411351741.0000-1$ pr $34 \begin{array}{llllllll}4 & 4 & 5 & 75 & 1.0 & 0 & 0 & -1\end{array}$ pr $441551761.000-1$ pr $541651771.000-1$ pr $641751781.000-1$ pr $741851791.000-1$ pr $841951801.000-1$ pr $9411051811.000-1$ pr $10411151821.000-1$ pr $11411251831.000-1$ pr $12411351841.000-1$ pr $13411451851.000-1$ pr $14411551861.000-1$ pr $15411651871.000-1$ pr $16411751881.000-1$ pr $17411851891.000-1$ pr $18411951901.000-1$ pr $19412051911.000-1$ pr $204122151921.000-1$ pr $21412251931.000-1$ pr $22412351941.000-1$ pr $23412451951.000-1$ pr $24412551961.000-1$ pr $1512261971.0000-1$ pr $251361981.000-1$ pr $3514461991.0000-1$ pr $45115611001.0000-1$ pr $5516611011.0000-1$ pr $6517611021.0000-1$ pr $75186611031.0000-1$ pr $8519611041.0000-1$ pr $95110611051.000-1$ pr $105111611061.000-1$ pr $115112611071.0000-1$ pr $125113611081.000-1$ pr $135114611091.000-1$ pr $145115611101.000-1$ pr $155116611111.000-1$ pr $165117611121.000-1$ pr $175118611131.000-1$ pr $185119611141.000-1$ pr $195120611151.000-1$ pr $205121611161.000-1$ pr $215122611171.000-1$ pr $225123611181.000-1$ pr $235124611191.000-1$ pr $245125611201.000-1$ pr $1612711211.000-1$ pr $2613771221.000-1$ pr $3614711231.0000-1$ pr $4615711241.000-1$ pr $5616711251.000-1$ pr $6617711261.000-1$ pr $7618711271.000-1$ pr $8619711281.000-1$ pr $96110711291.000-1$ pr $106111711301.000-1$ pr $116112711311.000-1$ pr $126113711321.000-1$ pr $136114711331.0000-1$ pr $146115711341.000-1$ pr $156116711351.000-1$ pr $166117711361.000-1$ pr $176118711371.000-1$ pr $186119711381.000-1$ pr $196120711391.000-1$ pr $206121711401.000-1$ pr $216122711411.000-1$ pr $226123711421.0000-1$ pr $236124711431.000-1$ pr $246125711441.000-1$ pr $1712811451.000-1$ pr $2713811461.000-1$ pr $3714811471.000-1$ pr $4715811481.0000-1$ pr $5716811491.000-1$ pr $6717811501.000-1$ pr $77188811511.000-1$ pr $8719811521.0000-1$ pr $97110811531.000-1$ pr $1071111811541.000-1$ pr $117112811551.000-1$ pr $127113811561.000-1$ pr $137114811571.000-1$ pr $147115811581.000-1$ pr $157116811591.000-1$ 
pr $167117811601.000-1$ pr $177118811611.000-1$ pr $187119811621.000-1$ pr $197120811631.000-1$ pr $207121811641.000-1$ pr $217122811651.000-1$ pr $227123811661.000-1$ pr $237124811671.000-1$ pr $247125811681.000-1$ pr $1812911691.000-1$ pr $2813911701.000-1$ pr $38114911711.0000-1$ pr $4815911721.0000-1$ pr $5816911731.000-1$ pr $6817911741.000-1$ pr $7818911751.000-1$ pr $8819911761.000-1$ pr $98110911771.000-1$ pr $108111911781.000-1$ pr $118112911791.000-1$ pr $128113911801.000-1$ pr $138114911811.000-1$ pr $148115911821.0000-1$ pr $158116911831.000-1$ pr $168117911841.000-1$ pr $178118911851.000-1$ pr $188119911861.000-1$ pr $198120911871.000-1$ pr $208121911881.000-1$ pr $218122911891.000-1$ pr $228123911901.000-1$ pr $238124911911.000-1$ pr $248125911921.000-1$ pr $191210111931.000-1$ pr $29131011941.000-1$ pr $39141011951.000-1$ pr $49151011961.000-1$ pr $59161011971.000-1$ pr $69171011981.000-1$ pr $79181011991.000-1$ pr $89191012001.000-1$ pr $991101012011.000-1$ pr $1091111012021.000-1$ pr $1191121012031.000-1$ pr $1291131012041.000-1$ pr $1391141012051.000-1$ pr $1491151012061.000-1$ pr $1591161012071.000-1$ pr $1691171012081.000-1$ pr $1791181012091.000-1$ pr $1891191012101.000-1$ pr $1991201012111.000-1$ pr $2091211012121.000-1$ pr $2191221012131.000-1$ pr $2291231012141.000-1$ pr $2391241012151.000-1$ pr $2491251012161.000-1$ pr $1101221112171.000-1$ pr $210131112181.0000-1$ pr $310141112191.000-1$ pr $410151112201.0000-1$ pr $510161112211.000-1$ pr $6101771112221.000-1$ pr $710181112231.000-1$ pr $810191112241.000-1$ pr $9101101112251.0000-1$ pr $101011111112261.000-1$ pr $11101121112271.000-1$ pr $12101131112281.000-1$ pr 13101141112291.000 -1 pr $14 \begin{array}{llllllllll}10 & 15 & 11 & 1 & 230 & 1.0 & 0 & 0 & -1\end{array}$ pr $15101161112311.0000-1$ pr $16101171112321.000-1$ pr $17101181112331.000-1$ pr $18101191112341.000-1$ pr $19101201112351.000-1$ pr $20101211112361.000-1$ pr $21101221112371.000-1$ pr $22101231112381.000-1$ pr $23101241112391.000-1$ pr $24101251112401.000-1$ pr $111121212411.000-1$ pr $211131212421.0000-1$ pr $311141212431.000-1$ pr $411151212441.000-1$ pr $511161212451.0000-1$ pr $6111171212461.0000-1$ pr $711181212471.0000-1$ pr $811191212481.0000-1$ pr $91111101212491.0000-1$ pr $10111111212501.000-1$ pr $111111121212511.0000-1$ pr $1211111312112521.0000-1$ pr $131111141212531.0000-1$ pr $14 \begin{array}{llllllllll}11 & 15 & 12 & 1 & 254 & 1.0 & 0 & 0 & -1\end{array}$ pr $1511111612112551.0000-1$ pr $16111171212561.000-1$ pr $171111181212571.0000-1$ pr $181111191212581.0000-1$ pr $19111201212591.000-1$ pr $20111211212601.000-1$ pr $2111122212112611.0000-1$ pr $221112231212621.000-1$ pr $231112241212631.0000-1$ pr $24 \begin{array}{lllllllllll}11 & 25 & 12 & 1 & 264 & 1.0 & 0 & 0 & -1\end{array}$ pr $112121312651.0000-1$ pr $212131312661.0000-1$ pr $312141312671.0000-1$ pr $412151312681.0000-1$ pr $512161312691.0000-1$ pr $612171312701.0000-1$ pr $712181312711.0000-1$ pr $8121991312721.0000-1$ pr $9121101312731.000-1$ pr $10121111312741.000-1$ pr $11121121312751.0000-1$ pr $12121131312761.000-1$ pr $13121141312771.000-1$ pr $14121151312781.000-1$ pr $15121161312791.000-1$ pr $16121171312801.0000-1$ pr $17121181312811.000-1$ pr $18121191312821.0000-1$ pr $19121201312831.000-1$ pr $20121211312841.000-1$ pr $21121221312851.0000-1$ pr $2212122313122861.0000-1$ pr $23121241312871.000-1$ pr $24121251312881.0000-1$ pr $11312214122891.0000-1$ pr 213131412901.000 -1 pr $31314414122911.0000-1$ pr $41313 \quad 514112921.0000-1$ pr $513161412931.000-1$ pr 6131171412941.000 -1 pr $71318814122951.000-1$ pr $813191412961.000-1$ pr $9131101412971.000-1$ pr $10131111412981.000-1$ pr $11131121412991.0000-1$ pr $12131131413001.000-1$ pr $13131141413011.0000-1$ pr $14131151413021.0000-1$ pr $15131161413031.0000-1$ pr $16131171413041.0000-1$ pr $17131181413051.0000-1$ pr $18131191413061.000-1$ pr $19131201413071.000-1$ pr $20131211413081.0000-1$ pr $21131221413091.0000-1$ pr $22131231413101.0000-1$ pr $23131241413111.000-1$ pr $24131251413121.0000-1$ pr $1141221513131.0000-1$ pr $2141331513141.000-1$ pr $3141441513 \quad 3151.0000-1$ pr $41415515133161.0000-1$ pr $51416615133171.0000-1$ pr $6141771513181.0000-1$ pr $7141881513191.0000-1$ pr $8141991513201.0000-1$ pr $9141101513211.000-1$ pr $101411111513221.0000-1$ pr $11141121513231.0000-1$ pr $12141131513241.0000-1$ pr $13141141513251.0000-1$ pr $14141151513261.0000-1$ pr $15141161513271.0000-1$ 
pr $16141171513281.0000-1$ pr $17141181513291.0000-1$ pr $18141191513301.000-1$ pr $19141201513311.0000-1$ pr $20141211513321.000-1$ pr $21141221513331.000-1$ pr $22141231513341.000-1$ pr $23141241513351.000-1$ pr $24141251513361.000-1$ pr $1151221613371.0000-1$ pr $215131613381.0000-1$ pr $315141613391.000-1$ pr $415151613401.0000-1$ pr $515161613411.000-1$ pr $6151771613421.0000-1$ pr $7 \begin{array}{llllllllll}15 & 8 & 8 & 16 & 1 & 343 & 1.0 & 0 & 0 & -1\end{array}$ pr $815191613441.0000-1$ pr $9151101613451.000-1$ pr $10151111613461.000-1$ pr $11151121613471.0000-1$ pr $12151131613481.0000-1$ pr $13151141613491.000-1$ pr $14151151613501.000-1$ pr $15151161613511.000-1$ pr $16151171613521.000-1$ pr $17151181613531.0000-1$ pr $18151191613541.000-1$ pr $19151201613551.000-1$ pr $20151211613561.000-1$ pr $21151221613571.000-1$ pr $22151231613581.0000-1$ pr $23151241613591.000-1$ pr $24151251613601.000-1$ pr $1161217113611.0000-1$ pr $216131713621.0000-1$ pr $316141713631.0000-1$ pr $416151713641.0000-1$ pr $516161713651.0000-1$ pr $616171713661.0000-1$ pr $716181713671.000-1$ pr $816191713681.000-1$ pr $9161101713691.000-1$ pr $10161111713701.000-1$ pr $11161121713711.0000-1$ pr $12161131713721.000-1$ pr $13161141713731.000-1$ pr $14161151713741.000-1$ pr $15161161713751.000-1$ pr $16161171713761.000-1$ pr $17161181713771.000-1$ pr $18161191713781.000-1$ pr $19161201713791.000-1$ pr $20161211713801.000-1$ pr $21161221713811.000-1$ pr $22161231713821.000-1$ pr $23161241713831.000-1$ pr $24161251713841.000-1$ 
Appendix C:

RC Damping Example 
The following is a step-by-step example of how to use the Transformed Section Method. The beam is Faza's Case \#2, which is steel reinforced concrete, with a steel plate bonded to the bottom of the beam (Fig. C.1).

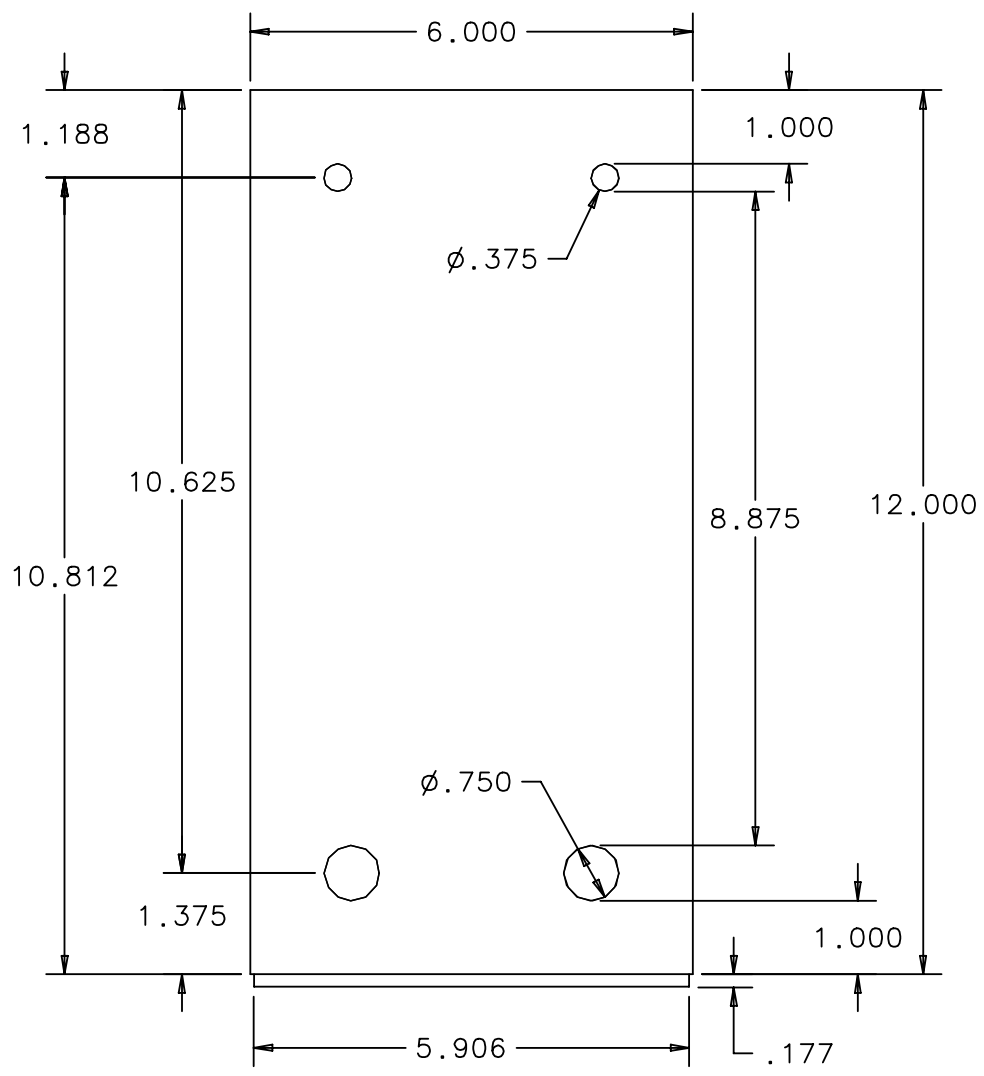

Figure C.1 - The Original Concrete Beam With a Steel Plate on the Bottom

Find the area of the two small reinforcing bars, diameter of $3 / 8$ in, shown in Fig. C.1.

$A_{S R}=2\left[\pi \frac{d^{2}}{4}\right]=\frac{\pi}{2}(0.375 \mathrm{in})^{2}=0.221 \mathrm{in}^{2}$

Find the new thickness of the small reinforcing bars combined. This uses a width of 6 in, the original width of the beam to make a new rectangular shape.

$t_{S R}=\frac{A}{w}=\frac{0.221 \mathrm{in}^{2}}{6 \mathrm{in}}=0.037 \mathrm{in}$

Find the area of the two large reinforcing bars, diameter of $3 / 4$ in, shown in Fig. C.1.

$A_{L R}=2\left[\pi \frac{d^{2}}{4}\right]=\frac{\pi}{2}(0.75 \mathrm{in})^{2}=0.884 \mathrm{in}^{2}$ 
Find the new thickness of the large reinforcing bars combined. This uses a width of 6 in., the original width of the beam to make a new rectangular shape.

$t_{L R}=\frac{A}{w}=\frac{0.884 \mathrm{in}^{2}}{6 \text { in }}=0.147 \mathrm{in}$

Fig. C.2 shows the first transformation of the beam.

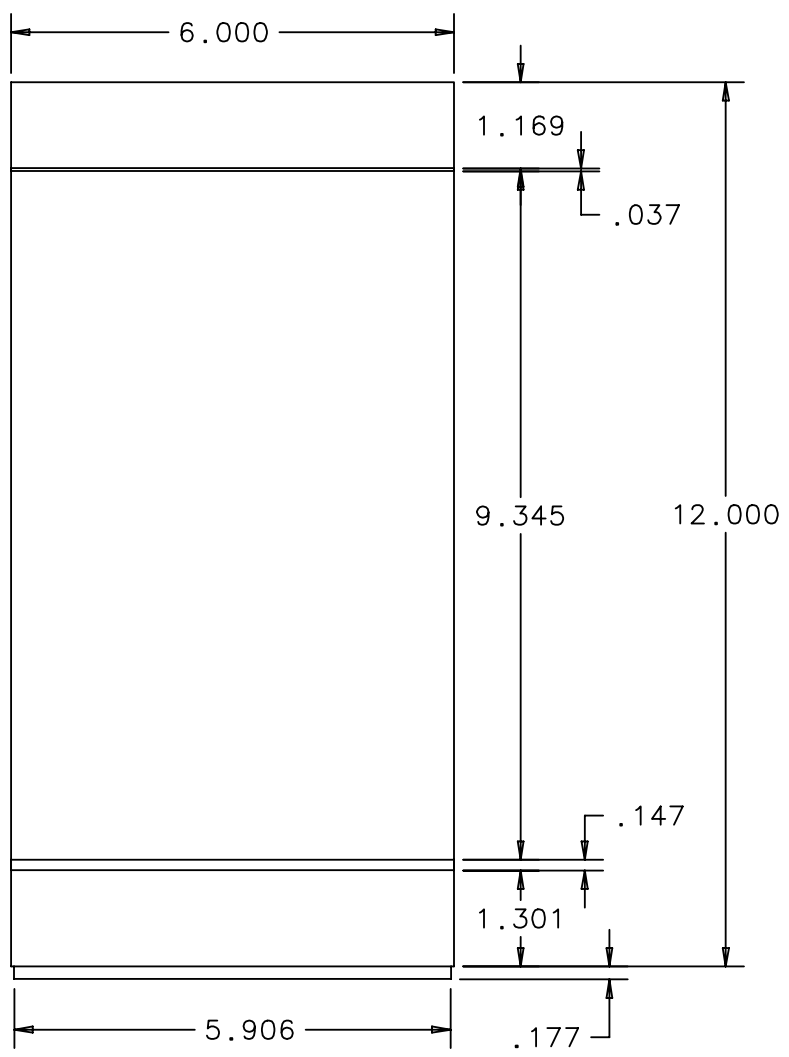

Figure C.2 - Beam after Transforming the Steel

Table C.1 shows the values of modulus of elasticity and density for the materials used.

\begin{tabular}{|c|c|c|}
\hline & E (psi) & $\rho\left(1 b^{*} \sec ^{2} / \mathrm{in}^{4}\right)$ \\
\hline Steel & $29.0 \times 10^{6}$ & $7.34 \times 10^{-4}$ \\
\hline Concrete & $3.47 \times 10^{6}$ & $1.77 \times 10^{-4}$ \\
\hline
\end{tabular}

By finding the relation between the modulus of steel and the modulus of concrete, a new width for the concrete can be calculated. 


$$
\eta=\frac{E_{\text {concrete }}}{E_{\text {steel }}}=\frac{3.47 \mathrm{psi}}{29.0 \mathrm{psi}}=0.120
$$

The transformed width of the concrete can now be calculated.

$$
w_{\text {concrete }}^{\prime}=\eta w_{\text {concrete }}=(0.120)(6 \text { in })=0.718 \text { in }
$$

The final transformed beam is shown in Fig. C.3.

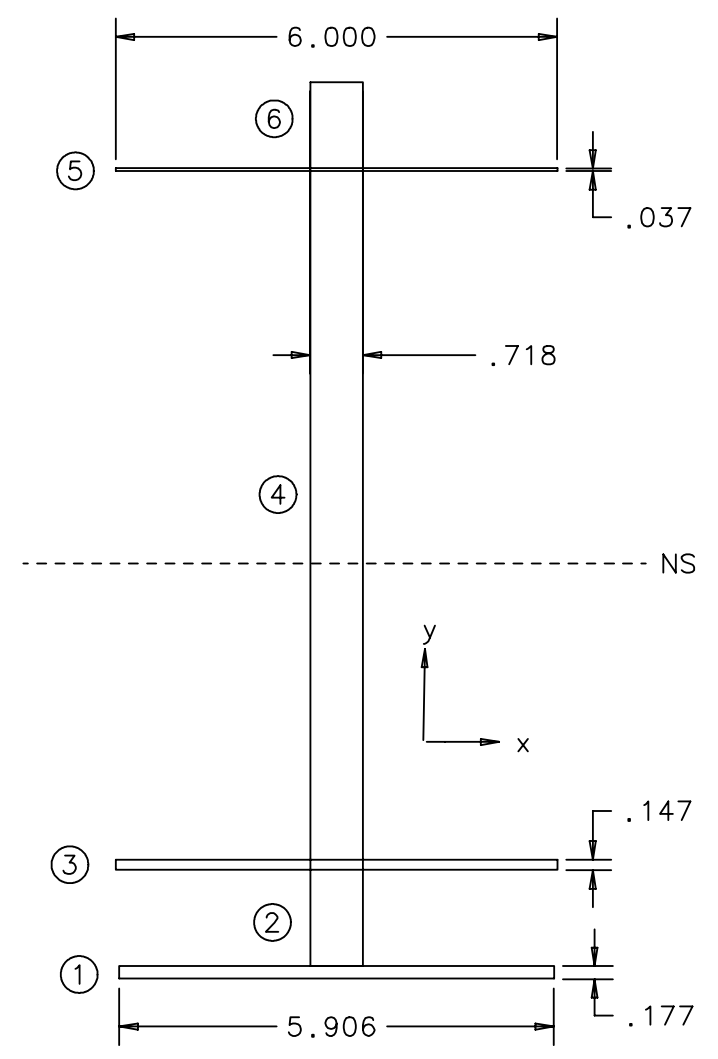

Figure C.3 - Completely Transformed Beam

The next step is to find the neutral surface of the beam, denoted NS in Fig. C.3. Calculation values are found in Table C.2. The area is denoted by A and the distance from the very bottom of the beam (the steel plate) to the center of each segment by $\tilde{y}$. 
Table C.2 - Neutral Surface Calculations

\begin{tabular}{|c|c|c|c|}
\hline Segment & $A\left(\right.$ in $\left.^{2}\right)$ & $\tilde{y}$ (in) & $\tilde{y} A\left(\right.$ in $\left.^{3}\right)$ \\
\hline 1 & 1.046 & 0.089 & 0.093 \\
\hline 2 & 0.934 & 0.828 & 0.773 \\
\hline 3 & 0.884 & 1.552 & 1.371 \\
\hline 4 & 6.575 & 6.205 & 40.795 \\
\hline 5 & 0.221 & 10.990 & 2.428 \\
\hline \multirow[t]{2}{*}{6} & 0.839 & 11.593 & 9.730 \\
\hline & $\sum A=10.499$ & & $\sum \tilde{y} A=55.190$ \\
\hline
\end{tabular}

The zero y-axis is chosen through the center of the beam, so the distance to the $\mathrm{x}$ neutral surface, $\bar{x}$, is zero. The distance to the neutral surface in the y direction is calculated.

$\bar{y}=\frac{\sum \tilde{y} A}{\sum A}=\frac{55.190 \mathrm{in}^{3}}{10.499 \mathrm{in}^{2}}=5.257 \mathrm{in}$

The area moment of inertia, $I_{x}$, must be found for the transformed section. This is accomplished by finding $I_{x}$ for each segment first. Needed are $d_{y}$, the distance from NS to the center of each segment, and the area moment of inertia for each rectangle as if it were by itself, $I_{x}$. Because all of the segments are rectangles, $I_{x}$ can be found by

$I_{x}^{\prime}=\frac{1}{12} b h^{3}$

Table C. 3 contains the calculated values.

Table C.3 - Area Moments of Inertia

\begin{tabular}{|c|c|c|c|c|c|}
\hline Segment & $A\left(\mathrm{in}^{2}\right)$ & $d_{\mathrm{y}}$ (in) & $A * d_{y}\left(\mathrm{in}^{3}\right)$ & $I_{x}\left(\right.$ in $\left.^{4}\right)$ & $I_{x}\left(i n^{4}\right)$ \\
\hline 1 & 1.046 & -5.168 & 27.944 & 0.003 & 27.947 \\
\hline 2 & 0.934 & -4.429 & 18.325 & 0.132 & 18.457 \\
\hline 3 & 0.884 & -3.704 & 12.125 & 0.002 & 12.127 \\
\hline 4 & 6.575 & 0.948 & 5.910 & 45.951 & 51.862 \\
\hline 5 & 0.221 & 5.733 & 7.260 & 0.000 & 7.260 \\
\hline 6 & 0.839 & 6.336 & 33.694 & 0.096 & 33.790 \\
\hline
\end{tabular}


The natural frequency can now be calculated using Eq. 3.5.

$\omega_{n}=\frac{\xi_{n}^{2}}{L^{2}} \sqrt{\frac{E I}{\rho H b}}$

where,

$\xi_{n}=n \pi$

$L=120$ in

$E I=E_{\text {steel }} * \sum I_{x}$

$\rho H B=\rho_{1} A_{1}+\rho_{2} A_{2}+\rho_{3} A_{3}+\rho_{4} A_{4}+\rho_{5} A_{5}+\rho_{6} A_{6}=\rho_{s}\left(A_{1}+A_{3}+A_{5}\right)+\rho_{c}\left(A_{2}+A_{4}+A_{6}\right)$

Substituting these values yields

$\omega_{n}=n^{2}(821.6)$

With $\mathrm{n}=1, \omega_{1}=821.6$

The system damping is finally calculated, assuming the system is critically damped $(\zeta=1)$.

$D_{s}=2 \zeta \omega_{1}=1643$

The values for system damping for all of Faza's beams can be found in Table C.4.

Table C.4 - System Damping for Faza's Beams

\begin{tabular}{|c|c|c|c|}
\hline Case \# & ybar (in) & $\boldsymbol{\omega}_{1}$ & $\mathbf{D}_{\mathbf{s}}$ \\
\hline 1 & 5.651 & 846.7 & 1693.3 \\
\hline 2 & 5.257 & 821.6 & 1643.3 \\
\hline 3 & 5.507 & 835.4 & 1670.7 \\
\hline 4 & 5.658 & 848.0 & 1695.9 \\
\hline 5 & 5.661 & 848.3 & 1696.6 \\
\hline 6 & 5.665 & 848.4 & 1696.8 \\
\hline
\end{tabular}




\section{Appendix D:}

\section{Input Format for LS-DYNA3D}




\section{Material Type 43 (Kinematic Hardening Cap Model with Tensile Damage)}

Columns

Quantity

Format

$1-10$

Card 3

Initial bulk modulus, $\mathrm{K}$

E10.0

11-20

Non-linear bulk modulus, K1

E10.0

21-30

Non-linear bulk modulus, K2

E10.0

$31-40$

Initial shear modulus, $\mathrm{G}$

E10.0

$41-50$

Non-linear shear modulus, G1

E10.0

$51-60$

Non-linear shear modulus, G2

E10.0

$61-70$

Failure envelope parameter, $\alpha$

E10.0

$71-80$

Failure envelope exponential coefficient, $\gamma$

E10.0

$1-10$

Card 4

Failure envelope exponent, $\beta$

E10.0

$11-20$

Failure envelope linear coefficient, $\theta$

E10.0

21-30

Hardening law coefficient (porosity), W

E10.0

$31-40$

Hardening law exponent, D

E10.0

$41-50$

Hardening law parameter, $X_{0}$

E10.0

51-60

Cap, surface axis ratio, $\mathrm{R}$

E10.0

$61-70$

Tension cutoff, $\mathrm{T}<0$ (positive in compression)

E10.0

$71-80$

Tensile damage parameter, TDP $(=\mathrm{T} / 4)$

E10.0

$1-10$

Card 5

Formulation flag, LTYPE (ITYPE)

E10.0

EQ.1.0 compacting (soil or concrete, cap my contract) EQ.2.0 dilative material (rock, cap doesn't contract)

EQ.3.0 damage (must be used for this model)

1-10 Card 6

Plot database flag, IPLOT

E10.0

EQ.1.0 hardening variable $\kappa$, in units of $\mathrm{J} 1$

EQ.2.0 cap - J1 intercept, X( $\kappa)$

EQ.3.0 volumetric plastic strain, $\varepsilon^{p_{V}}$

EQ.4.0 first stress invariant, J1

EQ.5.0 second stress invariant, $\operatorname{sqrt}\left(\mathrm{J}_{2 \mathrm{D}}\right)$

EQ.6.0 not used

EQ.7.0 not used

EQ.8.0 response mode number

EQ.9.0 number of iterations

$61-70$

Card 8

Intersection of yield and J1, FCUT

E10.0

71-80

Initial $\mathrm{J} 1$ of intersection of $\mathrm{F}_{\mathrm{e}}$ and $\mathrm{F}_{\mathrm{c}}, \mathrm{L}_{\mathrm{o}}$

E10.0 


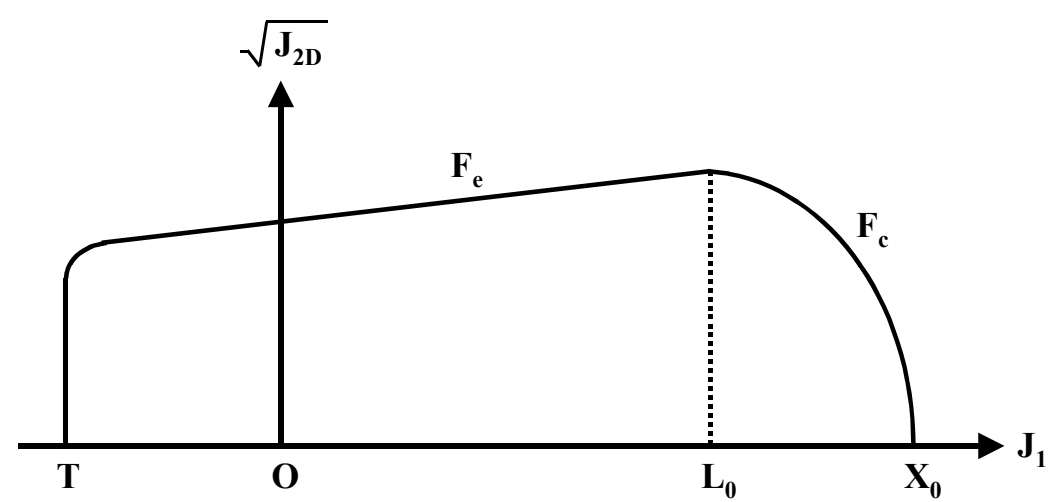

Figure D.1 - The Yield surface of the Two-Invariant Cap Model in Pressure $\sqrt{\mathrm{J}_{2 \mathrm{D}}}-J_{1}$ Space

Surface $\mathrm{F}_{\mathrm{e}}$ is the failure envelope (yield surface), $\mathrm{F}_{\mathrm{c}}$ is the cap surface and the tension cutoff is the vertical line above $\mathrm{T}$.

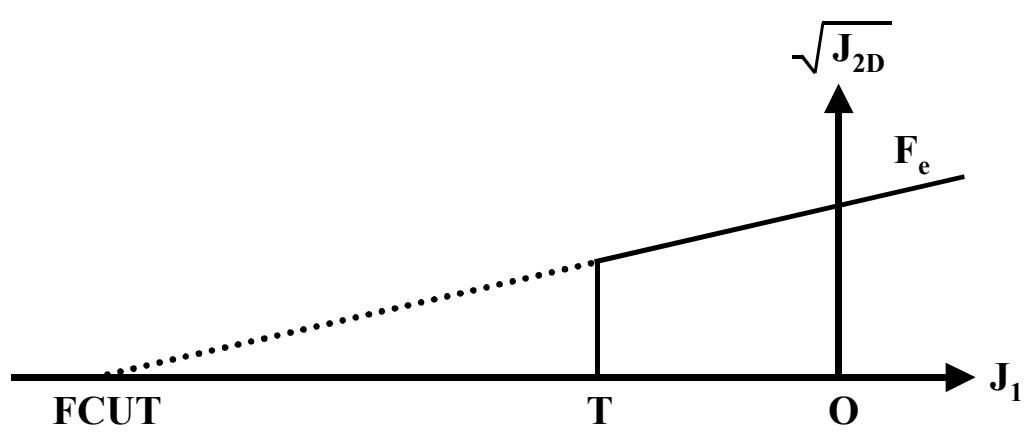

Figure D.2 - Representation of the Parameter FCUT

Solve the Tensile Damage Parameter using

$$
T D P=\frac{T C U T}{4}
$$

Solve the variable FCUT using

$$
F C U T=\frac{-1}{\beta} \ln \left(\frac{\alpha}{\gamma}\right)
$$

Solve the value $\mathrm{L}_{\mathrm{o}}$ using MAPLE $\mathrm{V}$ and

$$
\alpha-\gamma e^{-\beta L_{0}}-\frac{X_{0}-L_{0}}{R}=0
$$




\section{Appendix E:}

\section{UMAT43 Damage Model Fortran Program}


subroutine umat43 (cm,eps,sig,hisv,dt1,AKAPP, etype,time)

$\mathrm{c} * * * * * * * * * * * * * * * * * * * * * * * * * * * * * * * * * * * * * * * * * * * * * * * * * * * * * * * * * * * * * * * * * *$

c| Matthew J. Fox, Dr. Ever J. Barbero, West Virginia University

c|

c| copyright 1998 Dr. Ever J. Barbero, WVU

c| all rights reserved

$\mathrm{c} * * * * * * * * * * * * * * * * * * * * * * * * * * * * * * * * * * * * * * * * * * * * * * * * * * * * * * * * * * * * * * * * * *$

$\mathrm{c}$

c concrete model

c yield surface SJ2Y

c cap $\mathrm{SJ} 2 \mathrm{C}$

c tension cutoff with damage

$\mathrm{c}$

c $\quad$ eps $(1)=$ local $\mathrm{x}$ strain increment

c $\operatorname{eps}(2)=$ local y strain

c $\operatorname{eps}(3)=$ local z strain

c $\operatorname{eps}(4)=$ local xy strain

c $\operatorname{eps}(5)=$ local yz strain

c $\operatorname{eps}(6)=$ local zx strain

$\mathrm{c}$

c $\operatorname{sig}(1)=$ local $x$ stress accumulated

c $\operatorname{sig}(2)=$ local y stress

c $\operatorname{sig}(3)=$ local $\mathrm{z}$ stress

c $\operatorname{sig}(4)=$ local xy stress

c $\operatorname{sig}(5)=$ local yz stress

c $\operatorname{sig}(6)=$ local zx stress

$\mathrm{c}$

c $\quad \mathrm{dt} 1=$ current time step size

c capa $=$ reduction factor for transverse shear

c etype:

c eq."brick" for solid elements

c eq."shell" for all shell elements

c eq."beam" for all beam elements

c

c time $=$ current problem time.

$\mathrm{c}$

c All transformations into the element local system are

c performed prior to entering this subroutine. Transformations

c back to the global system are performed after exiting this

c routine.

$\mathrm{c}$

c All history variables are initialized to zero in the input

c phase. Initialization of history variables to nonzero values

c may be done during the first call to this subroutine for each

c element.

$\mathrm{c}$ 
c Energy calculations for the dyna3d energy balance are done

c outside this subroutine.

$\mathrm{c}$

$\mathrm{C}$

C MATERIAL MODEL

$\mathrm{C}$

C COMMON/STRESS/ SIGX,SIGY,SIGZ,SIGXZ,SIGYZ,SIGXY

C COMMON/STRAIN/ EPSX,EPSY,EPSZ,EPSXZ,EPSYZ,EPSXY

C COMMON/STRINC/ DEPSX,DEPSY,DEPSZ,DEPSXZ,DEPSYZ,DEPSXY

C COMMON/DUMMY / MTYPE,LTYPE,TCUT,FCUT,GEOP,NOCON,ISTAT

C COMMON/PROPER/AKI,AK1,AK2,AGI,AG1,AG2,AA,AB,AC

C COMMON/PREPRO/ CR0,CR1,CR2,AW,AD,AKAPP,AL0,LAYER

c implicit real*8 (a-h,o-z)

character* $(*)$ etype

dimension $\mathrm{cm}(*), \operatorname{eps}(*), \operatorname{sig}(*), \operatorname{hisv}(*)$

c

C External definitions

$\mathrm{C}$

c external $\operatorname{dmin} 1(\mathrm{x}, \mathrm{y})=\operatorname{amin} 1(\mathrm{x}, \mathrm{y})$

c external $\operatorname{dmax} 1(\mathrm{x}, \mathrm{y})=\operatorname{amax} 1(\mathrm{x}, \mathrm{y})$

$\mathrm{C}$

$\mathrm{C}$

THE POTENTIAL FUNCTIONS OF THE MODEL

$\mathrm{C}$

C FAILURE ENVELOPE FUNCTION FOR SJ2

$\mathrm{C}$

$\mathrm{F}(\mathrm{SJ} 1)=\mathrm{AA}-\mathrm{AC} * \mathrm{EXP}(-\mathrm{AB} * \mathrm{SJ} 1)$

$\mathrm{c}^{*} \mathrm{ejb} \quad \mathrm{F}(\mathrm{SJ} 1)=\mathrm{AA}-\mathrm{AC} * \mathrm{EXP}(-\mathrm{AB} * \mathrm{SJ} 1)+\mathrm{AT} * \mathrm{SJ} 1$

C

C HARDENING STATEMENT FUNCTIONS

$\mathrm{C}$

C $\quad$ BIGL(AKAPP) $=$ AMAX1(AL0,AKAPP)

C $\quad \mathrm{R}(\mathrm{CAPL})=\mathrm{CR} 0 *(1 .-\mathrm{CR} 1 * \mathrm{EXP}(-\mathrm{CR} 2 * \mathrm{BIGL}(\mathrm{AKAPP}))) /(1 .-\mathrm{CR} 1)$

c $\quad \mathrm{X}(\mathrm{AKAPP})=\mathrm{AMAX} 1(\mathrm{zero}, \mathrm{EP}+\mathrm{R}(\mathrm{BIGL}(\mathrm{EP})) * \mathrm{~F}(\mathrm{EP}))$

$\mathrm{C} \quad \mathrm{EVP}(\mathrm{XL})=\mathrm{AW}^{*}(1.0-\mathrm{EXP}(-\mathrm{AD} * \mathrm{XL}))$

C EJB

BIGL $($ AKAPP $)=$ AMAX1 $(A L 0, A K A P P)$

c*ejb $\mathrm{R}(\mathrm{CAPL})=\mathrm{CR} 0 *(1 .-\mathrm{CR} 1 * \mathrm{EXP}(-\mathrm{CR} 2 * \mathrm{CAPL})) /(1 .-\mathrm{CR} 1)$

$\mathrm{R}(\mathrm{CAPL})=\mathrm{CR} 0 *(1 .-\mathrm{CR} 1 * \mathrm{EXP}(-\mathrm{CR} 2 * \mathrm{BIGL}(\mathrm{AKAPP}))) /(1 .-\mathrm{CR} 1)$

$\mathrm{c}^{*}$ ejb $\mathrm{X}(\mathrm{CAPL})=\mathrm{AMAX} 1(\mathrm{zero}, \mathrm{CAPL}+\mathrm{R}(\mathrm{CAPL}) * \mathrm{~F}(\mathrm{CAPL}))$

$\mathrm{X}(\mathrm{AKAPP})=\mathrm{AMAX} 1$ (zero,AKAPP+R(BIGL(AKAPP))*F(AKAPP))

$c^{*}$ ejb $\quad \operatorname{EVP}(\mathrm{XL})=\mathrm{AW}^{*}(1.0-\mathrm{EXP}(-\mathrm{AD} *(\mathrm{XL}-\mathrm{X} 0)))$

$\operatorname{EVP}(\mathrm{XL})=\mathrm{AW}^{*}(1.0-\mathrm{EXP}(-\mathrm{AD} * \mathrm{XL}))$

$\mathrm{SJ} 2 \mathrm{C}(\mathrm{SJ} 1, \mathrm{XL}, \mathrm{CAPL})=\mathrm{SQRT}(\mathrm{ABS}((\mathrm{XL}-\mathrm{CAPL}) * * 2-$

$*$

$(\mathrm{SJ} 1-\mathrm{CAPL}) * * 2)) / \mathrm{R}(\mathrm{CAPL})$

$\mathrm{C}$ 


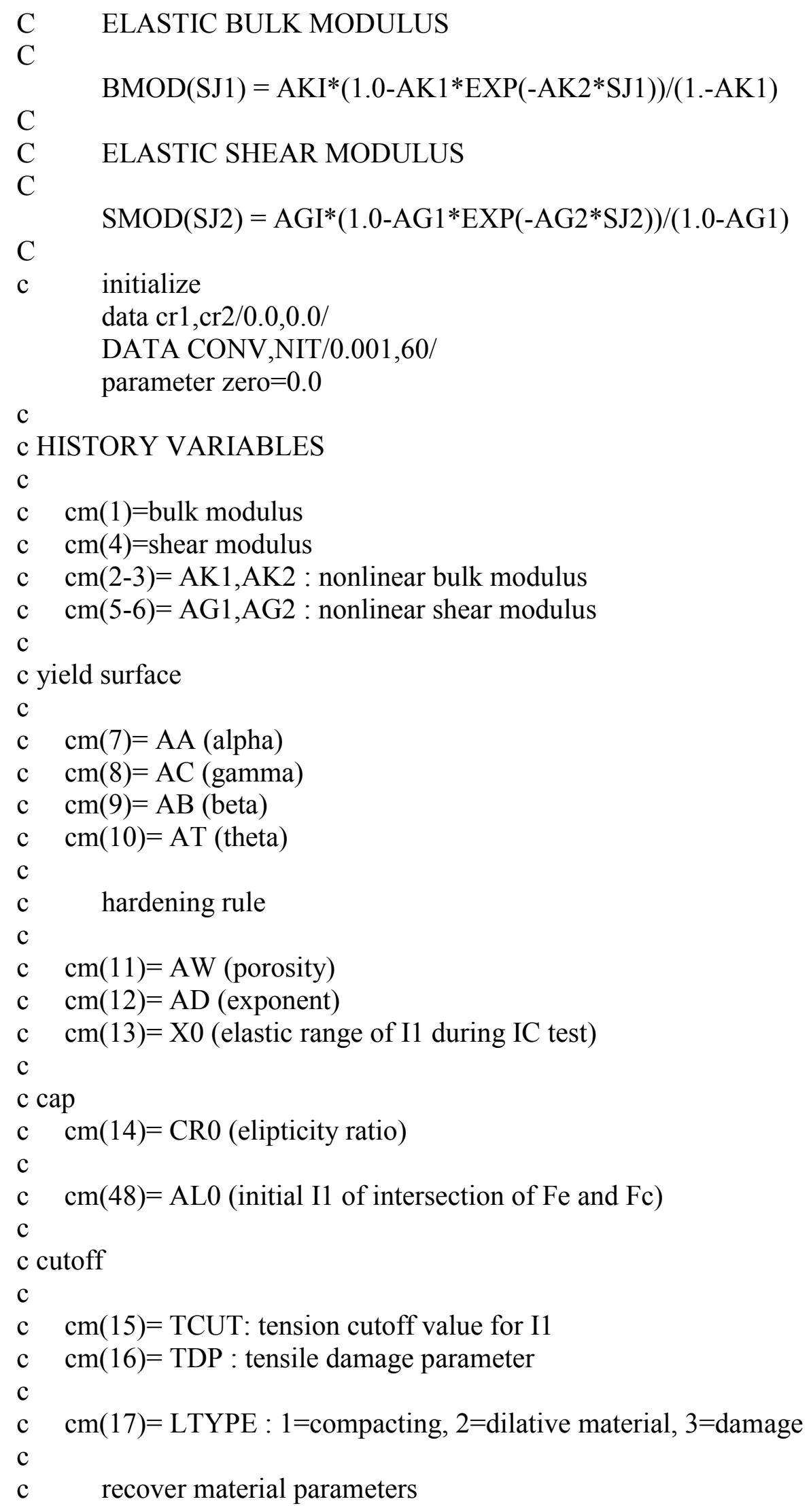


c
$\mathrm{AKI}=\mathrm{CM}(1)$
$\mathrm{AK} 1=\mathrm{CM}(2)$
$\mathrm{AK} 2=\mathrm{CM}(3)$
$\mathrm{AGI}=\mathrm{CM}(4)$
$\mathrm{AG} 1=\mathrm{CM}(5)$
$\mathrm{AG} 2=\mathrm{CM}(6)$
$\mathrm{AA}=\mathrm{CM}(7)$
$\mathrm{AC}=\mathrm{CM}(8)$
$\mathrm{AB}=\mathrm{CM}(9)$
$\mathrm{AT}=\mathrm{CM}(10)$
$\mathrm{AW}=\mathrm{CM}(11)$
$\mathrm{AD}=\mathrm{CM}(12)$
$\mathrm{X} 0=\mathrm{CM}(13)$
$\mathrm{CR0}=\mathrm{CM}(14)$
TCUT $=\mathrm{cm}(15)$
$\mathrm{TDP}=\mathrm{cm}(16)$
LTYPE $=\mathrm{cm}(17)$

c

c recover history variables

c

c hisv(1): printed as plastic-strain in taurus

c same as material 25

c if

c $\quad \operatorname{cm}(25)=1$ : hardening parameter $\mathrm{k}$ in units of I1

c $\quad \mathrm{cm}(25)=2$ : cap J1 intercept X(k)

c $\quad \mathrm{cm}(25)=3:$ volumetric plastic strain

c $\quad \mathrm{cm}(25)=4:$ first stress invariant I1

c $\quad \mathrm{cm}(25)=5$ : second stress invariant $\operatorname{sqrt}(\mathrm{J} 2)$

c $\quad \mathrm{cm}(25)=6$ :

c $\quad \mathrm{cm}(25)=7$ :

c $\quad \operatorname{cm}(25)=8:$ response mode number

c $\quad \operatorname{cm}(25)=9:$ number of iterations

$\mathrm{c}$

c $\operatorname{hisv(2)=AKAPP~:~kappa~(value~of~I1~at~the~last~yield/cap/cutoff~point)~}$

c $\quad \operatorname{hisv}(3)=$ omega : damage parameter

$\mathrm{c}$

$\operatorname{AKAPP}=\operatorname{hisv}(2)$

OMEGA $=\operatorname{hisv}(3)$

c

c

$\mathrm{c}$

ASSUMING eps(i) are increments \& sig(i) are accumulated values from dyna

$\mathrm{c}$

c

c recover stress from dyna array

c (-)sign for soil-mech. convention 
c

$$
\begin{aligned}
& \text { SIGX }=-\operatorname{sig}(1) \\
& \text { SIGY }=-\operatorname{sig}(2) \\
& \text { SIGZ }=-\operatorname{sig}(3) \\
& \text { SIGXZ = -sig(6) } \\
& \text { SIGYZ = -sig(5) } \\
& \text { SIGXY }=-\operatorname{sig}(4)
\end{aligned}
$$

$\mathrm{c}$

recover strain increment

c (-)sign for soil-mech. convention

$\mathrm{c}$

DEPSX $=-$ eps $(1)$

DEPSY $=-\operatorname{eps}(2)$

DEPSZ $=-\operatorname{eps}(3)$

DEPSXZ $=-\operatorname{eps}(6)$

DEPSYZ $=-\operatorname{eps}(5)$

DEPSXY $=-\operatorname{eps}(4)$

$\mathrm{c}$

c compute intersection of yield with tensile I1 axis

c Il $(+)$ in compression; TCUT is (-)

$\mathrm{c}$

c if(AB.eq.0.or.AC.eq.0.or.AA.eq.0) then

c write $\left(*,{ }^{*}\right)$ 'The yield surface does not intecepts the I1 axis'

c stop 1

c else

c $\quad \mathrm{FCUT}=-1.0 / \mathrm{AB} * \mathrm{ALOG}(\mathrm{AA} / \mathrm{AC})$

c endif

$\mathrm{FCUT}=\mathrm{CM}(47)$

$\mathrm{c}$

c compute initial position I1 of the intersection between Fe and FC

$\mathrm{c}$

$\mathrm{ALO}=\mathrm{CM}(48)$

$\mathrm{c}$

c The initial I1 at intersection of cap and I1 axis is X0, or

c $\quad \mathrm{XI}=\mathrm{ALO}+\mathrm{R}(\mathrm{ALO}) * \mathrm{~F}(\mathrm{AL} 0)$

$\mathrm{c}$

C COMPUTE VOLUMETRIC STRAIN INCREMENT

C AND STRAIN DEVIATION INCREMENT TENSOR

C

$\mathrm{DEV}=\mathrm{DEPSX}+\mathrm{DEPSY}+\mathrm{DEPSZ}$

c

$\mathrm{DEVO} 3=\mathrm{DEV} / 3.0$

DEXX $=$ DEPSX - DEVO3

DEYY $=$ DEPSY - DEVO3

$\mathrm{C}$

C COMPUTE INITIAL MEAN NORMAL STRESS, 


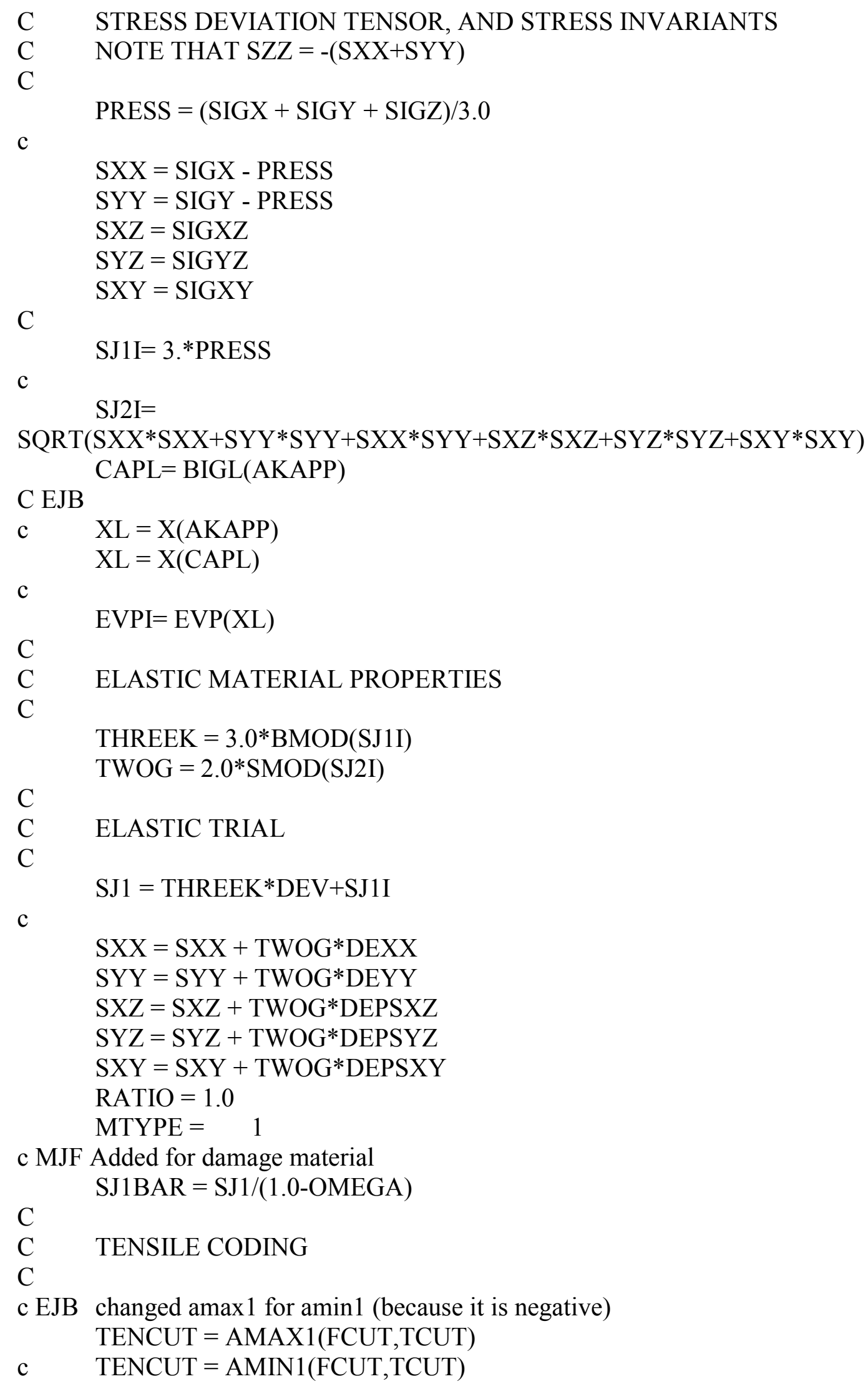


c

IF(SJ1BAR.GT.TENCUT) GO TO 10

$\mathrm{SJ} 1 \mathrm{BAR}=\mathrm{TENCUT}$

c MJF Calculate E (AEI), the modulus of elasticity

$\mathrm{AEI}=9.0 * \mathrm{AGI} * \mathrm{AKI} /(3.0 * \mathrm{AKI}+\mathrm{AGI})$

DOMEGA $=(1.0 / \mathrm{TDP})^{*} \mathrm{AEI} \mathrm{I}^{*} \mathrm{DEV}$

DOMEGA $=$ AMAX1(zero,DOMEGA)

OMEGA $=$ OMEGA + DOMEGA

IF(OMEGA.GT.0.95) OMEGA=0.95

$\mathrm{SJ} 1=\mathrm{SJ} 1 \mathrm{BAR} *(1-\mathrm{OMEGA})$

$\mathrm{MTYPE}=0$

IF(LTYPE.EQ.2 .OR. LTYPE.EQ.3 .OR. AKAPP.LE.AL0) GO TO 200

$\mathrm{C}$

C TENSION DILATANCY CODING

C

$\mathrm{ELL}=\mathrm{AMAX} 1(\mathrm{AL} 0, \mathrm{AKAPP}+\mathrm{CONV} * \mathrm{~F}(\mathrm{AKAPP}))$

$\mathrm{XLL}=\mathrm{X}(\mathrm{ELL})$

DENOM $=$ EVP(XLL)-EVPI

IF(DENOM.GT.zero) GO TO 5

$\mathrm{AKAPP}=\mathrm{ALO}$

GO TO 200

$5 \quad$ DEVP $=$ DEV-(SJ1-SJ1I)/THREEK

AKAPP $=$ AKAPP + DEVP $*($ ELL-AKAPP $) / D E N O M$

AKAPP $=$ AMIN1(AL0,AKAPP)

GO TO 200

C

C CHECK FAILURE ENVELOPE

C

10 CONTINUE

$\mathrm{SJ} 2=$

SQRT(SXX*SXX+SYY*SYY+SXX*SYY+SXZ*SXZ+SYZ*SYZ+SXY*SXY)

IF(SJ1.GT.CAPL) GO TO 30

TMISES = SJ2C(CAPL,XL,CAPL)

$\mathrm{FJ} 1=\mathrm{F}(\mathrm{SJ} 1)$

$\mathrm{FF}=\mathrm{SJ} 2$ - AMIN1(FJ1,TMISES)

IF(FF.LE.zero) GO TO 200

$\mathrm{C}$

C YIELD SURFACE CALCULATION

$\mathrm{C}$

MTYPE $=2$

DFDJ1 = zero

IF(FJ1.LT.TMISES) DFDJ1 $=(\mathrm{F}(\mathrm{SJ} 1+\mathrm{CONV} * \mathrm{SJ} 2)-\mathrm{FJ} 1) /(\mathrm{CONV} * \mathrm{SJ} 2)$

$\mathrm{DLAMD}=\mathrm{FF} /(3 . * \mathrm{THREEK} * \mathrm{DFDJ} 1 * * 2+0.5 * \mathrm{TWOG})$

$\mathrm{DEVP}=-3 \cdot{ }^{*} \mathrm{DFDJ} 1 *$ DLAMD

$\mathrm{SJ} 1 \mathrm{E}=\mathrm{SJ} 1$

$\mathrm{SJ} 1=\mathrm{SJ} 1$ - THREEK ${ }^{*}$ DEVP 


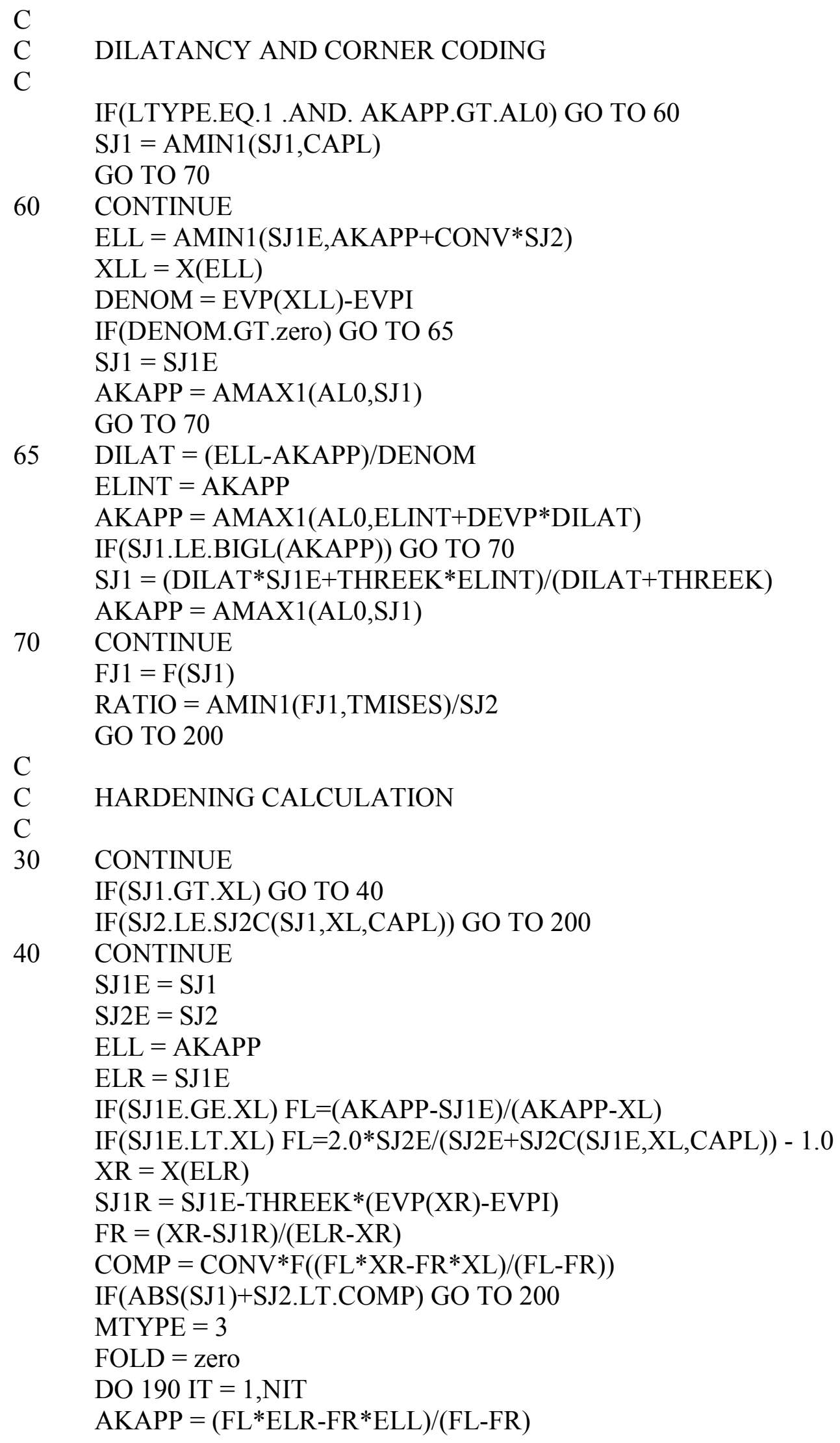




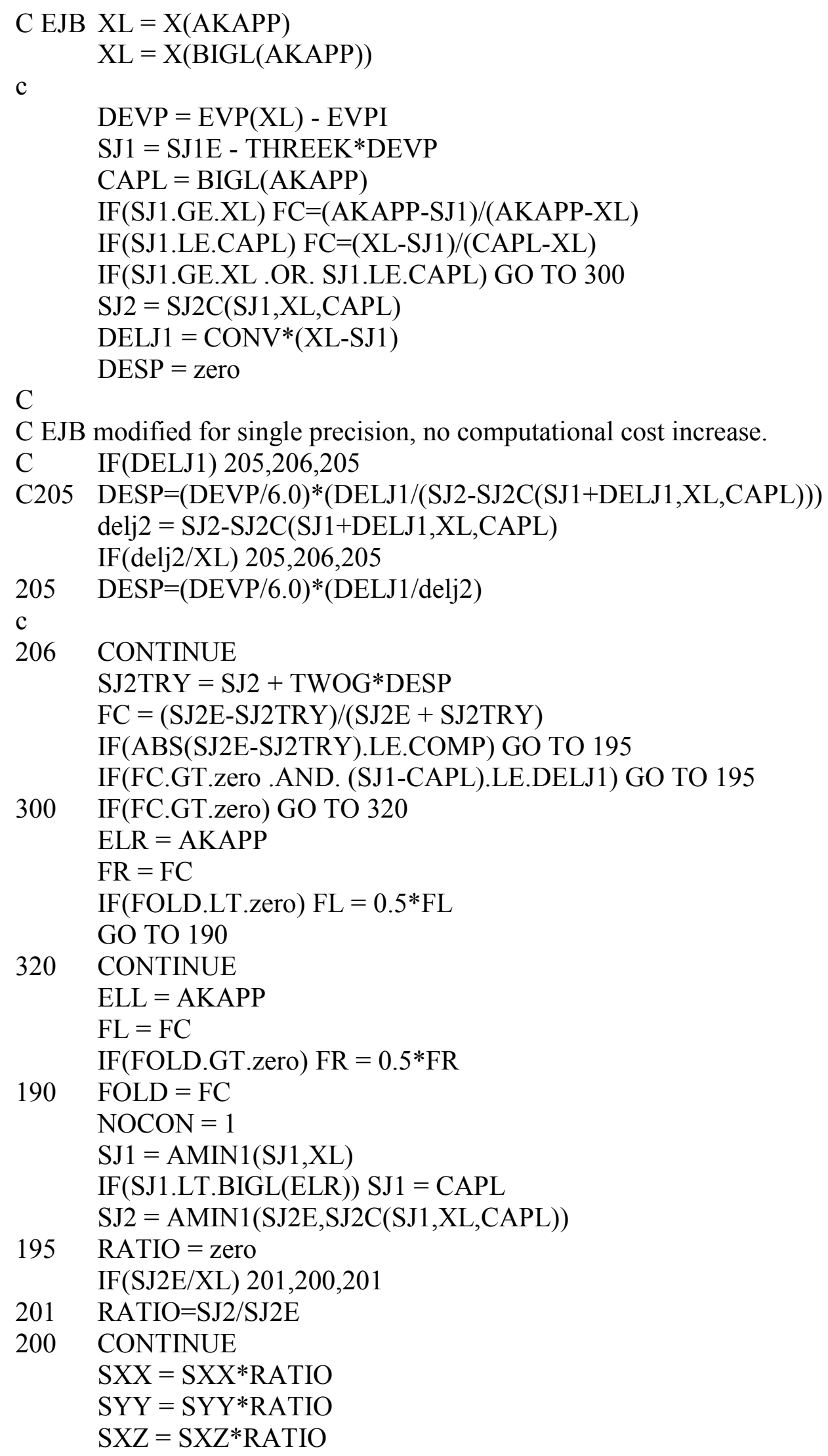




$$
\begin{aligned}
& \text { SYZ = SYZ } * \text { RATIO } \\
& \text { SXY = SXY*RATIO } \\
& \text { PRESS }=\text { SJ } 1 / 3 .
\end{aligned}
$$

$\mathrm{C}$

SIGX $=$ SXX + PRESS

SIGY $=$ SYY + PRESS

SIGZ $=$ PRESS - SXX - SYY

$\mathrm{SIGXZ}=\mathrm{SXZ}$

$\mathrm{SIGYZ}=\mathrm{SYZ}$

$\mathrm{SIGXY}=\mathrm{SXY}$

$\mathrm{c}$

c return stress to dyna

c (-)sign for soil-mech. convention

c

$$
\begin{aligned}
& \operatorname{sig}(1)=- \text { SIGX } \\
& \operatorname{sig}(2)=- \text { SIGY } \\
& \operatorname{sig}(3)=- \text { SIGZ } \\
& \operatorname{sig}(6)=- \text { SIGXZ } \\
& \operatorname{sig}(5)=- \text { SIGYZ } \\
& \operatorname{sig}(4)=- \text { SIGXY }
\end{aligned}
$$

c

c update history

$\mathrm{c}$

$\operatorname{hisv}(2)=$ AKAPP

$\operatorname{hisv}(3)=$ OMEGA

c

c output to taurus as "plastic strain"

$\mathrm{i}=\mathrm{cm}(25)$

select case (i)

case (1)

$$
\text { hisv }(1)=\text { AKAPP }
$$

$\operatorname{case}(2)$

$$
\operatorname{hisv}(1)=\mathrm{X}(\mathrm{BIGL}(\mathrm{AKAPP}))
$$

case(3)

case(4)

$$
\operatorname{hisv}(1)=\operatorname{EVP}(\mathrm{X}(\mathrm{BIGL}(\mathrm{AKAPP})))
$$

$$
\operatorname{hisv}(1)=\operatorname{sig}(1)+\operatorname{sig}(2)+\operatorname{sig}(3)
$$

case (5)

$$
\operatorname{hisv}(1)=
$$

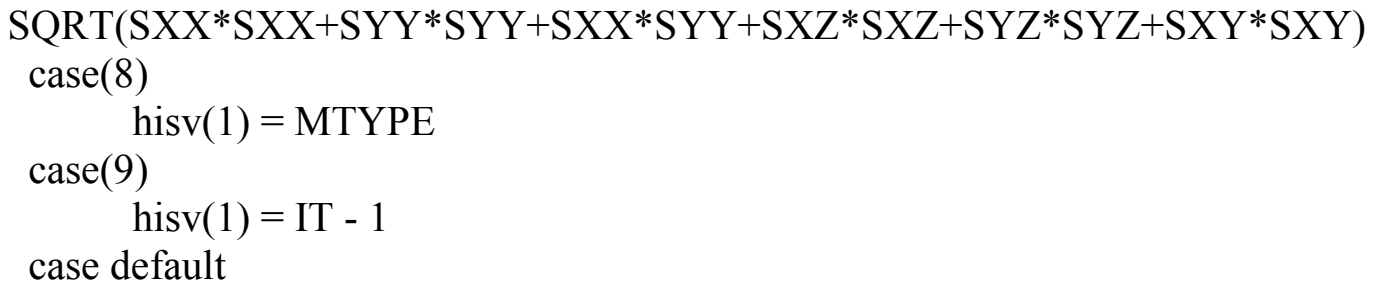




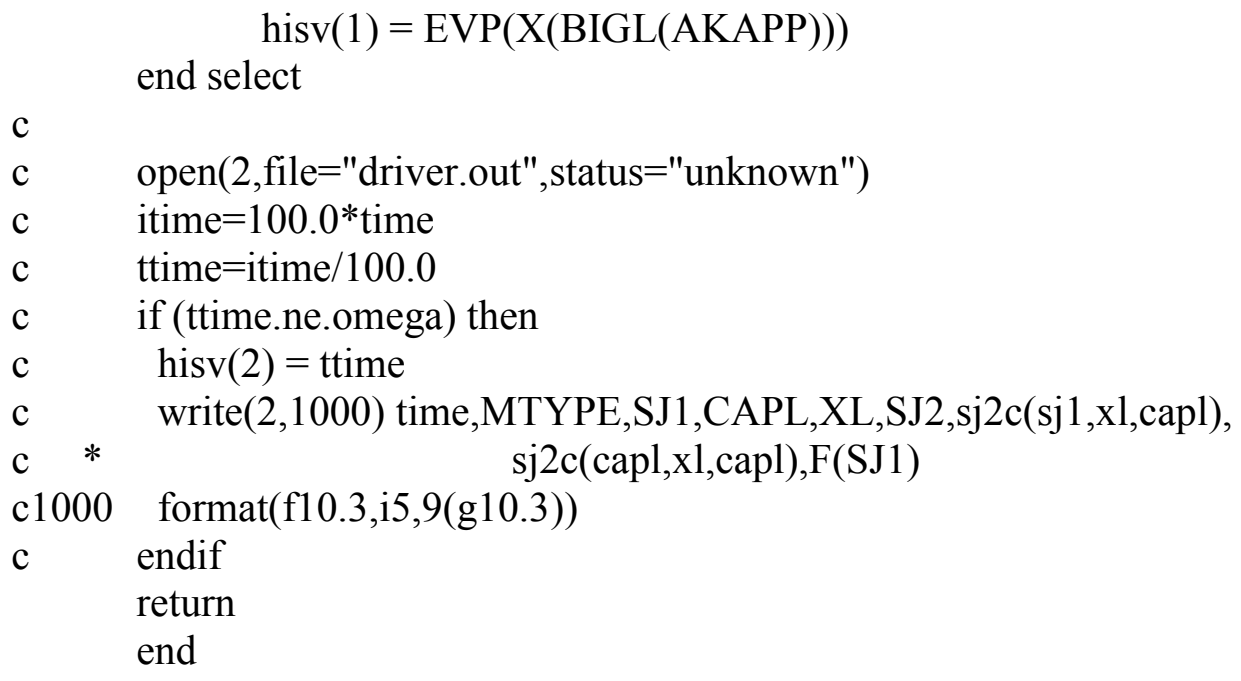


Appendix F:

UMAT43 Driver Program 


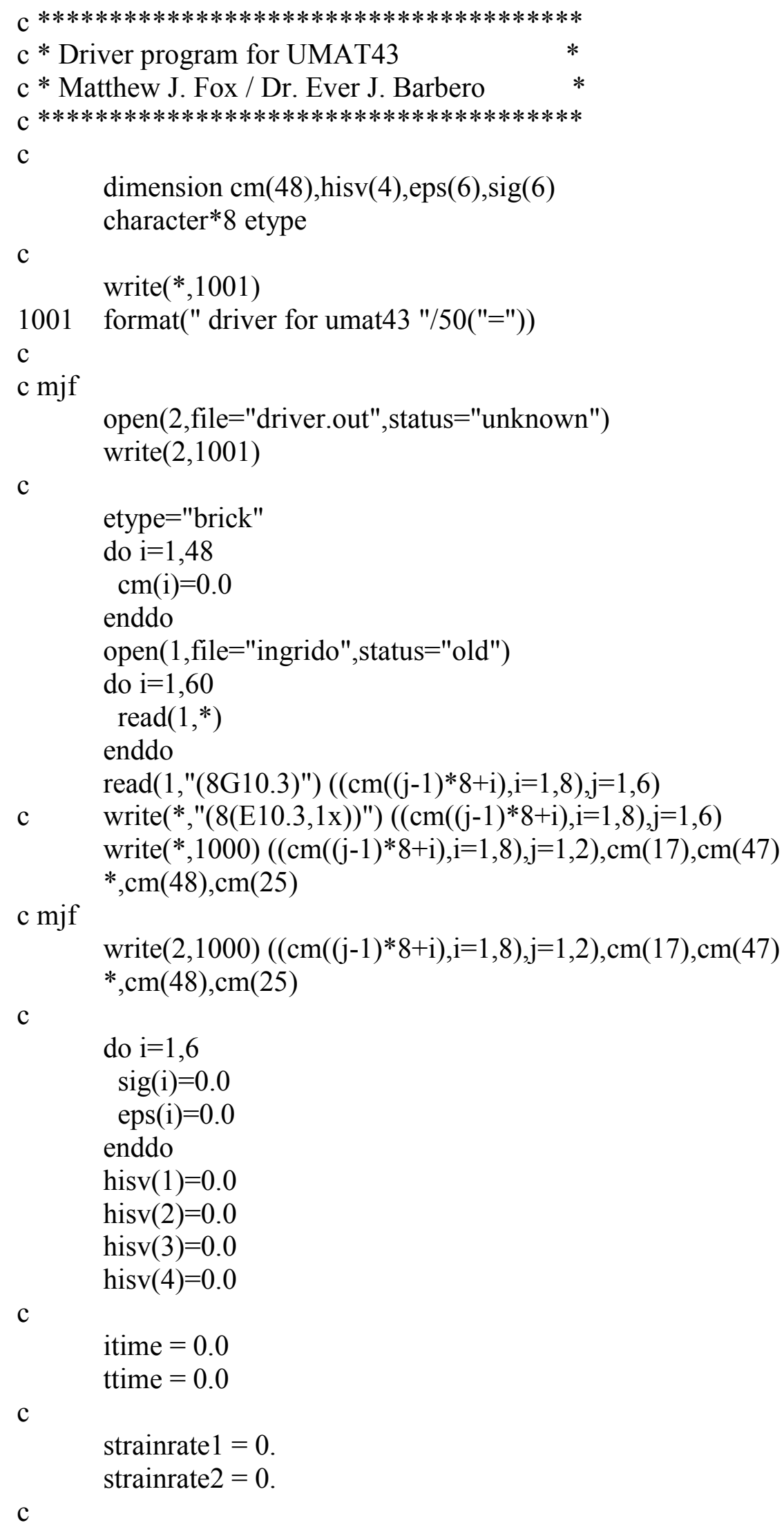


c IC test

strainrate $1=-0.001 \mathrm{E}-0$

c

c with $-90 / 30$ hits the yield, then the cap

c $\quad$ pressure $=-90$

c $\quad$ strainrate $1=$ pressure $/ 3 / \mathrm{cm}(1)$

c shear $=30$

c $\quad$ strainrate $2=$ shear $/ \mathrm{cm}(4)$

c

c tension cutoff

c $\quad$ pressure $=1$

c $\quad$ strainrate $1=$ pressure $/ 3 / \mathrm{cm}(1)$

c $\quad$ strainrate $2=$ strainrate $1 * 11.25$

c

c mjf

write $(*, *)$ " strain rates ",strainrate1,strainrate2

write $\left(2,{ }^{*}\right)$ " strain rates ",strainrate1,strainrate2

c

c mjf

$\mathrm{dt} 1=0.001 \mathrm{E}-0$

c $\quad \mathrm{dt} 1=3.7 \mathrm{E}-6$

c mjf removed next 5 lines from loop

c compute strain increment eps(i)

do $\mathrm{i}=1,3$

eps $(\mathrm{i}+3)=$ strainrate $2 * \mathrm{dt} 1$

eps(i) $=$ strainrate $1 * \mathrm{dt} 1$

enddo

c loop over time

time $=0.0$

$\mathrm{N} 1=0$

$\mathrm{N} 2=20 / \mathrm{dt} 1$

do it $=\mathrm{N} 1, \mathrm{~N} 2$

time $=$ time + dt 1

c update stress

call umat43 (cm,eps,sig,hisv,dt1,capa,etype,time)

c

itime $=10 *$ time

ttime $=$ itime $/ 10$

if(ttime.ne.hisv(4)) then

write $(*, *)$ ttime,hisv(1)

c mjf

write $(2, *)$ ttime,hisv(1)

c

$$
\begin{aligned}
& \operatorname{hisv}(4)=\text { ttime } \\
& \text { endif }
\end{aligned}
$$




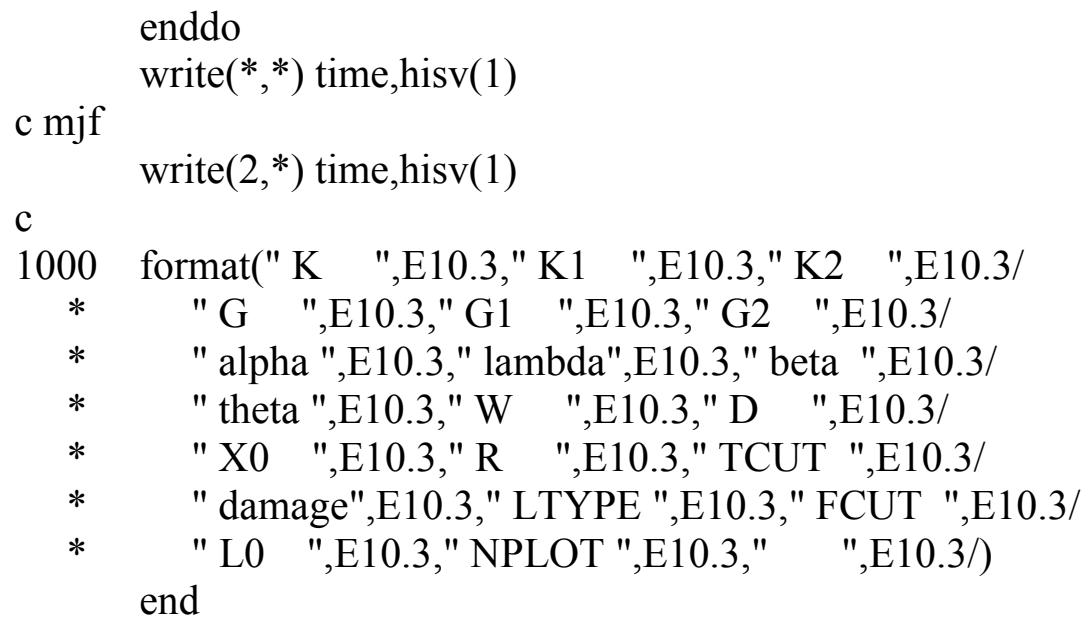


Appendix G:

\section{UC Model - Plain Concrete}


Jerome Model Plain (UMAT43)

93 large

* CARD 1: Model Size-General

$\begin{array}{lllllllll}1 & 176 & 90 & 0 & 0 & 0 & 1 & 0 & 0\end{array}$

* CARD 2: Model Size-Boundary Conditions

$\begin{array}{llllllll}0 & 0 & 0 & 0 & 0 & 0 & 0 & 0\end{array}$

* CARD 3: Model Size-Loading

$\begin{array}{llllllll}2 & 4 & 0 & 0 & 0 & 0 & 0 & 0\end{array}$

* CARD 4: Model Size-Constraints and Contact

$\begin{array}{lllllllllll}0 & 0 & 0 & 0 & 0 & 0 & 0 & 0 & 0 & 0 & 0\end{array}$

* CARD 5: Model Size-Rigid Body Parameters

$\begin{array}{lllllll}0 & 0 & 0 & 0 & 0 & 0 & 0\end{array}$

* CARD 6: Model Size-Seat Belts

$\begin{array}{lllllllllll}0 & 0 & 0 & 0 & 0 & 0 & 0 & 0 & 0 & 0 & 0\end{array}$

* CARD 7: Model Size-Output Options

$\begin{array}{llll}0 & 0 & 0 & 0\end{array}$

* CARD 8: Computation Options-Termination

1.60000-3 $00.0000000 \quad 0$

* CARD 9: Computation Options-Time Step Size Control

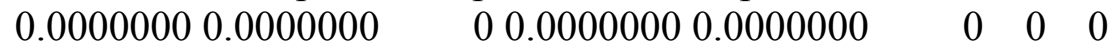

* CARD 10: Computation Options-Body Forces

$\begin{array}{lllllll}0 & 0 & 0 & 0 & 0 & 0 & 0\end{array}$

* CARD 11: Computation Options-Input Control

$\begin{array}{lllll}0 & 0 & 0 \mathrm{e} 20.0 & 0 & 0\end{array}$

* CARD 12: Computation Options-Beams and Shells

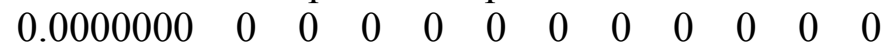

* CARD 13: Computation Options-Material Related Input

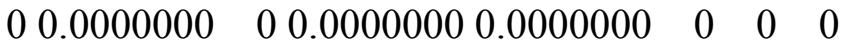

* CARD 14: Computation Options-Damping/Dynamic Relaxation

$2000000000 \quad 0 \quad 00.00000000 .00000000 .00000000 .0000000 \quad 00.0000000$

* CARD 15: Computation Options-Contact

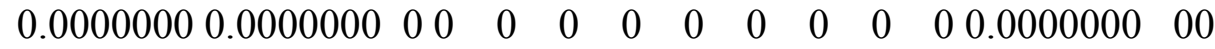

* CARD 16: Computation Options-Parallel and Subcycling

$\begin{array}{lll}1 & 0 & 0\end{array}$

* CARD 17: Computation Options-Coupling Control

$0.00000000 .00000000 .0000000 \quad 0 \quad 0000.0000000 \quad 0 \quad 000$

* CARD 18: Computation Options-Output Control

$\begin{array}{llllllllll}0 & 0 & 0 & 0 & 0 & 0 & 0 & 0 & 0 & 0.0000000\end{array}$

* CARD 19: Computation Options-Output Energy

$\begin{array}{llll}1 & 2 & 1 & 1\end{array}$

* CARD 20: Computation Options-TAURUS Database Control I

5.00000-5 0.0000000 0.0000000 000000000

* CARD 21: Computation Options-TAURUS Database Control II

$\begin{array}{llllllllllllllll}0 & 0 & 0 & 0 & 0 & 0 & 0 & 0 & 0 & 0 & 0 & 0 & 0 & 0 & 0 & 0\end{array}$

* CARD 22: Computation Options-ASCII Output Control I

0.00000000 .00000000 .00000000 .00000000 .00000000 .00000000 .00000000 .0000000

* CARD 23: Computation Options-ASCII Output Control II 
0.00000000 .00000000 .00000000 .00000000 .00000000 .00000000 .00000000 .0000000

* CARD 24: Computation Options-ASCII Output Control III 0.00000000 .00000000 .00000000 .00000000 .00000000 .00000000 .00000000 .0000000

* CARD 25: ALE Options-Control I

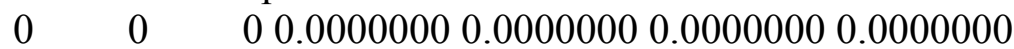

* CARD 26: ALE Options-Control II $0.00000000 .00000000 .0000000 \quad 00.00000000 .0000000 \quad 0$

* CARD 27: User Subroutine control card $\begin{array}{lllllllll}43 & 48 & 3 & 0 & 1 & 4 & 0 & 0\end{array}$

$*$

*------------- MATERIAL CARDS

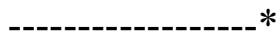

*** MATERIAL: 43 (cap/yield/tcut)

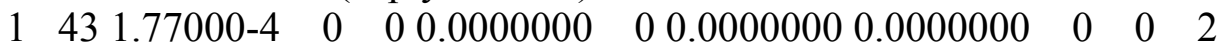

material type \# 43

$1.92800+60.00000000 .00000001 .44600+60.00000000 .00000000 .70000+3 \quad 0.20000+3$

$1.47300-30.10000000 .88400001 .54000-618000.00010 .800000-630.00000-157.50000$

3.00000000 .00000000 .00000000 .00000000 .00000000 .00000000 .00000000 .0000000 4.00000000 .00000000 .00000000 .00000000 .00000000 .00000000 .00000000 .0000000 0.00000000 .00000000 .00000000 .00000000 .00000000 .00000000 .00000000 .0000000 $0.00000000 .00000000 .00000000 .00000000 .00000000 .0000000-850.4840210440 .000$

*

$*$

$*$

NODAL POINT CARDS

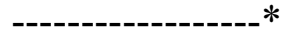

$* * * \mathrm{REMOVED} \mathrm{FOR} \mathrm{SPACE} * * *$

$*$

* BRICK ELEMENT CARDS

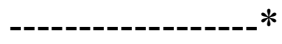

$*$

***REMOVED FOR SPACE***

$*$

$*$

$*$ LOAD CURVE DEFINITIONS $+*$

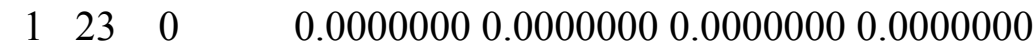

0.00000000 .0000000

$5.00000-524.000000$

$1.00000-467.000000$

1.50000-4 189.00000

2.00000-4 397.00000

2.50000-4 645.00000

3.00000-4 903.00000

$3.50000-41202.0000$

4.00000-4 1568.0000

4.50000-4 1925.0000

5.00000-4 2173.0000

5.50000-4 2324.0000

$6.00000-42457.0000$

$6.50000-42530.0000$ 
$7.00000-42385.0000$

$7.50000-42192.0000$

$8.00000-41537.0000$

$8.50000-41189.0000$

$9.00000-4893.00000$

$9.50000-4540.00000$

$1.00000-3199.00000$

$1.05000-30.0000000$

$1.60000-30.0000000$

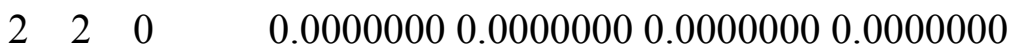

0.000000018 .616300

$1.60000-318.616300$

$*$

* CONCENTRATED NODAL LOADS AND FOLLOWER FORCES -- * $*$
$173 \quad 2 \quad 1-0.1250000$
$174 \quad 2 \quad 1-0.1250000$
$175 \quad 2 \quad 1-0.1250000$
$176 \quad 2 \quad 1-0.1250000$ 
Appendix H:

\section{UC Model - CFRP Reinforced}


Jerome Model CFRP (UMAT43)

93 large

* CARD 1: Model Size-General

$\begin{array}{lllllllll}2 & 264 & 120 & 0 & 0 & 0 & 1 & 0 & 0\end{array}$

* CARD 2: Model Size-Boundary Conditions

$\begin{array}{llllllll}0 & 0 & 0 & 0 & 0 & 0 & 0 & 0\end{array}$

* CARD 3: Model Size-Loading

$\begin{array}{llllllll}2 & 4 & 0 & 0 & 0 & 0 & 0 & 0\end{array}$

* CARD 4: Model Size-Constraints and Contact

$\begin{array}{llllllllllllll}0 & 1 & 0 & 0 & 0 & 0 & 0 & 0 & 0 & 0 & 0 & 0 & 0 & 0\end{array}$

* CARD 5: Model Size-Rigid Body Parameters

$\begin{array}{lllllll}0 & 0 & 0 & 0 & 0 & 0 & 0\end{array}$

* CARD 6: Model Size-Seat Belts

$\begin{array}{lllllllllll}0 & 0 & 0 & 0 & 0 & 0 & 0 & 0 & 0 & 0 & 0\end{array}$

* CARD 7: Model Size-Output Options

$\begin{array}{llll}0 & 0 & 0 & 0\end{array}$

* CARD 8: Computation Options-Termination

1.60000-3 $00.0000000 \quad 0$

* CARD 9: Computation Options-Time Step Size Control

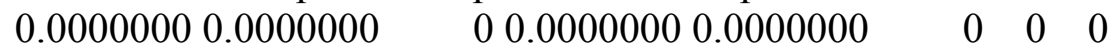

* CARD 10: Computation Options-Body Forces

$\begin{array}{lllllll}0 & 0 & 0 & 0 & 0 & 0 & 0\end{array}$

* CARD 11: Computation Options-Input Control

$\begin{array}{lllll}0 & 0 & 0 \mathrm{e} 20.0 & 0 & 0\end{array}$

* CARD 12: Computation Options-Beams and Shells

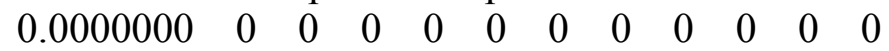

* CARD 13: Computation Options-Material Related Input

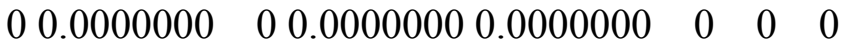

* CARD 14: Computation Options-Damping/Dynamic Relaxation

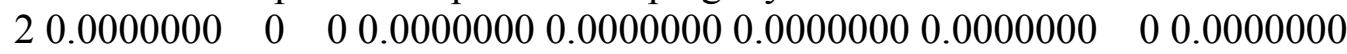

* CARD 15: Computation Options-Contact

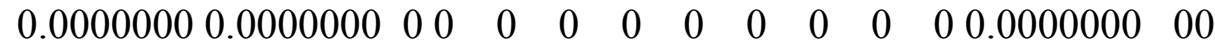

* CARD 16: Computation Options-Parallel and Subcycling

$\begin{array}{lll}1 & 0 & 0\end{array}$

* CARD 17: Computation Options-Coupling Control

$0.00000000 .00000000 .0000000 \quad 0 \quad 0000.0000000 \quad 0 \quad 000$

* CARD 18: Computation Options-Output Control

$\begin{array}{llllllllll}0 & 0 & 0 & 0 & 0 & 0 & 0 & 0 & 0 & 0.0000000\end{array}$

* CARD 19: Computation Options-Output Energy

$\begin{array}{llll}1 & 2 & 1 & 1\end{array}$

* CARD 20: Computation Options-TAURUS Database Control I

5.00000-5 0.0000000 0.0000000 000000000

* CARD 21: Computation Options-TAURUS Database Control II

$\begin{array}{llllllllllllllll}0 & 0 & 0 & 0 & 0 & 0 & 0 & 0 & 0 & 0 & 0 & 0 & 0 & 0 & 0 & 0\end{array}$

* CARD 22: Computation Options-ASCII Output Control I

0.00000000 .00000000 .00000000 .00000000 .00000000 .00000000 .00000000 .0000000

* CARD 23: Computation Options-ASCII Output Control II 
0.00000000 .00000000 .00000000 .00000000 .00000000 .00000000 .00000000 .0000000

* CARD 24: Computation Options-ASCII Output Control III 0.00000000 .00000000 .00000000 .00000000 .00000000 .00000000 .00000000 .0000000

* CARD 25: ALE Options-Control I

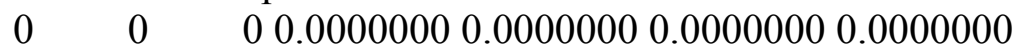

* CARD 26: ALE Options-Control II

$0.00000000 .00000000 .0000000 \quad 00.00000000 .0000000 \quad 0$

* CARD 27: User Subroutine control card

$$
\begin{array}{llllllll}
43 & 48 & 3 & 0 & 1 & 4 & 0 & 0
\end{array}
$$

$*$

*------------- MATERIAL CARDS

*** MATERIAL: 43 (cap/yield/tcut)

143 1.77000-4 $\quad 0 \quad 00.0000000 \quad 00.00000000 .0000000 \quad 00002$

material type \# 43

$1.92800+60.00000000 .00000001 .44600+60.00000000 .00000000 .70000+3 \quad 0.20000+3$

1.47300-3 0.1000000 0.8840000 1.54000-6 18000.000 10.800000-630.00000-157.50000

3.00000000 .00000000 .00000000 .00000000 .00000000 .00000000 .00000000 .0000000 4.00000000 .00000000 .00000000 .00000000 .00000000 .00000000 .00000000 .0000000

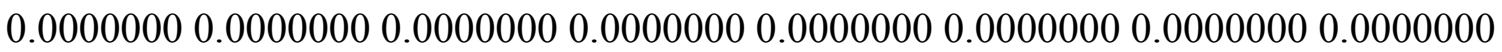
$0.00000000 .00000000 .00000000 .00000000 .00000000 .0000000-850.4840210440 .000$ *** MATERIAL: 2

$2 \quad 11.47500-4 \quad 0 \quad 00.0000000 \quad 00.00000000 .0000000 \quad 00000$ material type \# 1 (elastic)

$2.00000+70.00000000 .00000000 .00000000 .00000000 .00000000 .00000000 .0000000$

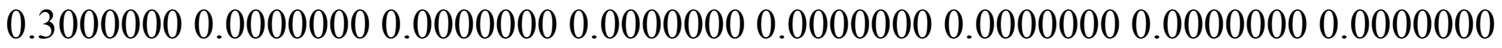
0.00000000 .00000000 .00000000 .00000000 .00000000 .00000000 .00000000 .0000000 0.00000000 .00000000 .00000000 .00000000 .00000000 .00000000 .00000000 .0000000 0.00000000 .00000000 .00000000 .00000000 .00000000 .00000000 .00000000 .0000000 0.00000000 .00000000 .00000000 .00000000 .00000000 .00000000 .00000000 .0000000 *

$*$

$*$

$* * * \mathrm{REMOVED} \mathrm{FOR} \mathrm{SPACE} * * *$

$*$

$*$ BRICK ELEMENT CARDS

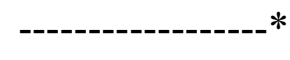

$*$

$* * * \mathrm{REMOVED} \mathrm{FOR} \mathrm{SPACE} * * *$

$*$

$*$ LOAD CURVE DEFINITIONS

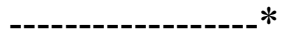

$*$

$\begin{array}{lllllll}1 & 19 & 0 & 0.0000000 & 0.0000000 & 0.0000000 & 0.0000000\end{array}$

0.00000000 .0000000

5.00000-5 669.00000

$1.00000-42178.0000$

$1.50000-44168.0000$

2.00000-4 5912.0000 
2.50000-4 6950.0000

$3.00000-47430.0000$

$3.50000-47763.0000$

4.00000-4 7970.0000

$4.50000-47545.0000$

$5.00000-46090.0000$

$5.50000-43955.0000$

$6.00000-42027.0000$

$6.50000-4892.00000$

$7.00000-4423.00000$

$7.50000-4205.00000$

$8.00000-462.000000$

$8.50000-40.0000000$

$1.60000-30.0000000$

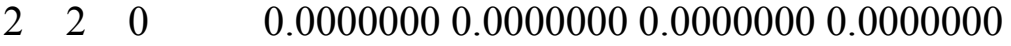

0.000000046 .364000

$1.60000-346.364000$

$*$

*---------- CONCENTRATED NODAL LOADS AND FOLLOWER FORCES

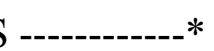

$*$
$173 \quad 2 \quad 1-0.1250000$
$174 \quad 2 \quad 1-0.1250000$
$175 \quad 2 \quad 1-0.1250000$
$176 \quad 2 \quad 1-0.1250000$

$*$

*--------------------- SLIDING INTERFACE DEFINITIONS

$*$

** INTERFACE NAME: 1 . Type: Tied

*

$* * *$ REMOVED FOR SPACE*** 
Appendix I:

RC Model - Internally

Reinforced Concrete 
Faza Fail Case 1 (UMAT43) 93 large

* CARD 1: Model Size-General

$\begin{array}{lllllllll}3 & 508 & 240 & 80 & 0 & 0 & 1 & 0 & 0\end{array}$

* CARD 2: Model Size-Boundary Conditions

$\begin{array}{llllllll}0 & 0 & 0 & 0 & 0 & 0 & 0 & 0\end{array}$

* CARD 3: Model Size-Loading

$\begin{array}{llllllll}2 & 4 & 0 & 0 & 0 & 0 & 0 & 0\end{array}$

* CARD 4: Model Size-Constraints and Contact

$\begin{array}{llllllllllllll}0 & 0 & 0 & 0 & 0 & 0 & 0 & 0 & 4 & 0 & 0 & 0 & 0 & 0\end{array}$

* CARD 5: Model Size-Rigid Body Parameters

$\begin{array}{lllllll}0 & 0 & 0 & 0 & 0 & 0 & 0\end{array}$

* CARD 6: Model Size-Seat Belts

$\begin{array}{lllllllllll}0 & 0 & 0 & 0 & 0 & 0 & 0 & 0 & 0 & 0 & 0\end{array}$

* CARD 7: Model Size-Output Options

$\begin{array}{llll}0 & 0 & 0 & 0\end{array}$

* CARD 8: Computation Options-Termination

$1.0000000 \quad 00.0000000 \quad 0$

* CARD 9: Computation Options-Time Step Size Control

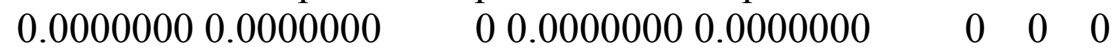

* CARD 10: Computation Options-Body Forces

$\begin{array}{lllllll}0 & 0 & 0 & 0 & 0 & 0 & 0\end{array}$

* CARD 11: Computation Options-Input Control

$\begin{array}{lllll}0 & 0 & 0 \mathrm{e} 20.0 & 0 & 0\end{array}$

* CARD 12: Computation Options-Beams and Shells

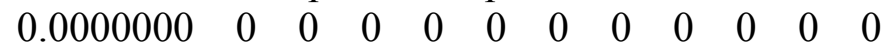

* CARD 13: Computation Options-Material Related Input

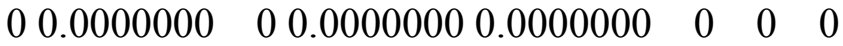

* CARD 14: Computation Options-Damping/Dynamic Relaxation

$20.0000000 \quad 0 \quad 00.00000000 .00000000 .00000000 .0000000 \quad 00.0000000$

* CARD 15: Computation Options-Contact

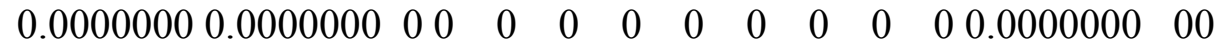

* CARD 16: Computation Options-Parallel and Subcycling $\begin{array}{lll}1 & 0 & 0\end{array}$

* CARD 17: Computation Options-Coupling Control

$0.00000000 .00000000 .0000000 \quad 0 \quad 0000.0000000 \quad 0 \quad 000$

* CARD 18: Computation Options-Output Control

$\begin{array}{llllllllll}0 & 0 & 0 & 0 & 0 & 0 & 0 & 0 & 0 & 0.0000000\end{array}$

* CARD 19: Computation Options-Output Energy

$\begin{array}{llll}1 & 2 & 1 & 1\end{array}$

* CARD 20: Computation Options-TAURUS Database Control I

1.00000-2 $0.00000000 .0000000 \quad 000000000$

* CARD 21: Computation Options-TAURUS Database Control II

$\begin{array}{llllllllllllllll}0 & 0 & 0 & 0 & 0 & 0 & 0 & 0 & 0 & 0 & 0 & 0 & 0 & 0 & 0 & 0\end{array}$

* CARD 22: Computation Options-ASCII Output Control I

0.00000000 .00000000 .00000000 .00000000 .00000000 .00000000 .00000000 .0000000

* CARD 23: Computation Options-ASCII Output Control II 
0.00000000 .00000000 .00000000 .00000000 .00000000 .00000000 .00000000 .0000000

* CARD 24: Computation Options-ASCII Output Control III 0.00000000 .00000000 .00000000 .00000000 .00000000 .00000000 .00000000 .0000000 * CARD 25: ALE Options-Control I

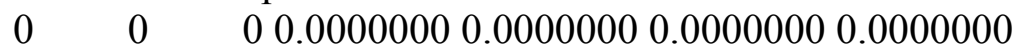

* CARD 26: ALE Options-Control II $0.00000000 .00000000 .0000000 \quad 00.00000000 .0000000 \quad 0$

* CARD 27: User Subroutine control card $\begin{array}{lllllllll}43 & 48 & 3 & 0 & 1 & 4 & 0 & 0\end{array}$

$*$ *------------- MATERIAL CARDS

*** MATERIAL: 43 (cap/yield/tcut)

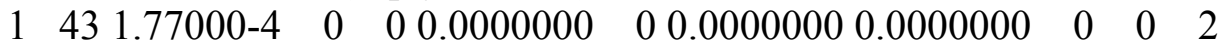
material type \# 43

$1.71429+60.00000000 .00000001 .56522+60.00000000 .00000003 .86000+31.16000+3$ 0.44000-3 0.1100000 0.4200000 3.20000-6 16000.000 4.4300000-414.20000-103.55000 3.00000000 .00000000 .00000000 .00000000 .00000000 .00000000 .00000000 .0000000 4.00000000 .00000000 .00000000 .00000000 .00000000 .00000000 .00000000 .0000000

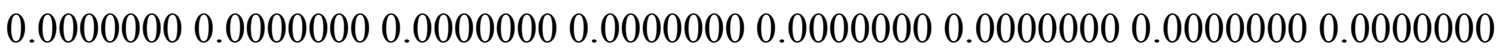
$0.00000000 .00000000 .00000000 .00000000 .00000000 .0000000-2732.38001525 .9927$ *** MATERIAL: 2

$2 \quad 37.33860-4 \quad 0 \quad 00.0000000 \quad 00.00000000 .0000000 \quad 1 \quad 003$ material type \# 3 (elastic-plastic)

$2.90000+70.00000000 .00000000 .00000000 .00000000 .00000000 .00000000 .0000000$

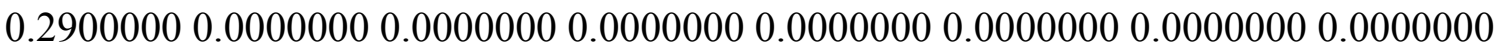
40000.0000 .00000000 .00000000 .00000000 .00000000 .00000000 .00000000 .0000000 $7.36380+40.00000000 .00000000 .00000000 .00000000 .00000000 .00000000 .0000000$ 1.00000000 .00000000 .00000000 .00000000 .00000000 .00000000 .00000000 .0000000 0.00000000 .00000000 .00000000 .00000000 .00000000 .00000000 .00000000 .0000000 section properties

$\begin{array}{llll}0.0000000 & 1 & 0 & 0\end{array}$ 0.44178650 .00000000 .00000000 .00000000 .00000000 .0000000

*** MATERIAL: 3

$\begin{array}{llllllllllll}3 & 3 & 7.33860-4 & 0 & 0 & 0.0000000 & 0 & 0.0000000 & 0.0000000 & 1 & 0 & 3\end{array}$ material type \# 3 (elastic-plastic)

$2.90000+70.00000000 .00000000 .00000000 .00000000 .00000000 .00000000 .0000000$

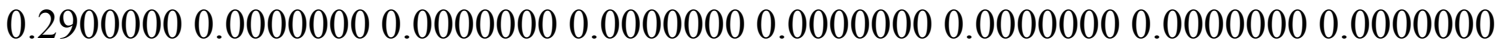
40000.0000 .00000000 .00000000 .00000000 .00000000 .00000000 .00000000 .0000000 $7.36380+40.00000000 .00000000 .00000000 .00000000 .00000000 .00000000 .0000000$ 1.00000000 .00000000 .00000000 .00000000 .00000000 .00000000 .00000000 .0000000 0.00000000 .00000000 .00000000 .00000000 .00000000 .00000000 .00000000 .0000000 section properties

$\begin{array}{llll}0.0000000 & 1 & 0 & 0\end{array}$

0.11044660 .00000000 .00000000 .00000000 .00000000 .0000000

$*$

$*$ NODAL POINT CARDS $*$ 


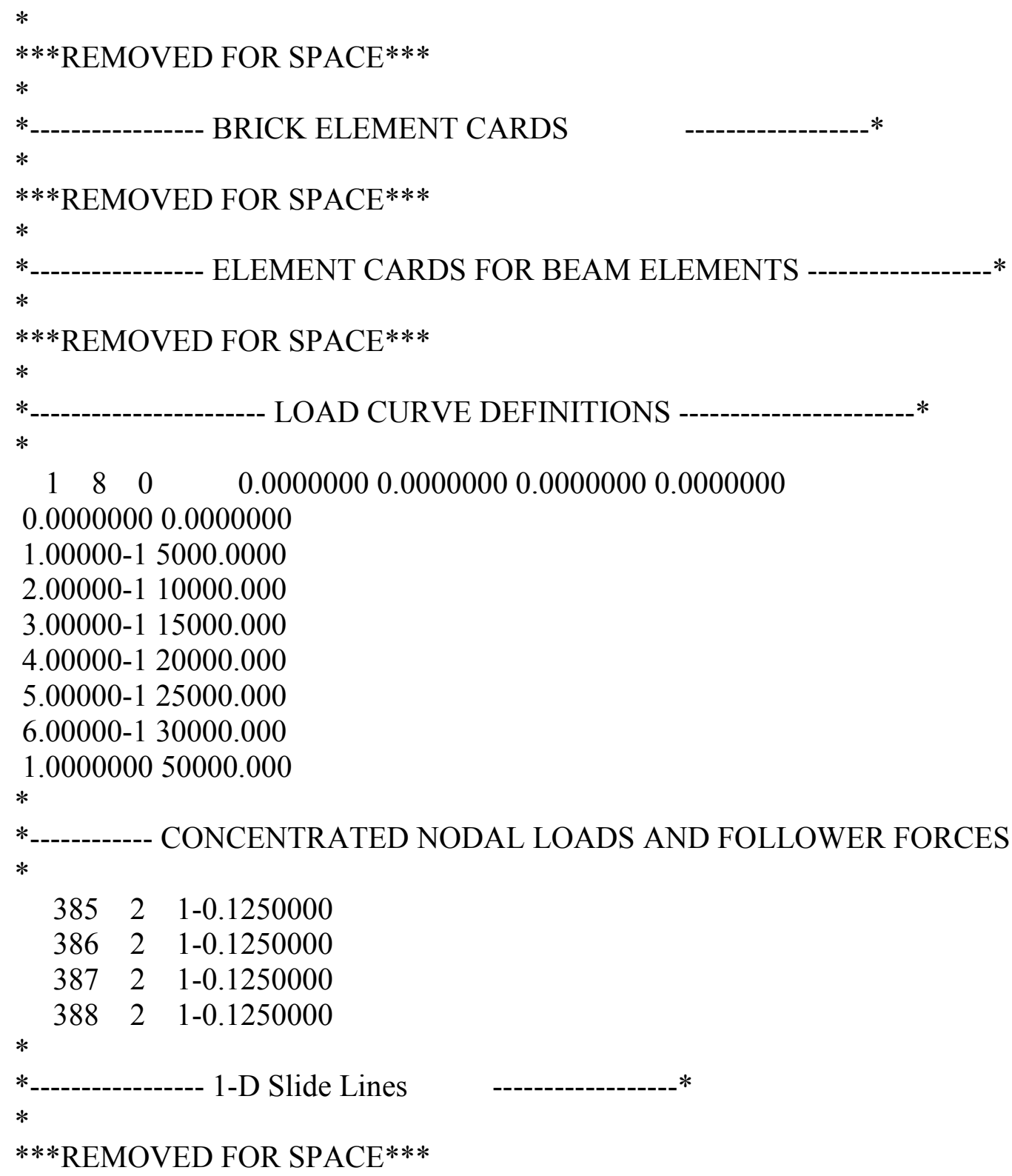


Appendix J:

Concrete Wall Model 
Concrete Wall Plain (UMAT43)

93 large

* CARD 1: Model Size-General

$\begin{array}{lllllllll}1 & 1275 & 768 & 0 & 0 & 0 & 1 & 0 & 0\end{array}$

* CARD 2: Model Size-Boundary Conditions

$\begin{array}{llllllll}0 & 0 & 0 & 0 & 0 & 0 & 0 & 0\end{array}$

* CARD 3: Model Size-Loading

$\begin{array}{llllllll}385 & 0 & 384 & 0 & 0 & 0 & 0 & 0\end{array}$

* CARD 4: Model Size-Constraints and Contact

$\begin{array}{llllllllllllll}0 & 0 & 0 & 0 & 0 & 0 & 0 & 0 & 0 & 0 & 0 & 0 & 0 & 0\end{array}$

* CARD 5: Model Size-Rigid Body Parameters

$\begin{array}{lllllll}0 & 0 & 0 & 0 & 0 & 0 & 0\end{array}$

* CARD 6: Model Size-Seat Belts

$\begin{array}{lllllllllll}0 & 0 & 0 & 0 & 0 & 0 & 0 & 0 & 0 & 0 & 0\end{array}$

* CARD 7: Model Size-Output Options

$\begin{array}{llll}0 & 0 & 0 & 0\end{array}$

* CARD 8: Computation Options-Termination

$0.5000000 \quad 00.0000000 \quad 0$

* CARD 9: Computation Options-Time Step Size Control

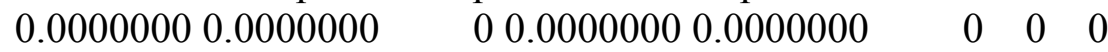

* CARD 10: Computation Options-Body Forces

$\begin{array}{lllllll}0 & 0 & 0 & 0 & 0 & 0 & 0\end{array}$

* CARD 11: Computation Options-Input Control

$\begin{array}{lllll}0 & 0 & 0 \mathrm{e} 20.0 & 0 & 0\end{array}$

* CARD 12: Computation Options-Beams and Shells

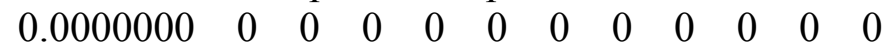

* CARD 13: Computation Options-Material Related Input

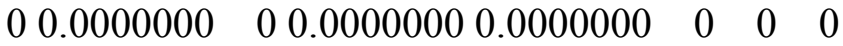

* CARD 14: Computation Options-Damping/Dynamic Relaxation

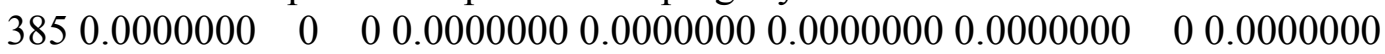

* CARD 15: Computation Options-Contact

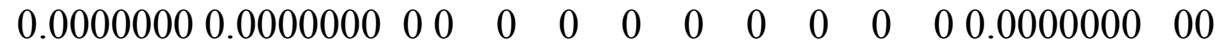

* CARD 16: Computation Options-Parallel and Subcycling $\begin{array}{lll}0 & 0 & 0\end{array}$

* CARD 17: Computation Options-Coupling Control

$0.00000000 .00000000 .0000000 \quad 0 \quad 0000.0000000 \quad 0 \quad 000$

* CARD 18: Computation Options-Output Control

$\begin{array}{llllllllll}0 & 0 & 0 & 0 & 0 & 0 & 0 & 0 & 0 & 0.0000000\end{array}$

* CARD 19: Computation Options-Output Energy

$\begin{array}{llll}1 & 2 & 1 & 1\end{array}$

* CARD 20: Computation Options-TAURUS Database Control I

5.00000-4 0.0000000 0.0000000 00000000

* CARD 21: Computation Options-TAURUS Database Control II

$\begin{array}{llllllllllllllll}0 & 0 & 0 & 0 & 0 & 0 & 0 & 0 & 0 & 0 & 0 & 0 & 0 & 0 & 0 & 0\end{array}$

* CARD 22: Computation Options-ASCII Output Control I

0.00000000 .00000000 .00000000 .00000000 .00000000 .00000000 .00000000 .0000000

* CARD 23: Computation Options-ASCII Output Control II 
0.00000000 .00000000 .00000000 .00000000 .00000000 .00000000 .00000000 .0000000

* CARD 24: Computation Options-ASCII Output Control III 0.00000000 .00000000 .00000000 .00000000 .00000000 .00000000 .00000000 .0000000

* CARD 25: ALE Options-Control I

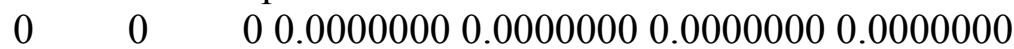

* CARD 26: ALE Options-Control II $0.00000000 .00000000 .0000000 \quad 00.00000000 .0000000 \quad 0$

* CARD 27: User Subroutine control card $\begin{array}{llllllll}43 & 48 & 3 & 0 & 1 & 4 & 0 & 0\end{array}$

$*$

*--------------- MATERIAL CARDS

$*$

*** MATERIAL: 43 (cap/yield/tcut)

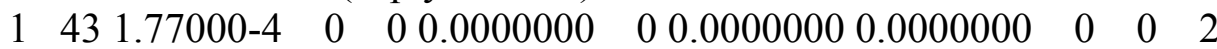

material type \# 43

$1.71429+60.00000000 .00000001 .56522+60.00000000 .00000003 .86000+31.16000+3$ 0.44000-3 0.1100000 0.4200000 3.20000-6 16000.000 4.4300000-414.20000-103.55000 3.00000000 .00000000 .00000000 .00000000 .00000000 .00000000 .00000000 .0000000 4.00000000 .00000000 .00000000 .00000000 .00000000 .00000000 .00000000 .0000000

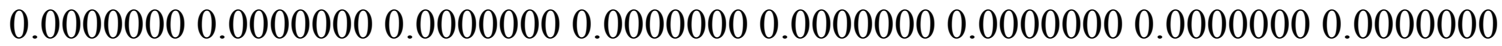
$0.00000000 .00000000 .00000000 .00000000 .00000000 .0000000-2732.38001525 .9927$

*

$*$ NODAL POINT CARDS

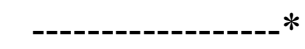

$*$

$* * * \mathrm{REMOVED} \mathrm{FOR} \mathrm{SPACE} * * *$

$*$

$*$

$*$

$* * * \mathrm{REMOVED} \mathrm{FOR} \mathrm{SPACE} * * *$

$*$ LOAD CURVE DEFINITIONS $-*$

$*$

$\# 1-\# 384 * * *$ REMOVED FOR SPACE***

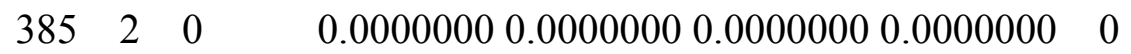

0.000000014 .020000

0.500000014 .020000

*

,

$*$ PRESSURE BOUNDARY CONDITION CARDS

***REMOVED FOR SPACE*** 
Appendix K:

\section{CFRP Reinforced Concrete Wall Model}


Concrete Wall with CFRP on Back (UMAT43)

* CARD 1: Model Size-General

93 large

$\begin{array}{lllllllll}2 & 2125 & 1152 & 0 & 0 & 0 & 1 & 0 & 0\end{array}$

* CARD 2: Model Size-Boundary Conditions

$\begin{array}{llllllll}0 & 0 & 0 & 0 & 0 & 0 & 0 & 0\end{array}$

* CARD 3: Model Size-Loading

$\begin{array}{llllllll}385 & 0 & 384 & 0 & 0 & 0 & 0 & 0\end{array}$

* CARD 4: Model Size-Constraints and Contact

$\begin{array}{llllllllllllll}0 & 1 & 0 & 0 & 0 & 0 & 0 & 0 & 0 & 0 & 0 & 0 & 0 & 0\end{array}$

* CARD 5: Model Size-Rigid Body Parameters

$\begin{array}{lllllll}0 & 0 & 0 & 0 & 0 & 0 & 0\end{array}$

* CARD 6: Model Size-Seat Belts

$\begin{array}{lllllllllll}0 & 0 & 0 & 0 & 0 & 0 & 0 & 0 & 0 & 0 & 0\end{array}$

* CARD 7: Model Size-Output Options

$\begin{array}{llll}0 & 0 & 0 & 0\end{array}$

* CARD 8: Computation Options-Termination

$0.5000000 \quad 00.0000000 \quad 0$

* CARD 9: Computation Options-Time Step Size Control

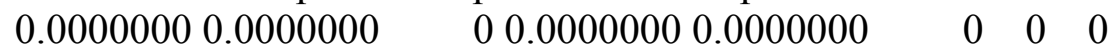

* CARD 10: Computation Options-Body Forces

$\begin{array}{lllllll}0 & 0 & 0 & 0 & 0 & 0 & 0\end{array}$

* CARD 11: Computation Options-Input Control

$\begin{array}{lllll}0 & 0 & 0 \mathrm{e} 20.0 & 0 & 0\end{array}$

* CARD 12: Computation Options-Beams and Shells

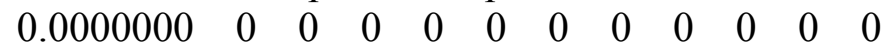

* CARD 13: Computation Options-Material Related Input

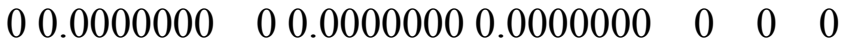

* CARD 14: Computation Options-Damping/Dynamic Relaxation

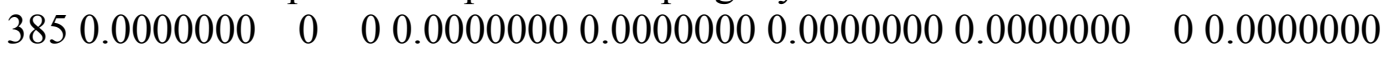

* CARD 15: Computation Options-Contact

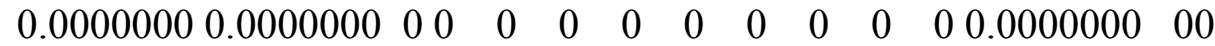

* CARD 16: Computation Options-Parallel and Subcycling

2000

* CARD 17: Computation Options-Coupling Control

$0.00000000 .00000000 .0000000 \quad 0 \quad 0000.0000000 \quad 0 \quad 000$

* CARD 18: Computation Options-Output Control

$\begin{array}{llllllllll}0 & 0 & 0 & 0 & 0 & 0 & 0 & 0 & 0 & 0.0000000\end{array}$

* CARD 19: Computation Options-Output Energy

$\begin{array}{llll}1 & 2 & 1 & 1\end{array}$

* CARD 20: Computation Options-TAURUS Database Control I

5.00000-4 0.0000000 0.0000000 00000000

* CARD 21: Computation Options-TAURUS Database Control II

$\begin{array}{llllllllllllllll}0 & 0 & 0 & 0 & 0 & 0 & 0 & 0 & 0 & 0 & 0 & 0 & 0 & 0 & 0 & 0\end{array}$

* CARD 22: Computation Options-ASCII Output Control I

0.00000000 .00000000 .00000000 .00000000 .00000000 .00000000 .00000000 .0000000

* CARD 23: Computation Options-ASCII Output Control II 
0.00000000 .00000000 .00000000 .00000000 .00000000 .00000000 .00000000 .0000000

* CARD 24: Computation Options-ASCII Output Control III 0.00000000 .00000000 .00000000 .00000000 .00000000 .00000000 .00000000 .0000000

* CARD 25: ALE Options-Control I

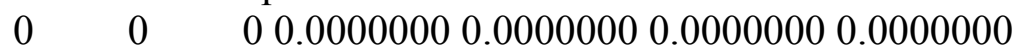

* CARD 26: ALE Options-Control II $0.00000000 .00000000 .0000000 \quad 00.00000000 .0000000 \quad 0$

* CARD 27: User Subroutine control card

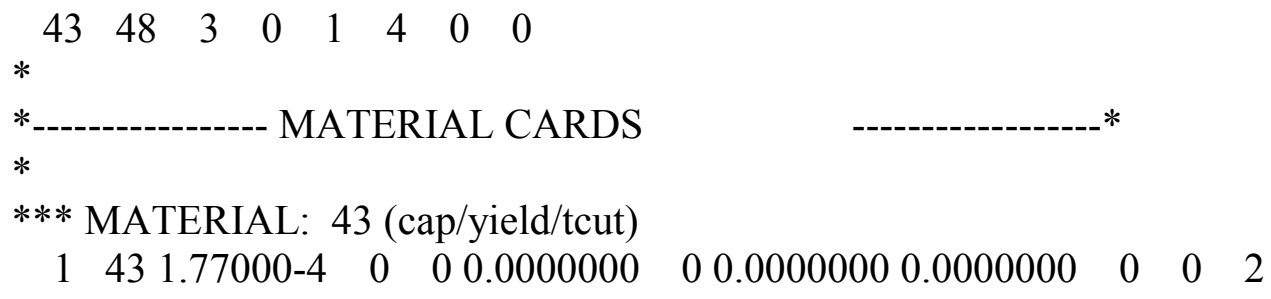




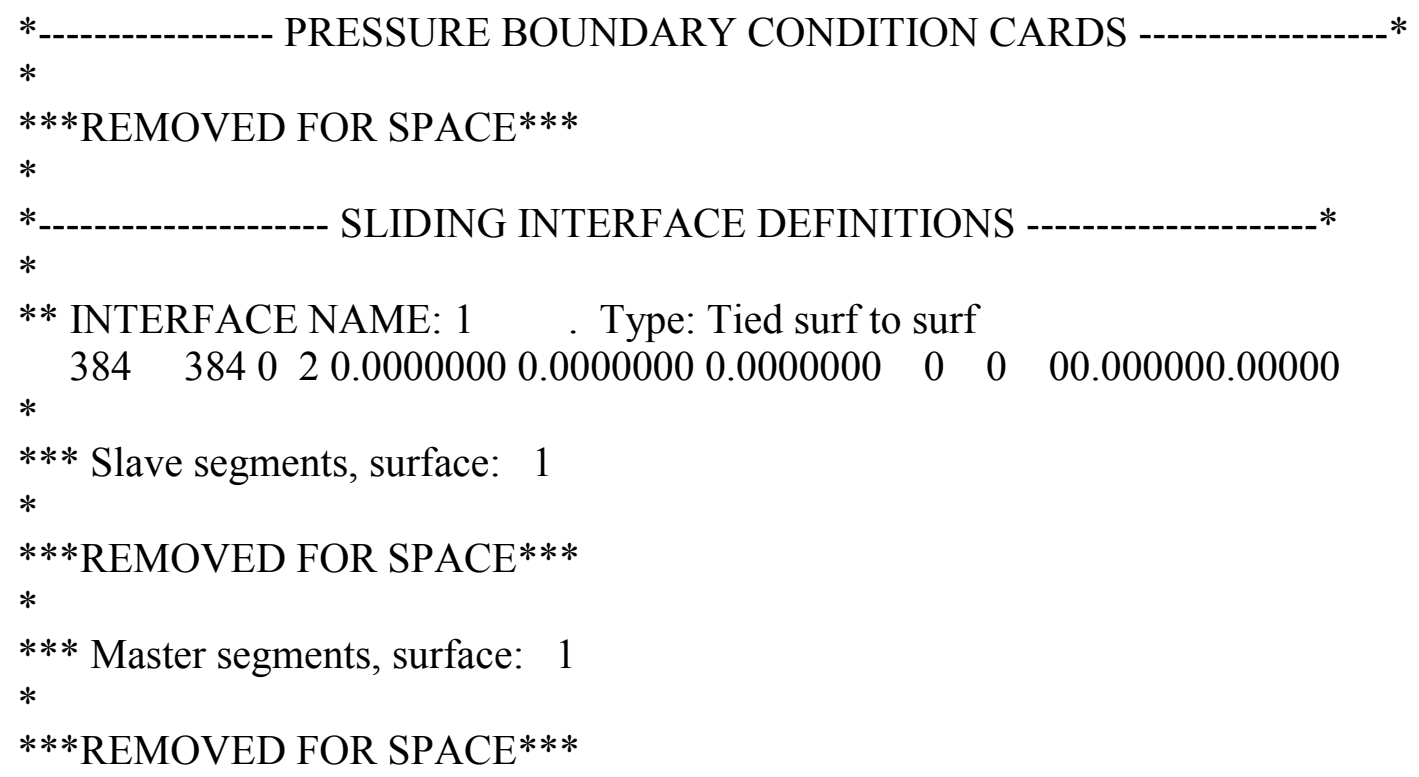

